INSTITUTO DE PESQUISAS ENERGÉTICAS E NUCLEARES

Autarquia Associada à Universidade de São Paulo

ESTUDO MICROESTRUTURAL E PROPRIEDADES

MAGNÉTICAS EM ÍMÃS PERMANENTES

SINTERIZADOS À BASE DE PrFeCoBNb COM

ADIÇÕES DE ELEMENTOS DE LIGA

TEÓFILO MENDES NETO

Tese apresentada como parte dos requisitos para obtenção do Grau de Doutor em Ciências na Área de Tecnologia Nuclear - Materiais

Orientador:

Dr. Hidetoshi Takiishi

SÃO PAULO

2011 


\section{AGRADECIMENTOS}

Ao Dr. Hidetoshi Takiishi pela motivação, apoio e amizade durante o transcorrer de toda essa jornada.

Ao Dr. Rubens Nunes de Faria Jr. pela oportunidade e co-orientação desse trabalho.

Ao Instituto de Pesquisas Energéticas e Nucleares por suas instalações e oportunidade da realização desse trabalho.

Aos colegas do Laboratório de Materiais Magnéticos do IPEN pela paciência e ajuda na realização e caracterização dos ímãs estudados nesse trabalho.

Ao colega Élio Périgo pelas proveitosas discussões e sugestões.

Ao Dr. Ricardo M. Leal Neto do Laboratório de tecnologia do pó e intermetálicos pela utilização do moinho de alta energia.

Ao LABMAT do Centro Experimental ARAMAR pelo auxílio na realização do processo metalográfico das amostras de MEV.

Ao Laboratório Nacional de Luz Síncrotron pela utilização de suas instalações, especialmente ao departamento de microscopia eletrônica e nanociência.

Aos colegas do LNLS, Conrado, Bettini e Paulo Silva pelas preciosas orientações e ajuda na confecção das amostras e operação dos microscópios de transmissão.

Ao Centro Tecnológico da Marinha em São Paulo pela oportunidade da realização deste estudo.

A todos os colegas do Centro Experimental ARAMAR que apoiaram e incentivaram a realização dessa pesquisa.

Às colegas, Ana Maria e Sarita do Centro Tecnológico da Marinha pela oportunidade da realização das amostras e micrografias com MEV.

Aos meus pais e à minha avó Artemide (in memória), eternamente.

À Cíntia e ao Thales, geradores da minha motivação mesmo nos momentos mais árduos.

A todos aqueles que contribuíram direta ou indiretamente para realização desse trabalho. 


\section{ÍNDICE}

RESUMO iv

ABSTRACT V V

LISTA DE FIGURAS vi

CAPÍTULO 1 - INTRODUÇÃO

1.1 - Breve Histórico 1

1.2 - Importância Tecnológica 4

1.3 - Objetivos 6

1.4 - Organização do Trabalho 6

CAPÍTULO 2- REVISÃO DA LITERATURA 8

2.1 - Momentos Magnéticos $\quad 8$

2.2 - Anisotropia Magnetocristalina 9

2.3 - Domínios Magnéticos 11

2.4 - Paredes de Domínio 12

2.5 - Segundo Quadrante do Ciclo de Histerese 13

2.6 - Remanência 15

2.7 - Coercividade Intrínseca 16

2.8 - Fator de Quadratura 17

2.9 - Produto de Energia Máximo 17

2.10 - Microestrutura e Coercividade 18

2.11 - Adições e Substituições 19

2.12 - Os Contornos de Grãos 23

2.13 - A Influência do Oxigênio 28

CAPÍTULO 3 - MATERIAIS E MÉTODOS 30

3.1 - Preparações de ímãs HD sinterizados 30

3.2 - Preparação de amostras - MEV 34

3.3 - Tratamento Computacional das Micrografias 35

3.4 - Preparações de Amostras - MET 37

3.4.1 - Corte em serra com disco diamantado 38

3.4.2 - Corte em discos de 3,0 mm 39

3.4.3 - Pré- afinamento dos discos de $3,0 \mathrm{~mm} \quad 39$ 
3.4.4 - Dimpler dos discos pré-afinados

3.4.5 - Sistema de polimento iônico de precisão

CAPÍTULO 4 - RESULTADOS E DISCUSSÃO

4.1 - Resultados obtidos - Curvas do Segundo Quadrante 51

4.2 - Análises com Microscopia Eletrônica de Varredura 53

4.3 - Distribuições dos tamanhos de grão 60

4.4 - Investigações com MET 61

4.4.1 - Investigações nos pontos triplos (Ga e P) 62

4.4.2 - Imagens de alta resolução para o ímã com Ga 70

4.4.3 - Estudo dos Contornos de Grão - Ga e padrão 72

4.4.4 - Defeitos e precipitados 77

CAPÍTULO 5 - CONCLUSÕES 81

REFERÊNCIAS BIBLIOGRÁFICAS 84 


\title{
ESTUDO MICROESTRUTURAL E PROPRIEDADES MAGNÉTICAS EM ÍMÃS PERMANENTES SINTERIZADOS À BASE DE PrFeCoBNb COM ADIÇÕES DE ELEMENTOS DE LIGA
}

\author{
TEÓFILO MENDES NETO
}

\section{RESUMO}

Neste estudo, as propriedades magnéticas dos ímãs sinterizados, produzidos a partir de uma mistura de ligas $\operatorname{Pr}_{16} \mathrm{Fe}_{76} \mathrm{~B}_{8}$ e $\operatorname{Pr}_{14} \mathrm{Fe}_{\text {bal }} \mathrm{Co}_{16} \mathrm{~B}_{6} \mathrm{Nb}_{0,1} \mathrm{M}_{\mathrm{x}}$, onde $\mathrm{M}=\mathrm{Al}, \mathrm{Cu}, \mathrm{P}$, $\mathrm{Si}, \mathrm{Gd}, \mathrm{Ga}$, Dy, Tb e x=0,1, 0,3, 0,5 \% at. em iguais proporções, foram correlacionadas com as características microestruturais através de microscopia eletrônica de varredura (MEV) e de transmissão (MET). Utilizou-se microscopia eletrônica de varredura (MEV) e processamento computacional das micrografias, na investigação das características associadas ao tamanho e formato dos grãos magnéticos $(\Phi)$. A correlação utilizada indicou que fatores de quadratura superiores estão associados a grãos mais arredondados e com distribuição de tamanho mais estreita. Considerando que a variação no tamanho de grão e os valores de coercividade não se mostraram conclusivas com MEV, utilizou-se o recurso da microscopia eletrônica de transmissão (MET), microanálise com EDS e padrão de difração eletrônica. A associação da coercividade com a microestrutura foi feita com base nas investigações das fases não magnéticas, ricas em praseodímio dos pontos triplos e nos contornos de grãos. Com o microscópio de transmissão de alta resolução (HRTEM), foi possível observar a presença de uma camada contínua e regular entre os grãos da fase magnética para o ímã com adição de Ga 0,25\% at. A modificação da microestrutura no contorno de grão do ímã com adição de Ga pode ser indicada como responsável pelo aumento de 10\% na coercividade (1100 mT) comparado com o ímã $\operatorname{Pr}_{15} \mathrm{Fe}_{\text {bal }} \mathrm{Co}_{8} \mathrm{~B}_{7} \mathrm{Nb}_{0,05}$. 


\title{
MICROSTRUCTURAL STUDY AND MAGNETIC PROPERTIES OF PrFeCoBNb-BASED PERMANENT SINTERED MAGNETS WITH ALLOY ADDITIONS
}

\author{
TEÓFILO MENDES NETO
}

\begin{abstract}
In this study the magnetic properties of sintered magnets, prepared with a mixture of $\operatorname{Pr}_{16} \mathrm{Fe}_{76} \mathrm{~B}_{8}$ and $\operatorname{Pr}_{14} \mathrm{Fe}_{\mathrm{bal}} \mathrm{Co}_{16} \mathrm{~B}_{6} \mathrm{Nb}_{0.1} \mathrm{M}_{\mathrm{x}}$ alloys, where $\mathrm{M}=\mathrm{Al}, \mathrm{Cu}, \mathrm{P}, \mathrm{Si}, \mathrm{Gd}$, $\mathrm{Ga}, \mathrm{Dy}, \mathrm{Tb}$ and $\mathrm{x}=0.1,0.3,0.5$ at.\% in the same proportions, were correlated with the microstructural features by scanning electron microscopy (SEM) and transmission electron microscopy (TEM). SEM and computer processing of the micrographs were used in order to provide the characteristics associated with the size and shape of the magnetic grains ( $\Phi$ phase). The correlation used shows that superior squareness factors are associated with rounder and narrower size distribution grains. Considering that the variation in the grain size and coercivity values were not conclusive with SEM, it has been used TEM, micro analysis by EDS and electron diffraction pattern. The coercivity relation with the microstructure was based on investigations of non-magnetic phases, in triple points, and in the grain boundary. With a high resolution transmission microscope (HRTEM), it was possible to observe a regular and continuous layer between the grains of the magnetic phase for the magnet with 0.25 at.\% of $\mathrm{Ga}$. The presence of such boundary can be indicated as responsible for higher coercivity values of this magnet. Microstructure was modified in the grain boundary by $\mathrm{Ga}$ addition and can be indicated as responsible for coercivity value (1100 mT) $10 \%$ higher than $\mathrm{Pr}_{15} \mathrm{Fe}_{\mathrm{bal}} \mathrm{Co}_{8} \mathrm{~B}_{7} \mathrm{Nb}_{0.05}$ magnet.
\end{abstract}




\section{LISTA DE FIGURAS}

FIG. 1.1.1: Célula unitária de estrutura tetragonal da fase $\mathrm{Nd}_{2} \mathrm{Fe}_{14} \mathrm{~B} \quad 02$

FIG. 1.1.2: Evolução dos resultados obtidos para o $\mathrm{BH}_{\operatorname{Max}} 03$

FIG. 1.2.1: Ilustrativo de motor elétrico com ímãs sinterizados - Nd-Fe-B 05

FIG. 2.2.1: Definição dos eixos cristalográficos 09

FIG. 2.2.2: Curvas de magnetização para um monocristal de Fe em função 10

da direção dos eixos cristalográficos

FIG. 2.3.1: Esquema de um "policristal" ferromagnético - orientações dos 11 domínios magnéticos

FIG. 2.3.2: Representação esquemática da mudança de orientação de $180^{\circ} 12$ na parede de domínio

FIG. 2.5.1: Curva de desmagnetização intrínseca $\left(J \times \mu_{0} H\right)$ e indutiva $(B \times 15$ $\left.\mu_{0} H\right)$

FIG. 2.10.1: Esquemático do processo de reversão da magnetização 19 devido a um defeito

FIG. 2.12.1: Modelo esquemático dos contornos não magnéticos para os 24 ímãs permanentes a base de Nd-Fe-B

FIG. 2.12.2: Configuração de magnetização reversa devido a grandes 26 campos de tensão e a situação após tratamento térmico otimizado

FIG. 2.12.3: Micrografias em alta resolução: influência do tratamento 27 térmico

FIG. 2.13.1: Gráfico de fases em função das concentrações de Nd e O 29

FIG. 3.1.1: Sistema de transferência do pó magnético em atmosfera 32 controlada

FIG. 3.1.2: Curva de sinterização em forno a vácuo 33

FIG. 3.2.1: Micrografia obtida a partir de processo metalográfico - MEV 34

FIG. 3.2.2: Imagem digitalizada a partir da micrografia gerada no MEV 35

FIG. 3.4.1.1: Corte dos ímãs sinterizados - ISOMET 38

FIG. 3.4.2.1: Esquema de corte para obtenção dos discos de 3,0mm 39 
FIG. 3.4.3.1: Tipos de "grinder" utilizados no processo de afinamento 40

FIG. 3.4.3.2: Discos de 3,0mm em processo de afinamento sucessivo 41

FIG. 3.4.4.1: "Dimpler" Gattan utilizado na preparação da amostra 42

FIG. 3.4.4.2: Esquemático de uma amostra pós "dimpler" 43

FIG. 3.4.5.1: Sistemas de fixação no equipamento de polimento iônico 44

FIG. 3.4.5.2: Dispositivo para montagem da amostra no sistema de fixação 44

FIG. 3.4.5.3: Esquemático do equipamento utilizado no polimento iônico 45 das amostras

FIG. 3.4.5.4: Esquemático do sistema de canhões de íons 46

FIG. 3.4.5.5: Esquemático do feixe iônico na obtenção da área fina 46

FIG. 3.4.5.6: (a) Foto de amostra transmissão e (b) amostra com grade 47 cobre para transmissão

FIG. 3.4.5.7: Amostra de ímã sinterizado Pr-Fe-B após preparação em "íon 48 milling" - ocorrência de trincas

FIG. 3.4.5.8: Imagem em alta resolução da região entre um grão da fase 49 matriz magnética danificada por bombardeamento iônico

FIG. 4.1.1: Curvas de desmagnetização do segundo quadrante para os 52 ímãs padrão e com adições de P e Ga (0,25\% at.)

FIG. 4.2.1: Micrografia com MEV do ímã padrão $\left(\mathrm{Pr}_{15} \mathrm{Fe}_{\mathrm{bal}} \mathrm{Co}_{8} \mathrm{~B}_{7} \mathrm{Nb}_{0.05}\right) \quad 53$

FIG. 4.2.2: Micrografia com MEV do ímã $\operatorname{Pr}_{15} \mathrm{Fe}_{\mathrm{bal}} \mathrm{Co}_{8} \mathrm{~B}_{7} \mathrm{Nb}_{0.05} \mathrm{Al}_{0,25}$

FIG. 4.2.3: Micrografia com MEV do ímã $\operatorname{Pr}_{15} \mathrm{Fe}_{\text {bal }} \mathrm{Co}_{8} \mathrm{~B}_{7} \mathrm{Nb}_{0.05} \mathrm{Si}{ }_{0,25}$

FIG. 4.2.4: Micrografia com MEV do ímã $\operatorname{Pr}_{15} \mathrm{Fe}_{\text {bal }} \mathrm{Co}_{8} \mathrm{~B}_{7} \mathrm{Nb}_{0.05} \mathrm{Cu}_{0,05}$

FIG. 4.2.5: Micrografia com MEV do ímã $\operatorname{Pr}_{15} \mathrm{Fe}_{\text {bal }} \mathrm{Co}_{8} \mathrm{~B}_{7} \mathrm{Nb}_{0.05} \mathrm{P}_{0,25}$

FIG. 4.2.6: Micrografia com MEV do ímã $\mathrm{Pr}_{15} \mathrm{Fe}_{\text {bal }} \mathrm{Co}_{8} \mathrm{~B}_{7} \mathrm{Nb}_{0.05} \mathrm{Ga}_{0,25}$

FIG. 4.2.7: Micrografia com MEV do ímã $\mathrm{Pr}_{15} \mathrm{Fe}_{\mathrm{bal}} \mathrm{Co}_{8} \mathrm{~B}_{7} \mathrm{Nb}_{0.05} \mathrm{Gd}_{0,15} \quad 56$

FIG. 4.2.8: Micrografia com MEV do ímã $\operatorname{Pr}_{15} \mathrm{Fe}_{\mathrm{bal}} \mathrm{Co}_{8} \mathrm{~B}_{7} \mathrm{Nb}_{0.05} \mathrm{~Tb}_{0,15}$

FIG. 4.2.9: Micrografia com MEV do ímã $\mathrm{Pr}_{15} \mathrm{Fe}_{\text {bal }} \mathrm{Co}_{8} \mathrm{~B}_{7} \mathrm{Nb}_{0.05} \mathrm{Dy}_{0,15}$

FIGURA 4.3.2.1 - Distribuição do tamanho de grão para o ímã, 60

$\operatorname{Pr}_{15} \mathrm{Fe}_{\text {bal }} \mathrm{CO}_{8} \mathrm{~B}_{7} \mathrm{Nb}_{0.05}$

FIGURA 4.3.2.2 - Distribuição do tamanho de grão para o ímã 61 $\mathrm{Pr}_{15} \mathrm{Fe}_{\text {bal }} \mathrm{Co}_{8} \mathrm{~B}_{7} \mathrm{Nb}_{0.05} \mathrm{Ga}_{0,25}$

FIG. 4.4.1.1: Imagem em campo claro, ponto triplo contendo a fase rica em 62 
Pr envolvida por grãos magnéticos da fase matriz com padrões de difração nas áreas selecionadas

FIG. 4.4.1.2: Padrão de difração na região de fase rica do ímã com adição de $\mathrm{Ga}(0,25 \%$ at. $)$

FIG. 4.4.1.3: Imagem em campo claro na região de ponto triplo do ímã 64 $\mathrm{Pr}_{15} \mathrm{Fe}_{\text {bal }} \mathrm{Co}_{8} \mathrm{~B}_{7} \mathrm{Nb}_{0.05} \mathrm{Ga}_{0,25}$

FIGURA 4.4.1.4 - Imagem em campo claro mostra uma região com fases 65 ricas em boro e oxigênio confirmadas com EDS

FIG. 4.4.1.5: EDS, modo STEM na linha indicada em região de contorno de 67 grão magnético no ímã com adição de Ga (0,25\% at.)

FIG.4.4.1.6: Imagem em campo claro da região entre grãos da fase matriz 68 do ímã $\operatorname{Pr}_{15} \mathrm{Fe}_{\text {bal }} \mathrm{Co}_{8} \mathrm{~B}_{7} \mathrm{Nb}_{0.05} \mathrm{P}_{0,25}$

FIG.4.4.1.7 Mapa de elementos do ponto triplo identificado na imagem em 69 campo claro para os elementos $\mathrm{P}$, Pr e Fe.

FIG. 4.4.2.1 - Imagens em alta resolução na região de fase rica em Pr para 70 o ímã $\operatorname{Pr}_{15} \mathrm{Fe}_{\text {bal }} \mathrm{Co}_{8} \mathrm{~B}_{7} \mathrm{Nb}_{0,05} \mathrm{Ga}_{0,25}$.

FIG. 4.4.2.2- Imagem de alta resolução do ímã $\operatorname{Pr}_{15} \mathrm{Fe}_{b_{a}} \mathrm{Co}_{8} \mathrm{~B}_{7} \mathrm{Nb}_{0,05} \mathrm{Ga}_{0,25 .}, 71$ na fase matriz identificada pela distância interplanar, $d_{\mathrm{hkl}} \sim 0,9 \mathrm{~nm}$.

FIG. 4.4.3.1: Imagem em campo claro na região do contorno selecionada 72 entre dois grãos da fase matriz no ímã permanente padrão $\left(\mathrm{Pr}_{15} \mathrm{Fe}_{\mathrm{bal}} \mathrm{Co}_{8} \mathrm{~B}_{7} \mathrm{Nb}_{0,05}\right)$.

FIG. 4.4.3.2: Imagens em alta resolução na região do contorno entre dois 73 grãos da fase matriz selecionadas no ímã $\mathrm{Pr}_{15} \mathrm{Fe}_{\text {bal }} \mathrm{Co}_{8} \mathrm{~B}_{7} \mathrm{Nb}_{0,05}$.

FIG. 4.4.3.3: Imagem de alta resolução no contorno de grão para o ímã 74 permanente PrFeCoBNbGa 0,25 . com modificação na matriz.

FIG. 4.4.3.4: Imagem de alta resolução no contorno de grão para o ímã 75 permanente PrFeCoBNbGa $0,25$. com alta magnificação.

FIG. 4.4.4.1: Imagem em campo claro para o ímã com adição de Cu 0,15\% 77 at. com ponto triplo de alta concentração de $\mathrm{Nb}$.

FIG. 4.4.4.2: EDS na região central da FIG. 4.4.4.1, com pico de $\mathrm{Nb} 78$ identificado

FIG. 4.4.4.3: Precipitado da ordem de 100 nm com alta concentração de $\operatorname{Pr} 78$ 
FIG. 4.4.4.4: $\mathrm{Em} \mathrm{(a),} \mathrm{tensões} \mathrm{de} \mathrm{rede,} \mathrm{na} \mathrm{região} \mathrm{do} \mathrm{contorno} 79$ $\mathrm{PrFeCoBNbP}_{0,25}$ e em (b) precipitado na fase matriz do ímã PrFeCoBNbGa 0,25

FIGURA 4.4.4.5 - Imagem de alta resolução na região entre dois grãos 80 magnéticos da fase matriz no ímã PrFeCoBNbGa ${ }_{0,25}$ com distorções dos planos atômicos e ausência do material de contorno 


\section{CAPÍTULO 1}

\section{Introdução}

As pesquisas com materiais magnéticos de alto desempenho tem sido alvo de grande interesse do ponto de vista tecnológico nos últimos vinte anos devido à grande diversidade de aplicações, envolvendo especialmente os ímãs permanentes sinterizados à base de compostos ternários, principalmente os de $\mathrm{Nd}-\mathrm{Fe}-\mathrm{B}$. A compreensão dos fenômenos físicos e dos mecanismos de controle das propriedades magnéticas envolvidas são questões fundamentais para as pesquisas visando à intensificação das propriedades desses materiais, que hoje, tem aplicações em importantes seguimentos tecnológicos como áreas ligadas à energia e à computação. Nesse estudo inédito serão examinadas amostras de ímãs permanentes à base de PrFeB processadas com adições de elementos de liga, através de microscopia eletrônica de varredura e transmissão.

\section{1- Breve Histórico}

Os ímãs permanentes sinterizados à base de a $\mathrm{NdFeB}$ desenvolvidos por Sagawa et al. (1984), tiveram sua exata estequiometria e estrutura cristalina confirmada por difração de nêutrons por Herbst et al. (1985). Apresentavam estrutura cristalina tetragonal - grupo espacial $\mathrm{P} 4_{2} / \mathrm{mnm}$, mostrada na Figura 1.1.1 e substituíram os ímãs da classe SmCo impulsionando as pesquisas nessa área, não só pelas propriedades magnéticas que se apresentaram superiores, más também pela questão envolvendo o custo e a disponibilidade do Samário no mundo. Posteriormente, Jinghua et al. (1987), descobriram que a estrutura cristalina do composto $\mathrm{Pr}_{2} \mathrm{Fe}_{14} \mathrm{~B}$ era análoga a do $\mathrm{Nd}_{2} \mathrm{Fe}_{14} \mathrm{~B}$, porém, com os átomos do $\mathrm{Pr}$ ocupando o lugar do $\mathrm{Nd}$. Num extenso trabalho de revisão sobre a classe de materiais $\mathrm{R}_{2} \mathrm{Fe}_{14} \mathrm{~B}$, Herbst (1991), realça que as propriedades magnéticas do composto $\operatorname{Pr}_{2} \mathrm{Fe}_{14} \mathrm{~B}$, são aproximadamente similares as do 
composto $\mathrm{Nd}_{2} \mathrm{Fe}_{14} \mathrm{~B}$. Neiva et al. (1995), obtiveram o diagrama de fase para $\circ$ sistema $\mathrm{Pr}-\mathrm{Fe}-\mathrm{B}$ e confirmaram grande similaridade com o sistema $\mathrm{Nd}-\mathrm{Fe}-\mathrm{B}$ tanto no diagrama de fase quanto na microestrutura. Questões referentes às diferenças na sinterização dos dois compostos também foram estudadas por Taylor et al. (2002) e concluíram que o composto a base de Pr apresentava densificação mais rápida que o composto com $\mathrm{Nd}$, indicando diferenças na característica da molhabilidade e na solubilidade desses compostos. A utilização do $\operatorname{Pr}$ ao invés do $\mathrm{Nd}$ pode ser justificada com vantagens devido à não reorientação de spin em baixas temperaturas, abaixo de $135 \mathrm{~K}$, e aos altos valores para o campo de anisotropia uniaxial com fácil magnetização a $4 \mathrm{~K}$ (Kim et al., 2000). Disponível no mercado de terras raras, devido à própria extração do $\mathrm{Nd}$, o $\mathrm{Pr}$ pode apresentar preço de mercado interessante de acordo com a demanda embora seja menos abundante que o Nd (( McGuiness et al., 2001), (Sinton et al.,2004)).

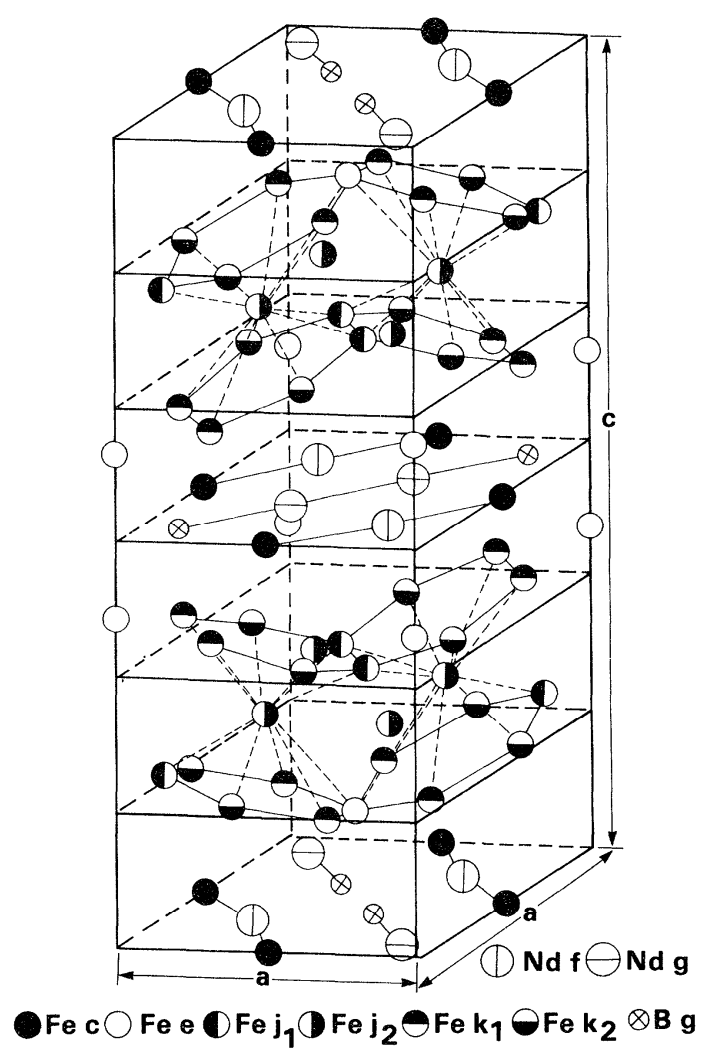

FIGURA 1.1.1 - Célula unitária de estrutura tetragonal da fase $\mathrm{Nd}_{2} \mathrm{Fe}_{14} \mathrm{~B}$, análoga a fase $\mathrm{Pr}_{2} \mathrm{Fe}_{14} \mathrm{~B}$ (Herbst et al.,1985a ). 
O indicador utilizado na avaliação de desempenho dos materiais magnéticos pode ser ilustrado pela propriedade denominada produto máximo de energia $\left(\mathrm{BH}_{\max }\right)$, que é o máximo valor do produto entre a indução magnética $\left(B_{r}\right)$ e o campo aplicado $(H)$ no segundo quadrante da curva magnética de histerese. Em linhas gerais diz que quanto maior o $\mathrm{BH}_{\max }$, maior o potencial para se reduzir o volume e o peso dos ímãs nas aplicações a que se destinam.

A Figura 1.1.2 apresenta os valores dos produtos máximos de energia $\left(\mathrm{BH}_{\max }\right)$ obtidos em laboratório para os ímãs a base de Nd-Fe-B com adições de Dy e Tb, de 1987 até 2005 com um valor máximo de 474 kJ.m³ estabelecido pelo fabricante japonês NEOMAX Co, Ltd. (Matsuura, 2006).

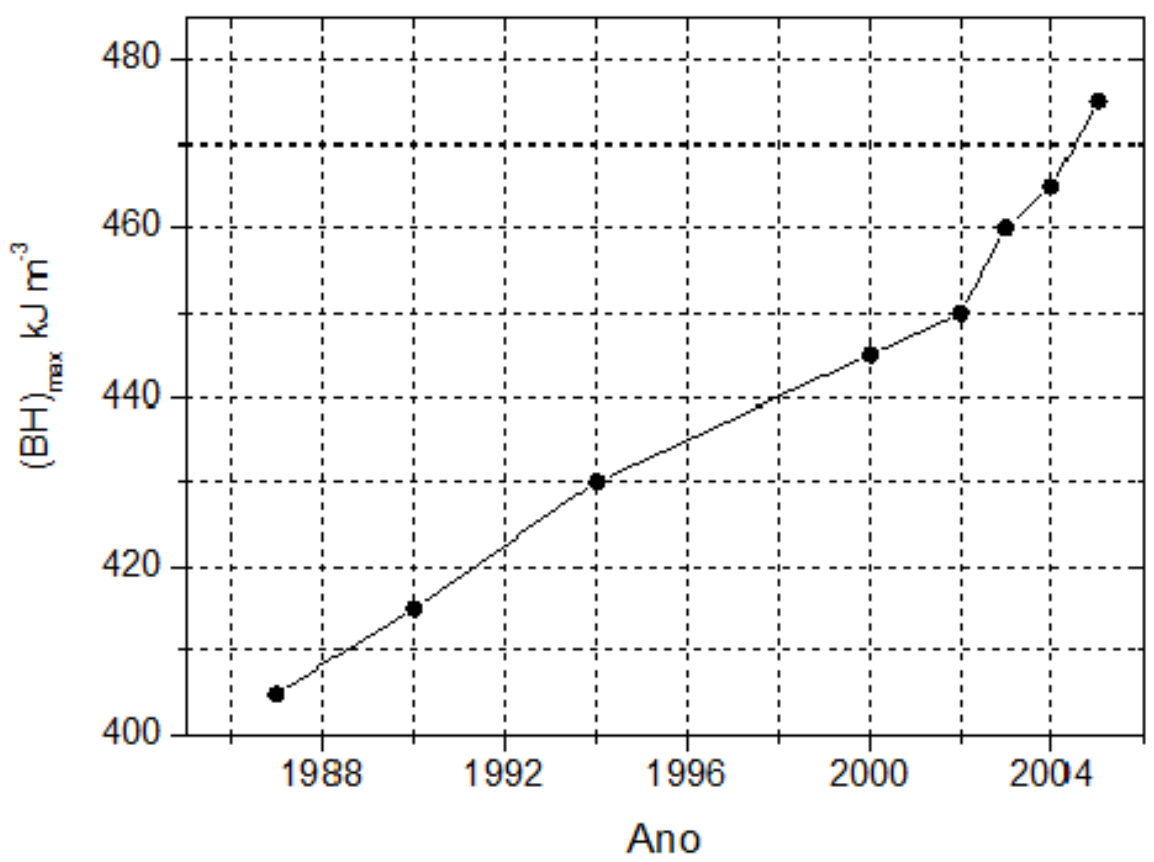

FIGURA 1.1.2 - Evolução dos resultados obtidos para o $\mathrm{BH}_{\max }$ em laboratório para ímãs do tipo Nd-Fe-B. (Matsuura, 2006).

Embora tenha sido considerável a evolução do produto de energia, $\mathrm{BH}_{\max }$, nos ímãs a base de TR-Fe-B, problemas envolvendo a baixa estabilidade de temperatura e à corrosão, levaram às novas pesquisas visando minimizar esses fatores. A modificação dessas ligas ternárias através da adição de outros elementos que alteram a microestrutura tem sido uma alternativa para 
intensificar algumas características de interesse, porém, quase sempre em detrimento de outras. Pelo menos três fases podem ocorrer nos ímãs sinterizados a base de TR-Fe-B: a fase magnética ou matriz $(\Phi)\left(\mathrm{Nd}_{2} \mathrm{Fe}_{14} \mathrm{~B}\right)$, a fase boreto $\left(\mathrm{Nd}_{1+\varepsilon} \mathrm{Fe}_{4} \mathrm{~B}_{4}\right)$ e a fase rica em $\mathrm{Nd}(\eta)$. As adições de liga feitas de maneira seletiva promovem algumas propriedades, mas afetam outras, por exemplo, a substituição parcial do $\mathrm{Fe}$ pelo Co resulta no aumento da temperatura de Curie $\left(T_{c}\right)$, porém, reduz a coercividade $\left(H_{c i}\right)$ (Kim et al., 1996).

A coercividade nos ímãs permanentes sinterizados depende significativamente da microestrutura da fase rica em $\mathrm{Nd}$, que ocorre em torno dos $650^{\circ} \mathrm{C}$, age na fase líquida da sinterização e promove a formação de uma fina camada que separa os grãos da fase magnética $\mathrm{Nd}_{2} \mathrm{Fe}_{14} \mathrm{~B}$.

Por aumentarem a anisotropia do material, a adição de terras raras pesadas como $\mathrm{Tb}$ e Dy também aumentam consideravelmente a coercividade e conseqüentemente o produto de energia $(\mathrm{BH})$. Hoje, no entanto, o alto custo do Dy (cerca de três vezes mais que $\circ \mathrm{Nd}$ ) faz com que as pesquisas com ímãs permanentes "livres de Dy" se intensifiquem. O processo de adições de elementos com baixo ponto de fusão, baixa solubilidade na fase matriz e com tratamento térmico adequado constitui uma boa alternativa tecnológica. Recentemente, as diversas aplicações com ímãs permanentes na indústria automotiva, levaram o Japão a rever as pesquisas buscando ímãs com alta coercividade livres de Dy.

Nesse trabalho foram estudados os ímãs sinterizados à base de PrFeB com adições de alguns elementos de liga visando modificar a microestrutura e posteriormente com auxílio de microscopia eletrônica de varredura e de transmissão, investigar a microestrutura e estabelecer uma relação com as propriedades magnéticas.

\section{2 - Importância Tecnológica}

A retomada das pesquisas visando aumentar as propriedades magnéticas dos ímãs permanentes sinterizados à base de Terras Raras - $\mathrm{Fe}-\mathrm{B}$, decorrem das atuais exigências de mercado. $O$ grande crescimento na produção de $\mathrm{NdFeB}$ no mundo se deu inicialmente pela expansão do mercado de 
computadores pessoais na década de noventa, com a utilização desses ímãs nos dispositivos leitores dos discos magnéticos (VCM) bem como em equipamentos de CD, DVD e auto-falantes. Devido à tendência da aplicação desses materiais em veículos elétricos, acredita-se que o consumo de NdFeB deve aumentar significativamente. Em 2007, a aplicação desses materiais em veículos elétricos e híbridos representou $13 \%$ do total produzido na China. Aplicações importantes envolvendo sistemas servo-controlados na indústria robótica, telefonia celular e ressonância magnética também são promissoras, bem como a inclusão da chamada "linha branca", onde produtos como lavadoras, refrigeradores, etc., também estariam incluídos visando-se melhor conservação e rendimento de energia (Brown et al., 2002).

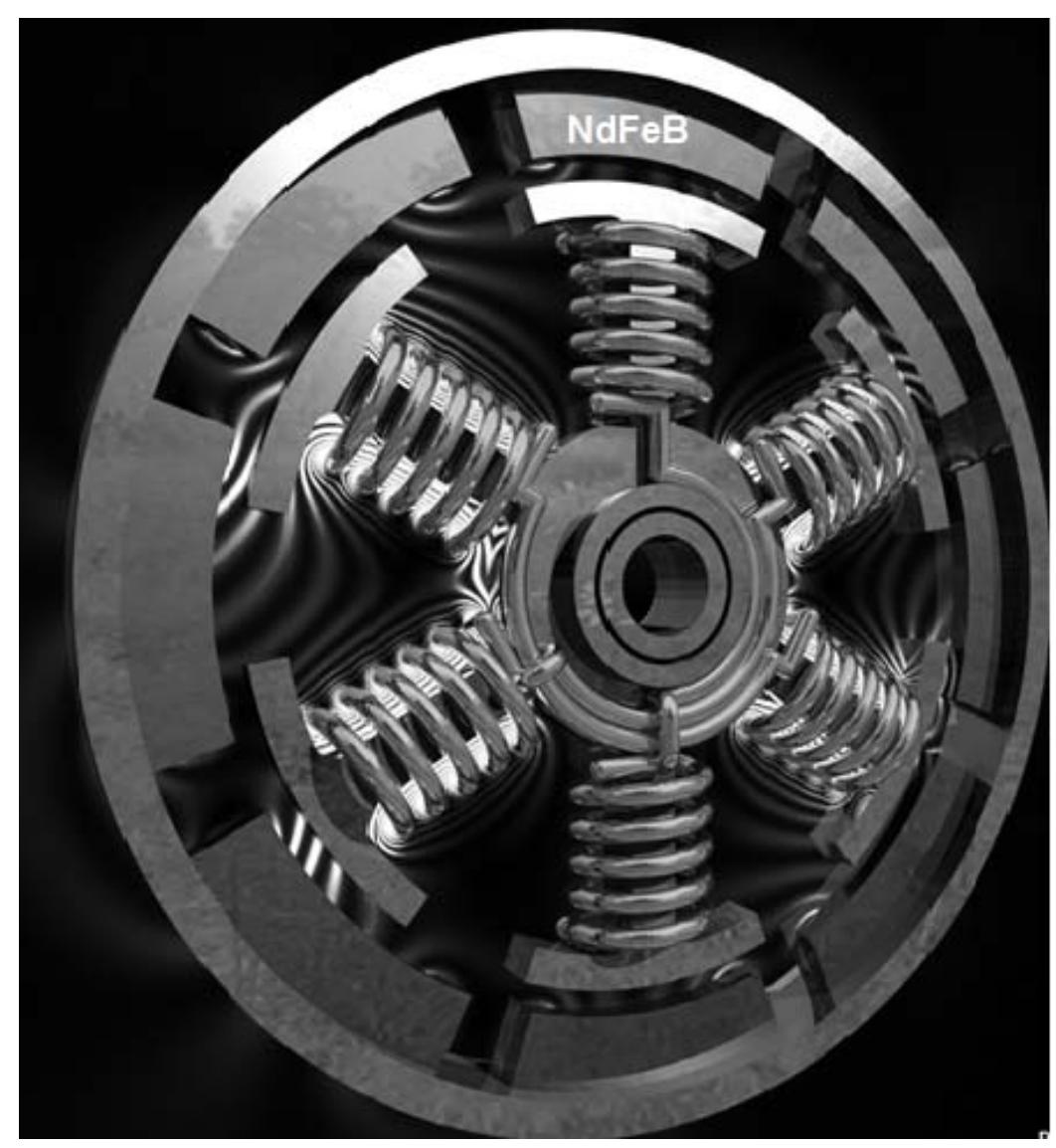

FIGURA 1.2.1 - Motor elétrico DC sem escovas que utiliza no rotor, ímãs sinterizados à base de $\mathrm{NdFeB}$. 


\section{3 - Objetivos}

Esse trabalho apresenta inicialmente o exame da microestrutura de ímãs produzidos pelo processo de mistura de ligas (Faria et al., 2001) que foram investigados com auxílio de microscopia eletrônica de varredura (MEV), para que se pudesse correlacionar as variáveis correspondentes ao tamanho e formato dos grãos magnéticos ao fator de quadratura e à coercividade dos ímãs dopados com Al, P, Si, Ga, Gd, Cu, Dy e Tb em diversas concentrações.

Elementos específicos quando adicionados em concentrações adequadas à liga padrão podem gerar resultados satisfatórios e estão apresentados na revisão da literatura. Visando-se avaliar a influência da adição de elementos de liga sobre a coercividade, investigou-se a microestrutura nas regiões de fase rica em $\operatorname{Pr}$ e nos contornos de grão com auxílio de microscopia eletrônica de transmissão (MET) e microanálise com EDS.

Questões como a composição da fase intergranular não magnética nos contornos entre grãos da fase matriz e a localização de defeitos e precipitados na fase matriz, também foram objetos desse estudo, bem como a análise com EDS buscando identificar a distribuição dos elementos de adição e a presença de $\mathrm{B}$ e O.

Portanto, o objetivo desta pesquisa consiste na investigação da microestrutura de ímãs à base de PrFeCoBNb com adições de elementos de liga, especialmente nas regiões de pontos triplos e nos contornos de grãos, cuja característica e composição pode afetar a coercividade desses ímãs.

\section{4 - Organização do Trabalho}

i)

A primeira etapa desse trabalho, apresentada no Capítulo 2, trata da revisão bibliográfica envolvendo a conceituação teórica do magnetismo aplicado aos materiais magnéticos e dos estudos anteriores sobre a influência da adição de elementos de liga em ímãs sinterizados à base de $\mathrm{NdFeB}$ e sua correlação com as propriedades magnéticas. 
ii)

No Capítulo 3 (materiais e métodos), estão discutidas as etapas do processamento dos ímãs permanentes sinterizados à base de $\mathrm{Pr}_{15} \mathrm{Fe}_{\text {bal }} \mathrm{Co}_{8} \mathrm{~B}_{7} \mathrm{Nb}_{0,05}$ com adições de elementos de liga à partir de uma mistura de ligas, por tecnologia do pó com decrepitação de hidrogênio (HD), moagem de alta energia e posterior sinterização em forno à vácuo. A seguir, realizou-se a preparação de amostras para microscopia eletrônica de varredura (MEV) e tratamento das imagens para investigação do formato e tamanho dos grãos. $\mathrm{Na}$ etapa seguinte, discorre-se sobre a preparação de amostras para utilização em microscopia eletrônica de transmissão (MET).

iii)

No Capítulo 4 (resultados e discussão), fez-se inicialmente uma análise com microscopia eletrônica de varredura (MEV) utilizando-se um programa computacional para tratamento de imagens. Finalmente, buscando-se associar os valores de coercividade à microestrutura, amostras contendo adições de $\mathrm{Ga} \mathrm{e}$ $\mathrm{P}$ foram comparadas ao padrão $\mathrm{Pr}_{15} \mathrm{Fe}_{\text {bal }} \mathrm{Co}_{8} \mathrm{~B}_{7} \mathrm{Nb}_{0.05}$ com a utilização de microscopia eletrônica de transmissão (MET), juntamente com os recursos de microanálise por EDS e difração eletrônica, que permitiram a investigação da modificação causada na microestrutura, comparada às propriedades magnéticas. Foram utilizados microscópios eletrônicos de transmissão JEOL / JEM-2100 (200 kV) com EDS acoplado para a microanálise e JEOL/JEM 3010 (300 kV) de alta resolução, para a investigação dos contornos de grãos.

Os ímãs escolhidos para esta análise se restringiram a àqueles que apresentaram valores de coercividade superiores em relação ao padrão $\mathrm{Pr}_{15} \mathrm{Fe}_{\text {bal }} \mathrm{Co}_{8} \mathrm{~B}_{7} \mathrm{Nb}_{0.05}$, caso do ímã com adição de $\mathrm{Ga}$ (0,25\% at.). $\mathrm{O}$ ímã com adição de $\mathrm{P}(0,25 \%$ at.) mostrou bons resultados para os valores do produto de energia máximo e do fator de quadratura, porém com baixa coercividade em relação ao padrão e também foi investigado com auxílio de MET.

iv)

O Capítulo 5 apresenta as conclusões finais. 


\section{CAPÍTULO 2}

\section{Revisão da Literatura}

A boa compreensão dos mecanismos de controle das propriedades magnéticas dos ímãs permanentes a base de terras raras - ferro - boro são fundamentais para o desenvolvimento tecnológico desses materiais. Esse capítulo aborda os conceitos físicos envolvidos no desempenho dos ímãs permanentes sinterizados a base de TR-Fe-B, tais como a anisotropia magnetocristalina, a teoria dos domínios magnéticos, as propriedades magnéticas extraídas do segundo quadrante da curva de histerese e finalmente uma revisão de trabalhos anteriores sobre a modificação da microestrutura devido à adição de elementos de liga e seu impacto sobre as propriedades magnéticas.

\section{1 - Momentos magnéticos}

Os momentos magnéticos são resultados do momento angular de rotação (spin) e do movimento orbital de translação dos elétrons em torno do núcleo.

A maioria dos elementos da tabela periódica não possui momentos magnéticos atômicos exceto alguns dos metais de transição $3 d$ ( $\mathrm{Ni}$, Fe, Co e $\mathrm{Mn}$ ) e os terras raras $4 f(\mathrm{Nd}, \mathrm{Gd}, \mathrm{Ga}$, etc.) que são os maiores constituintes dos materiais magnéticos importantes (Kaufmann, 2003). Os momentos magnéticos atômicos podem interagir uns com os outros via interações de troca explicadas pela mecânica quântica e não serão discutidas nesse trabalho. 


\section{2 - Anisotropia Magnetocristalina}

Diz-se que um material magnético possui anisotropia magnética se a energia interna depende da direção da magnetização espontânea em relação aos eixos cristalográficos. Fenomenologicamente, a energia de anisotropia pode ser descrita por uma série expandida, que para o caso de simetria tetragonal é dado por:

$$
E_{a n}(\theta, \varphi)=K_{1} \operatorname{sen}^{2} \theta+K_{2} \operatorname{sen}^{4} \theta+K_{3} \operatorname{sen}^{4} \theta \cos 4 \varphi
$$

onde $\mathrm{K}_{1}, \mathrm{~K}_{2}$ e $\mathrm{K}_{3}$ são as constantes de anisotropia e a direção da magnetização espontânea relativa ao eixo "c" e ao eixo "a" é dado pelos ângulos polares $\theta$ e $\varphi$ respectivamente (Buschow, 2004). A Figura (2.1.1) ilustra a definição dos eixos cristalográficos.

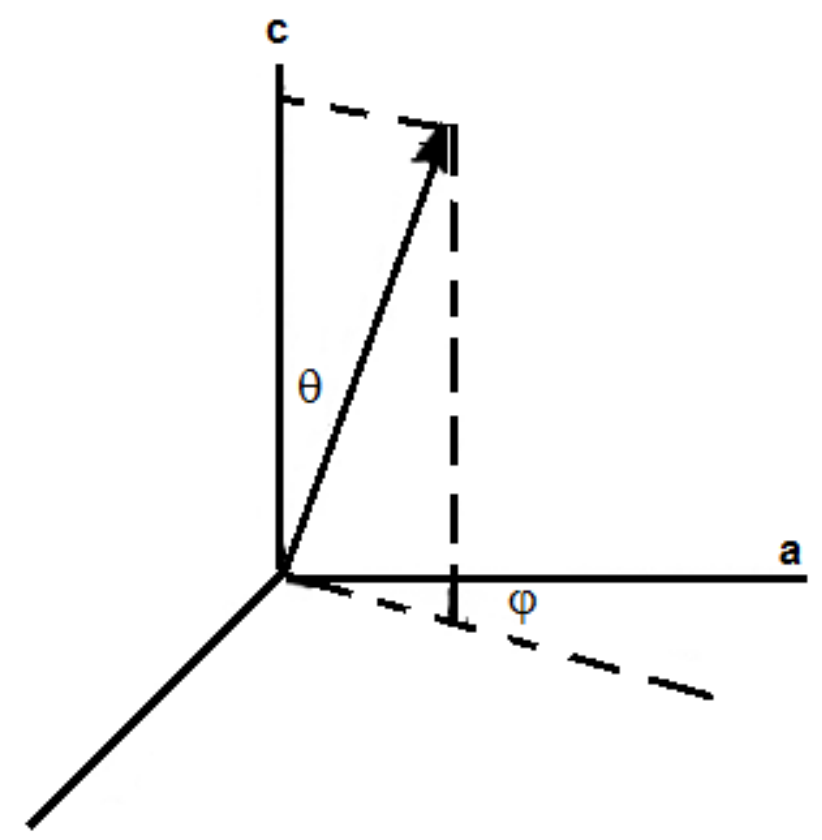

FIGURA 2.2.1 - Definição dos eixos "c" e "a" e os respectivos ângulos $\theta$ e $\varphi$. 
Para um material com um eixo de fácil magnetização (uniaxial), pode-se considerar somente o primeiro termo da equação (2.1.1) onde $K_{1}$ representa a constante de anisotropia e $M_{s}$ é a magnetização de saturação do material. A anisotropia também pode ser descrita, como a quantidade de energia necessária para movimentar a magnetização da direção fácil (paralela ao eixo "c"), para outra direção e é denominada campo de anisotropia $\left(\mathrm{H}_{\mathrm{a}}\right)$ (Faria et al., 2003). Pode ser expressa como:

$$
H_{a}=\frac{2 k_{1}}{M_{s}}
$$

Os valores experimentais do campo de anisotropia $\left(H_{a}\right)$ são comumente obtidos pela medida das curvas de polarização magnética, com aplicação de campo paralelo e perpendicular ao eixo de fácil magnetização (Buschow, 2004).

A figura 2.2.2 mostra a curva de magnetização para um monocristal de Fe nas direções [100], [110] e [111].

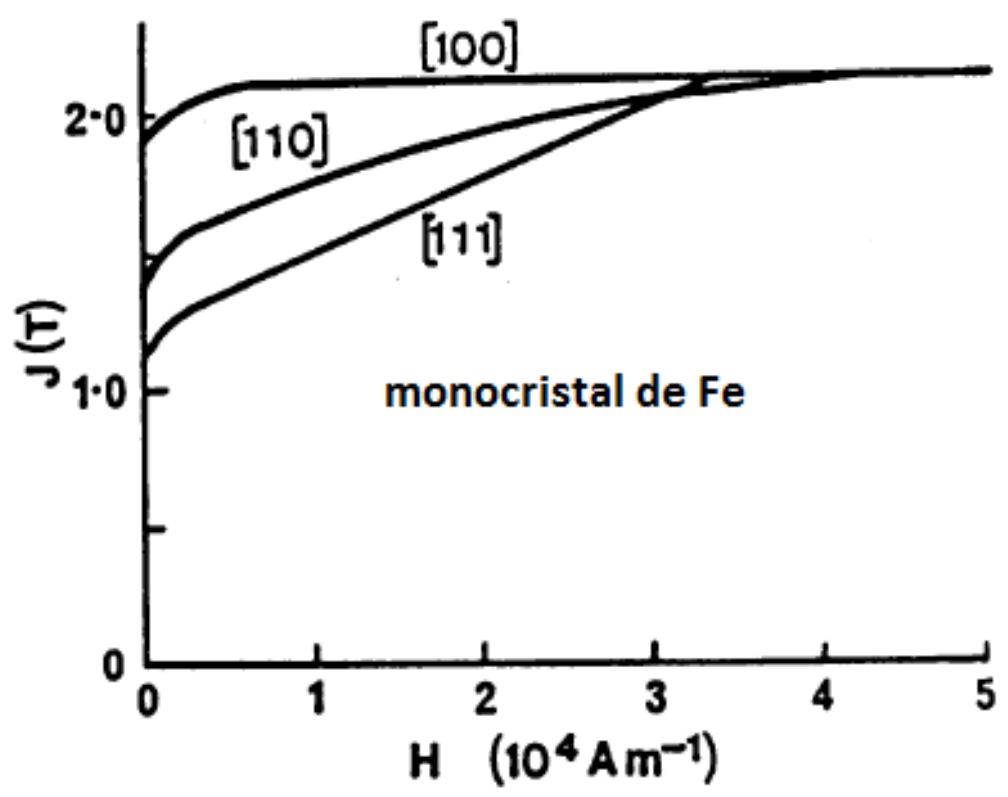

FIGURA 2.2.2 - Curvas de magnetização para um monocristal de Fe em função da direção dos eixos cristalográficos.

Observa-se da figura 2.2.2 que a direção [100], corresponde ao eixo "c" de fácil magnetização, onde a magnetização de saturação é alcançada na presença de um campo aplicado muito menor do que nas demais direções. 


\section{3 - Domínios Magnéticos}

Denomina-se domínio magnético a região de volume microscópico, onde os momentos de dipolo magnéticos tendem a se alinhar no mesmo sentido. Dentro de cada pequena região bem definida, a magnetização se apresenta em seu máximo valor, ou seja, está magneticamente saturada. Para materiais policristalinos, cada grão pode conter vários domínios. Quando se diz que um material ferromagnético está desmagnetizado isto significa que seus domínios estão orientados aleatoriamente e, portanto o momento magnético global é nulo. Quando um campo magnético externo $(\mathrm{H})$ é aplicado, os domínios tendem a se alinhar e atingem a saturação (Faria, 2003).

A Figura 2.3.1 ilustra em (a) a situação desmagnetizada e em (b) a saturação para um material poli cristalino onde $\mathrm{Jr}=\mathrm{J} s$ (situação de um ímã perfeito).

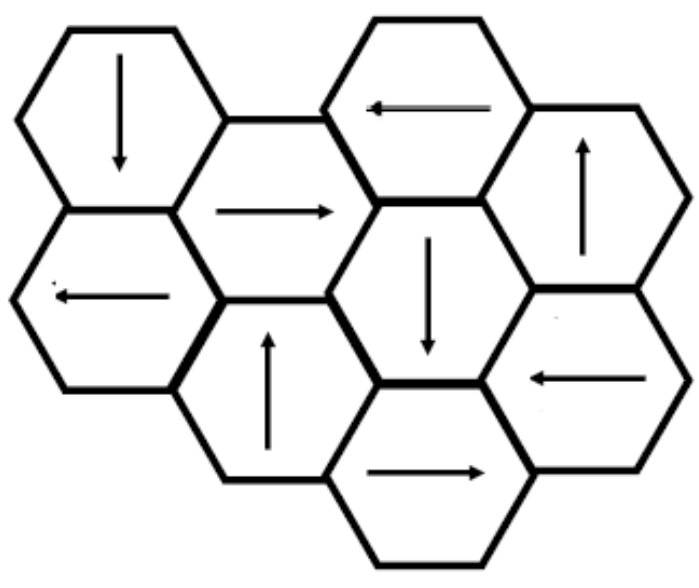

(a)

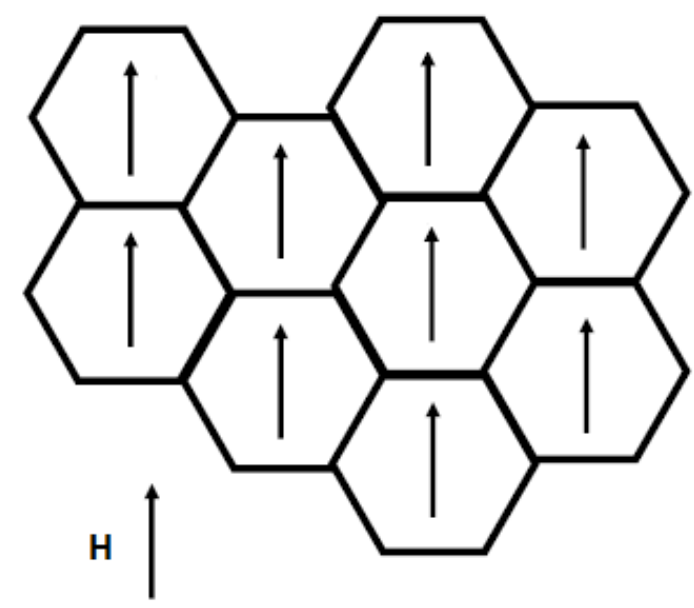

(b)

FIGURA 2.3.1 - Esquemático de um "policristal” ferromagnético desmagnetizado em (a) e saturado em (b). 


\section{4 - Paredes de Domínio}

As interfaces entre dois domínios adjacentes são denominadas paredes de domínio, através das quais existe a variação gradual da direção da magnetização. A transição entre dois domínios não poderia se dar de maneira abrupta pois isto envolveria uma energia de troca muito alta. Este tipo de interface entre dipolos magnéticos é denominada parede de Bloch de $180^{\circ}$ (Kittel, 1949).

A Figura 2.4.1 ilustra o modelo sugerido por Bloch.

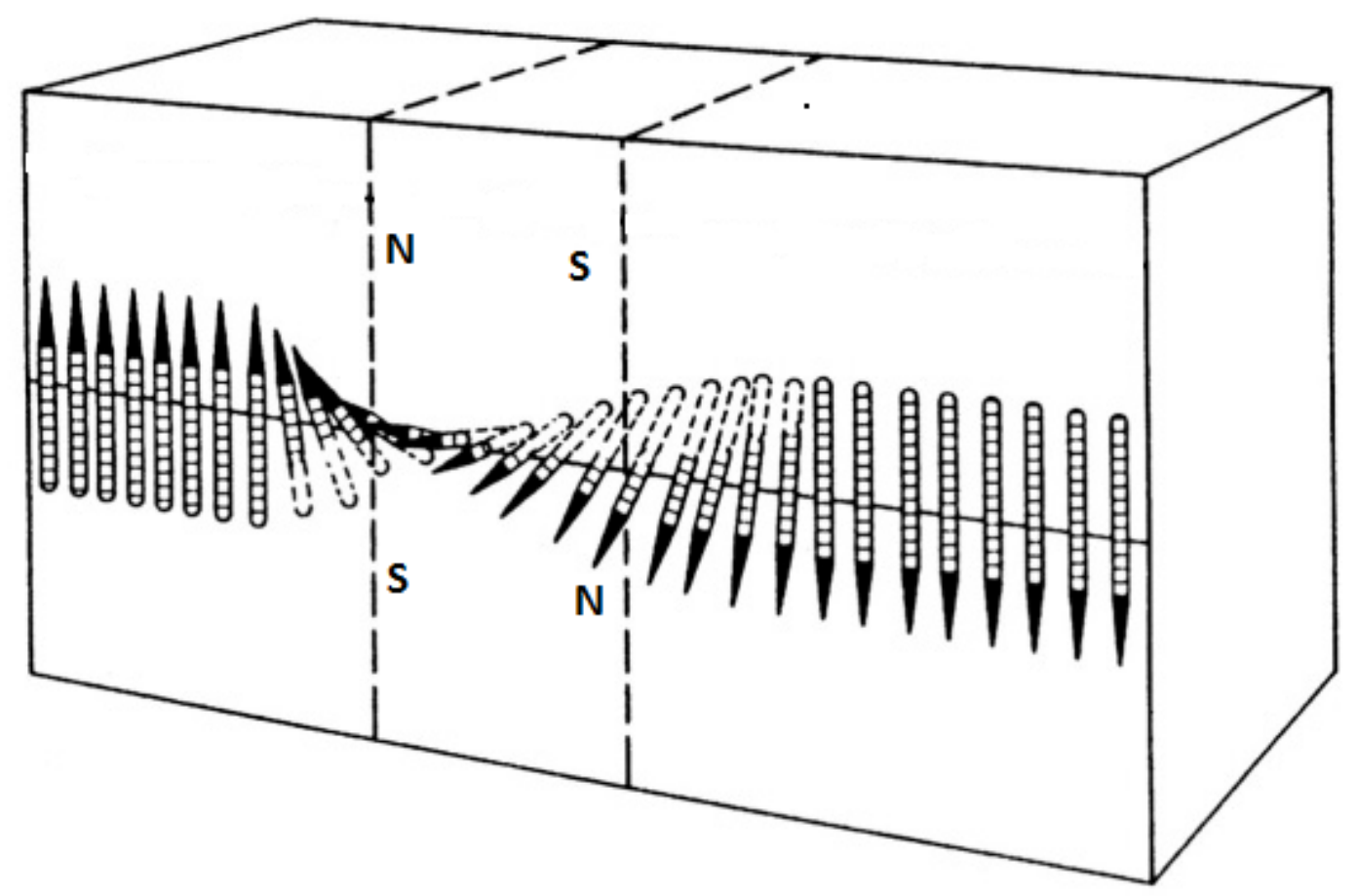

FIGURA 2.4.1 - Representação esquemática da mudança de orientação de $180^{\circ}$ na parede de domínio. (Kittel, 1949).

A mudança de direção dos momentos de magnetização envolve a chamada energia por unidade de área da parede que pode ser definida como a diferença entre a energia dos momentos magnéticos na região da interface delimitada na Figura 2.4.1 e a energia da região principal do domínio. 
A energia dos momentos na parede de domínio é causada pelo acoplamento entre os momentos magnéticos atômicos e a anisotropia. A anisotropia tende a fazer com que a parede fique mais fina uma vez a energia de anisotropia é menor com todos os momentos alinhados ao longo dos eixos cristalográficos equivalentes. A energia de troca tende a fazer com que a parede fique mais espessa uma vez que a energia de troca num ferromagnético é minimizada quando momentos vizinhos estão alinhados em paralelo (Jiles, 1998).

A energia de um campo magnético produzido pelo material, ou energia magnetostática, será mínima quanto menor for este campo externo e, finalmente, a energia associada à deformação de um corpo, provocada pela ação de um campo magnético (magnetostrição), será minimizada quando o material estiver orientado de tal maneira que ocorrerão mudanças em suas dimensões ao longo do eixo de magnetização (Faria, 2003). Considerando as contribuições descritas acima pode-se escrever a equação geral da energia de um sistema magnético como sendo:

$$
E=E_{\text {troca }}+E_{\text {anisotropia }}+E_{\text {magnetostição }}+E_{\text {magnetostáica }}
$$

\section{5 - Segundo Quadrante do Ciclo de Histerese}

As características magnéticas de um ímã são determinadas a partir do ciclo de histerese, e representam as respostas diante da ação de um campo magnetizante ou desmagnetizante. As grandezas envolvidas nesse processo são: o campo aplicado $\left(\mu_{0} H\right)$, a polarização $(J)$ e a densidade de fluxo que depende de $J$ e $\mu_{0} H$ e estão relacionadas da seguinte forma (Jiles, 1998):

$$
B=\mu_{0} H+J
$$

onde $B$ representa a indução magnética ou densidade de fluxo $\operatorname{com} B$ e $J$ grandezas vetoriais com módulo direção e sentido e são expressos em tesla (T) e $H$ em Ampére por metro $\left(\mathrm{Am}^{-1}\right)$ no sistema internacional de unidades.(S.I.). 
Embora hoje o sistema internacional seja mais utilizado, ainda é considerável a utilização do sistema C.G.S. nos estudos do magnetismo devido à igualdade dimensional entre $(B)$ e $(H)$. A conversão entre os dois sistemas pode ser expressa conforme ilustra a TAB. 2.5.1.

TABELA 2.5.1 - Conversão de unidades entre o sistema C.G.S. e S.I

\begin{tabular}{|c|c|c|c|}
\hline Grandeza & C.G.S. & S.I. & Conversão \\
\hline $\mathrm{H}$ & Oersted (Oe) & $\mathrm{A} / \mathrm{m}$ & 1 Oe $=79,6 \mathrm{~A} / \mathrm{m}$ \\
\hline$\mu_{0} \mathrm{H}$ & Oersted (Oe) & Tesla $(\mathrm{T})$ & $10 \mathrm{O}=10^{-4} \mathrm{~T}$ \\
\hline $\mathrm{B}$ & Gauss $(\mathrm{G})$ & Tesla $(\mathrm{T})$ & $10 \mathrm{Oe}=10^{-4} \mathrm{~T}$ \\
\hline$(\mathrm{BH})_{\max }$ & MGOe & $\mathrm{kJ} / \mathrm{m}^{3}$ & $1 \mathrm{MGOe}=7,96 \mathrm{~kJ} / \mathrm{m}^{3}$ \\
\hline
\end{tabular}

A partir da construção da curva de desmagnetização, pela aplicação de um campo de sentido inverso ao de saturação até que $(B)$ ou $(J)$ caiam a zero, pode-se determinar as grandezas $\mu_{0} \mathrm{H}, \mathrm{B}$ e $\mathrm{J}$, bem como o produto de energia máximo $(\mathrm{BH})_{\max }$ e o fator de quadratura (FQ) discutidos a seguir. O produto de energia máximo $(\mathrm{BH})_{\max }$ para uma ímã permanente representa o campo que pode ser produzido externamente ao magneto por unidade de volume e é encarado como um fator de mérito na monitoração da evolução desses materiais (Herbst, 1991).

A FIG. 2.5.1 mostra as curvas de desmagnetização que representam o segundo quadrante da curva completa de histerese e podem ser expressas na forma intrínseca $\left(J \times \mu_{0} H\right)$ ou indutiva $\left(B \times \mu_{0} H\right)$. 


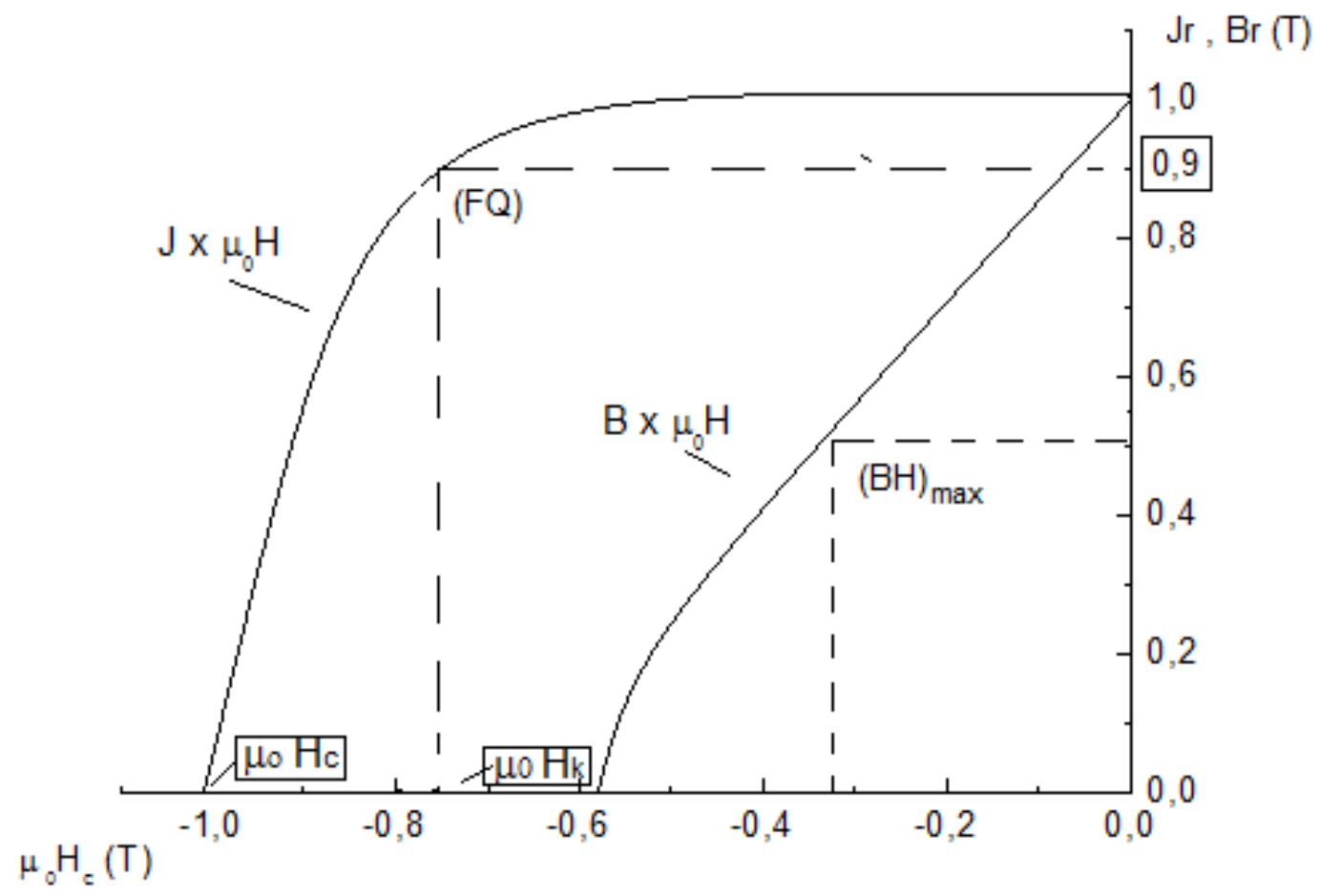

FIGURA 2.5.1 - Curva de desmagnetização intrínseca $\left(J \times \mu_{0} H\right)$ e indutiva $\left(B \times \mu_{0} H\right)$.

\section{6 - Remanência - $B_{r}$}

A remanência $\left(B_{r}\right)$, determina a densidade de fluxo que permanece após a remoção do campo magnetizante e portanto, uma medida da força do ímã (Buschow, 2004). A partir da curva de desmagnetização do ímã, pode-se extrair o valor da remanência onde a curva intercepta a ordenada e o campo desmagnetizante $\left(-\mu_{0} H\right)$ é nulo naquele instante.

A equação da remanência pode ser escrita como:

$$
B_{r}=<\cos \theta>f . P . \mu_{0} M_{s}
$$


Esta propriedade depende de fatores como: grau de orientação cristalográfica identificado como $(<\cos \theta>)$, onde $\theta$ é o ângulo entre a direção de fácil magnetização e a orientação média dos grãos contidos no material; $\boldsymbol{f}$ é a fração volumétrica da fase magnética; $\rho_{t} / \rho_{r}=\boldsymbol{P}$ é o fator de densidade calculado pela razão entre a densidade teórica e a densidade real; $\mu_{0}$ é a permeabilidade magnética no vácuo e $\boldsymbol{M}_{\boldsymbol{s}}$ a magnetização de saturação, que é uma propriedade intrínseca do material e quanto mais elevada for, maior será o campo produzido por um ímã.

\section{7 - Coercividade Intrínseca - $\mu_{0} \mathrm{H}_{\mathrm{c}}$}

A partir da curva intrínseca de desmagnetização é possível extrair-se o valor da coercividade correspondente ao ponto da curva que intercepta a abscissa e conseqüentemente com valor nulo para a polarização $(\mathrm{J})$. Os parâmetros microestruturais (distribuição de fases, composição química, e estrutura cristalina) e os de processamento (preparação das ligas, tamanho e formato dos grãos, alinhamento, sinterização e tratamento térmico) são determinantes nos valores da coercividade dos ímãs sinterizados (Fidler et al., 1989). A coercividade intrínseca ( $\mu_{0}$ ${ }_{\mathrm{i}} \mathrm{H}_{\mathrm{c}}$ ) de um ímã permanente sinterizado à temperatura ambiente pode ser expressa como:

$$
\mu_{\mathrm{O}} \mathrm{H}_{\mathrm{C}}=\mathrm{C} \mu_{\mathrm{O}} \mathrm{H}_{\mathrm{A}}-\mathrm{N} \mu_{\mathrm{O}} \mathrm{M}_{\mathrm{S}}
$$

onde c e $\mathrm{N}$ são dois fatores que dependem da microestrutura do ímã permanente, $H_{A}$ é o campo anisotrópico do material, $M_{s}$ a magnetização de saturação e $\mu_{0}$ a permeabilidade magnética (Hirosawa et al., 1990). O fator "c" é influenciado pelo tamanho de grão, enquanto o fator "N" varia com a uniformidade do contorno de grãos após tratamento térmico (Sagawa et al.,1988). Para se obter alta coercividade intrínseca, $\mathrm{c}$ deve ter valores elevados, enquanto que, $\mathrm{N}$ valores pequenos. Valores típicos para estes dois fatores são 0,40 e 1,10, respectivamente (Faria, 2003). 


\section{8 - Fator de Quadratura - FQ}

Indicador de estabilidade diante de um campo desmagnetizante, este fator pode ser determinado a partir da curva do segundo quadrante pela relação:

$$
F Q=\frac{\mu_{0} H_{k}}{\mu_{0} H_{c}}
$$

onde, $\mu_{0} \mathrm{H}_{k}$ é a intensidade do campo magnético $\mu_{0} \mathrm{H}$ quando a polarização $\mathrm{J}$ é reduzida a $90 \%$ de $J_{r}$ e $\mu_{0} \mathrm{H}_{c}$ é a coercividade intrínseca do material que corresponde ao valor da coercividade na curva intrínseca quando J é nulo. Ímãs de boa qualidade devem apresentar fatores da ordem de 0,9. O significado físico desse fator indica o número de grãos magnéticos que já reverteram a magnetização devido a ação de um campo desmagnetizante (Faria, 2003).

\section{9- Produto de Energia Máximo - $\mathrm{BH}_{\max }$}

Essa propriedade pode ser determinada pelo máximo valor do produto entre $B$ e $\mathrm{H}$ na curva de desmagnetização indutiva ilustrada na Figura 2.5.1. Representa o máximo valor de energia que pode ser armazenada, de um campo magnético aplicado externamente. É inversamente proporcional ao volume do material e, portanto, um fator importante na redução do tamanho e peso nos dispositivos de engenharia que empregam esses materiais. A evolução dos ímãs permanentes ao longo do tempo tem sido sempre mostrada a partir do produto de energia máximo. Pode ser calculado pela equação 2.9.1 como:

$$
(B H)_{\max }=\left(4 \pi M_{s}\right)^{2} / 4
$$

somente quando a magnetização de saturação for mantida num campo reverso de pelo menos $4 \rrbracket M_{s} / 2$ (Herbst, 1991). 


\subsection{0 - Microestrutura e Coercividade}

Os ímãs permanentes sinterizados a base de Nd-Fe-B exibem normalmente três fases: a matriz $\mathrm{Nd}_{2} \mathrm{Fe}_{14} \mathrm{~B}$, uma pequena fração de volume $\mathrm{NdFe}_{4} \mathrm{~B}_{4}$ denominada fase boreto e a fase rica em $\mathrm{Nd}$ nos contornos de grão e nos pontos triplos.

Composições com diversas fases adicionais à fase matriz podem ocorrer dependendo da composição e das condições de processamento desses ímãs. Isto se deve a complexa relação de fases no respectivo diagrama. A adição de elementos com baixa solubilidade forma fases intragranulares adicionais ou fases boreto. Essas fases mudam a característica de acoplamento entre os grãos da fase matriz e podem levar a um aumento de coercividade (Fidler et al., 1996). Uma das fases constituintes desses ímãs é a fase eutética de baixo ponto de fusão $\left(650^{\circ} \mathrm{C}\right)$ que age como aditivo de sinterização na fase líquida, promovendo alta densificação sem apresentar um crescimento de grão significativo (Pandian et al.,2002). A distribuição dessa fase como uma fina camada separando os grãos da fase magneticamente dura é uma característica microestrutural que traz significante intensificação para a coercividade intrínseca.

A influência da microestrutura na coercividade desses ímãs está relacionada na equação (2.7.1), onde os fatores c e N são influenciados pelas características da microestrutura. O fator $\mathrm{c}$ depende da composição e dos parâmetros de processamento (tamanho de grão) e o parâmetro $\mathrm{N}$ está relacionado com o campo de desmagnetização local. A nucleação e a expansão de domínios magnéticos reversos controlam o campo coercivo durante o processo de magnetização reversa nos ímãs permanentes sinterizados a base de $\mathrm{Nd}_{2} \mathrm{Fe}_{14} \mathrm{~B}$ (Fidler et al. 1996).

Paredes de Block e domínios reversos podem ser gerados perto de todos os tipos de regiões de defeitos onde os valores do "campo de troca" e da anisotropia se tornam suficientemente reduzidos em relação ao volume do material a ponto de tornar a magnetização reversa possível (Buschow et al. 2004). A inversão da magnetização ocorre não por rotação irreversível no grão inteiro, mas por nucleação de domínios contrários e movimento de paredes. Essa nucleação ocorre numa região com algum defeito, onde possivelmente K1 seja menor (Landgraf, 2008).

efeito do tamanho de grão pode ser explicado afirmando-se que quanto menor o tamanho de grão, menor a probabilidade de se ter uma região com baixo $\mathrm{K} 1$ no 
contorno de grão. A FIG. 2.10.1 mostra o início do processo de nucleação de domínios contrários em uma determinada região.

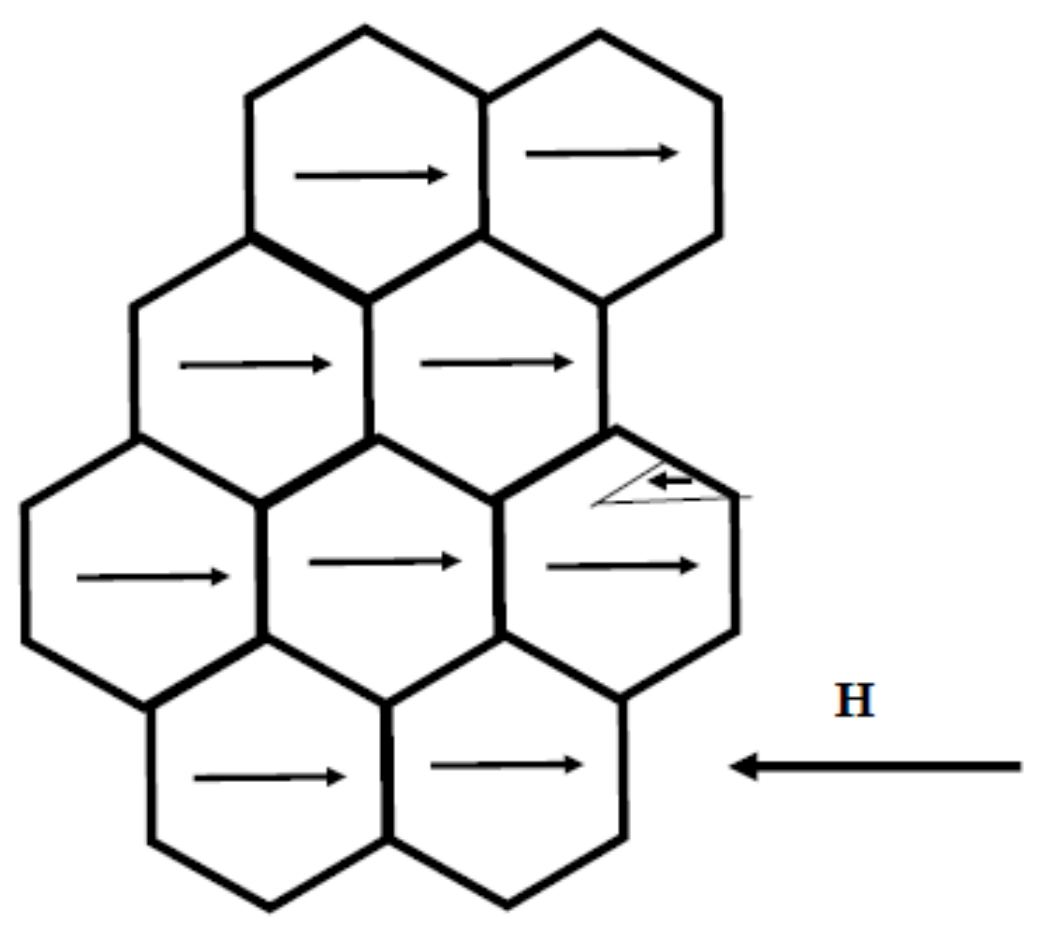

FIGURA 2.10.1 - Processo de reversão da magnetização devido a um defeito, numa região onde K1 provavelmente é menor. (Landgraf, 2008).

\subsection{1 - Adições e Substituições}

As aplicações tecnológicas dos ímãs permanentes a base de TR-Fe-B tiveram sua limitação devido a baixas temperaturas de Curie da fase $T_{2}-\mathrm{Fe}_{14}-\mathrm{B}$ que resultam em alta dependência do campo coercivo com a temperatura. Os parâmetros microestruturais (distribuição de fases, composição química, estrutura cristalina das fases e distribuição do tamanho de grão) e os parâmetros de 
processamento (preparação da liga, tamanho e forma do grão, alinhamento dos grãos e tratamento térmico), determinam o valor da coercividade de um ímã a base de $\mathrm{Nd}_{2} \mathrm{Fe}_{14} \mathrm{~B}$ que possui uma microestrutura complexa com várias fases (Fidler et al., 1989).

Visando aumentar a estabilidade térmica dos ímãs sinterizados à base de $\mathrm{Nd}$ Dy-Fe-Co-B, Tokunaga et al. (1987), estudaram a influencia das adições de Al, Nb e $\mathrm{Ga}$ e verificaram que o Al e o Ga promoviam aumento na coercividade e que o elemento $\mathrm{Ga}$ associado ao $\mathrm{Nb}$ também se mostrou efetivo na diminuição das perdas irreversíveis.

Pesquisas com ímãs permanentes comparando ligas magnéticas com uso de Dy substituindo parcialmente o $\mathrm{Nd}$ e com elementos de adição tais como $\mathrm{Nb}, \mathrm{Al}$ e $\mathrm{Ga}$ mostraram a influência desses materiais sobre as propriedades magnéticas. Obtiveram elevados valores de coercividade (15-20 KOe) porém com redução nos valores da remanência (Kim et al. 1988, 1996).

Parker et al. (1987), estudaram com microscopia eletrônica de transmissão, ímãs com adição de $\mathrm{Nb}$ de composição $\mathrm{Nd}_{14,5} \mathrm{Dy}_{1,5} \mathrm{Fe}_{76} \mathrm{~B}_{7} \mathrm{Nb}_{1,0}$ e constataram duas fases contendo $\mathrm{Nb}$ inseridas na fase $(\Phi)$ magnética.sendo a primeira apresentando inclusões da ordem de $2 \mu \mathrm{m}$ de diâmetro e a segunda com finos precipitados entre 20-50 nm.

Grossinger et al. (1990), observaram uma queda significativa nos valores da coercividade em ímãs produzidos sem a utilização de terras raras pesadas como $\mathrm{Tb}$ e Dy, uma vez que a substituição do $\mathrm{Nd}$ ou $\mathrm{Pr}$, por Tb ou Dy promove o aumento do campo de anisotropia $\left(\mathrm{H}_{\mathrm{a}}\right)$ e conseqüentemente aumenta a coercividade $\left({ }_{i} \mathrm{H}_{\mathrm{c}}\right)$.

Takiishi et al. (2004) reportaram bons valores para as propriedades magnéticas com ímãs processados com decrepitação de hidrogênio (HD) a partir de ligas com estequiometria $\mathrm{Nd}_{14,5} \mathrm{Dy}_{1,5} \mathrm{Fe}_{76} \mathrm{~B}_{7} \mathrm{Nb}_{1}$ e realçaram a influência do Dy na coercividade e sua relação com os tempos de moagem durante o processo.

Fernengel (1989), estudou o efeito da substituição parcial do Fe pelo Si sobre as propriedades magnéticas e concluiu que a adição de Si resultou num decréscimo da coercividade intrínseca e num pequeno acréscimo na temperatura de Curie.

Knoch et al. (1990) estudaram a influência do Ga e do Al na separação dos grãos magnéticos após sinterização com fase líquida e concluíram que esta separação depende da molhabilidade entre o sistema líquido-sólido e é determinado 
pelo ângulo-diedro que é definido como o ângulo de contato entre o material fundido (liquido) em equilíbrio com um substrato sólido.

Grieb et al. (1991), realizaram estudo comparativo entre as adições de Al e Ga em material a base de Nd-Fe-B e confirmaram que ambos os aditivos provocavam intensificação sobre a coercividade embora o resultado com adição de Ga tenha sido superior devido a solubilidade limitada do Ga na fase matriz.

Jinfang et al. (1992) e Rodewal et al. (1989) estudaram a microestrutura e a influencia do $\mathrm{Nb}$ sobre as propriedades magnéticas dos ímãs a base de $\mathrm{Nd} F e \mathrm{~B}$ e verificaram a presença de finos precipitados inseridos na fase matriz cuja densidade seria muito baixa e com dimensões incompatíveis para promover o ancoramento das paredes de domínio.

Yin et al. (1992) estudaram as mudanças microestruturais causadas pelas adições de V, Co e Dy em ímãs sinterizados a base de Nd-Fe-B com microscopia eletrônica de transmissão e identificaram dois tipos de precipitados envolvidos na fase intergranular rica em $\mathrm{Nd}$, um lamelar e um circular, ambos boretos, analisados com EELS (espectrometria eletrônica por perda de energia).

Seeger et al.(1994) estudando a adição de Ga e Nb em ímãs sinterizados de $\mathrm{Nd}-\mathrm{Fe}-\mathrm{B}$ também relataram a presença de finos precipitados contendo $\mathrm{Nb}$ bem como a presença de Ga e boretos nas fases intergranulares promovendo a separação dos grãos magnéticos.

Fidler et al., (1996) em um importante trabalho de revisão dividem os tipos de dopantes utilizados em dois grupos independentemente do tipo de processamento, onde ambos provocam modificações na microestrutura. São eles: Tipo1 - (Al, Cu, Zn, Ga, Ge, Sn) e Tipo 2- (Ti, Zr, V, Mo, Nb, W). Os elementos do Tipo 1, exercem influência sobre a característica da molhabilidade na fase líquida durante a sinterização e portanto afetam o desacoplamento magnético dos grãos. Fases intergranulares não magnéticas eliminam a interação direta da energia de troca e também reduzem a grande faixa de acoplamento magnetostático entre os grãos da fase matriz e ambos os efeitos levam a um aumento da coercividade. Por outro lado, devido à redução da fração volumétrica da fase magnética a remanência diminui. Elementos do Tipo 2 que exibem baixa solubilidade com a matriz à temperatura de sinterização, podem formar precipitados na fase matriz e boretos intergranulares. 
Mottran et al., (2000), estudaram a influência da adição de Co em diversas concentrações e constataram que o aumento das quantidades de Co adicionadas provocam um aumento da remanência e correspondente queda na coercividade explicada pela introdução de uma fase ferromagnética no contorno de grão, que reduz a isolação magnética entre os grãos.

Pandian et al. (2001a, 2001b, 2002) estudaram as adições com Nb, Ga, Al, e $\mathrm{Cu}$ individualmente em ímãs a base de $\mathrm{Nd}-\mathrm{Fe}-\mathrm{B}$ e confirmaram o aumento significativo da coercividade com esses elementos. Também consideraram plausível o auxílio do $\mathrm{Nb}$ com função de ancoramento. As adições de $\mathrm{Cu}$ e Al causaram maiores reduções na temperatura de Curie e na remanência, enquanto Ga e Nb apresentaram melhores características na desmagnetização. Também atribuem ao $\mathrm{Nb}$ a função de suprimir a precipitação do Fe. O pico nos valores de coercividade foi atingido com tratamento térmico a $600^{\circ} \mathrm{C}$ durante 1 hora.

Cheng et al., (2001), estudaram o efeito do Ga adicionado pelo método de mistura de ligas e concluíram que este procedimento é simples e efetivo pois adiciona o Ga diretamente sobre a superfície dos grãos e portanto consome menos Ga que o processo metalúrgico convencional.

Devido ao alto custo do Dy, as pesquisas visando melhores propriedades magnéticas e com maior estabilidade térmica, tem sido realizadas através da inserção de aditivos específicos e de tratamento térmico adequado após a sinterização, que modificam a microestrutura (Brown et al. 2002).

Kim (1988), comparou os valores de coercividade de ímãs com adições de Dy, Al e Ga em diferentes concentrações de adição e verificou que a coercividade aumentava proporcionalmente com a concentração de Al e Dy embora reduzissem significativamente a remanência.

A TABELA 2.11.1 compara as propriedades magnéticas de alguns ímãs com adições de $\mathrm{Dy}, \mathrm{Al}$ e Ga, com ímãs processados sem Dy. Pode-se observar valores da ordem de $20 \mathrm{kOe}$ na coercividade para os ímãs com Dy, enquanto aqueles livres da adição de Dy apresentaram valores até $50 \%$ menores. 
TABELA 2.11.1 - Comparação das propriedades magnéticas em ímãs sinterizados com e sem adições de Dy.

\begin{tabular}{|c|c|c|c|c|}
\hline Composição & $\begin{array}{c}\mathrm{Br} \\
(\mathrm{kG})\end{array}$ & $\begin{array}{c}\mathrm{Hci} \\
(\mathbf{k O e})\end{array}$ & $\begin{array}{c}(\mathrm{BH}) \\
(\mathrm{MGO})\end{array}$ & Ref. \\
\hline$\left(\mathrm{Nd}_{0,86} \mathrm{Dy}_{0,14}\right)_{15} \mathrm{Fe}_{77} \mathrm{~B}_{8}$ & 12,08 & $\mathbf{2 0 , 6}$ & 34,4 & Kim, 1988 \\
\hline$\left(\mathrm{Nd}_{0,88} \mathrm{Dy}_{0,12}\right)_{15} \mathrm{Fe}_{77} \mathrm{Co}_{5} \mathrm{Al}_{1,8} \mathrm{~B}_{8}$ & 12,60 & $\mathbf{2 0 , 2}$ & 38,4 & Kim, 1988 \\
\hline$\left(\mathrm{Nd}_{0,86} \mathrm{Dy}_{0,14}\right)_{15} \mathrm{Fe}_{77} \mathrm{Co}_{5} \mathrm{Nb}_{1,6} \mathrm{Al}_{1,8} \mathrm{~B}_{8}$ & 11,90 & $\mathbf{2 0 , 4}$ & 34,4 & Kim, 1988 \\
\hline $\mathrm{Nd}_{15} \mathrm{Fe}_{79} \mathrm{~B}_{6}$ & 13,50 & $\mathbf{9 , 4 5}$ & 34,5 & Shinba et al., 2005 \\
\hline $\mathrm{Pr}_{15} \mathrm{Fe}_{\text {bal }} \mathrm{Co}_{8} \mathrm{~B}_{7} \mathrm{Nb}_{0,05} \mathrm{Ga}_{0,25}$ & 10,60 & $\mathbf{1 1 , 0}$ & 26,0 & Mendes et al., 2008 \\
\hline
\end{tabular}

\subsection{2 - Os Contornos de Grãos}

O modelo da modificação da interface dos grãos através de tratamento térmico é baseado na precipitação de fase na superfície dos grãos da fase matriz, que é causado por decomposições eutétóides dentro das camadas intergranulares (Menushenkov, 2005). A fase líquida da sinterização ocorre quando o líquido molha completamente as partículas sólidas à temperatura de sinterização. O líquido nas frestas estreitas entre as partículas sólidas resulta em uma pressão capilar substancial. O tamanho da partícula, a temperatura e o tempo de sinterização, a uniformidade do empacotamento das partículas, o formato e a distribuição do tamanho das mesmas e o ângulo diedro entre os grãos da fase matriz e o tratamento térmico adequado são parâmetros extremamente importantes para a formação de um contorno de grão suave e contínuo. Pós compostos por finas partículas, podem ser sinterizadas mais rapidamente e a temperaturas menores do que pós mais grosseiros (Fidler et al., 1989). Estudos com MET revelaram que é possível a existência de dois tipos diferentes de contorno de grão identificados na Figura 2.12.1 como GB1 e GB2 que se diferenciam pela presença da fase não magnética em GB2 e pela ausência de qualquer fase intergranular na região de contorno identificada por GB1. 

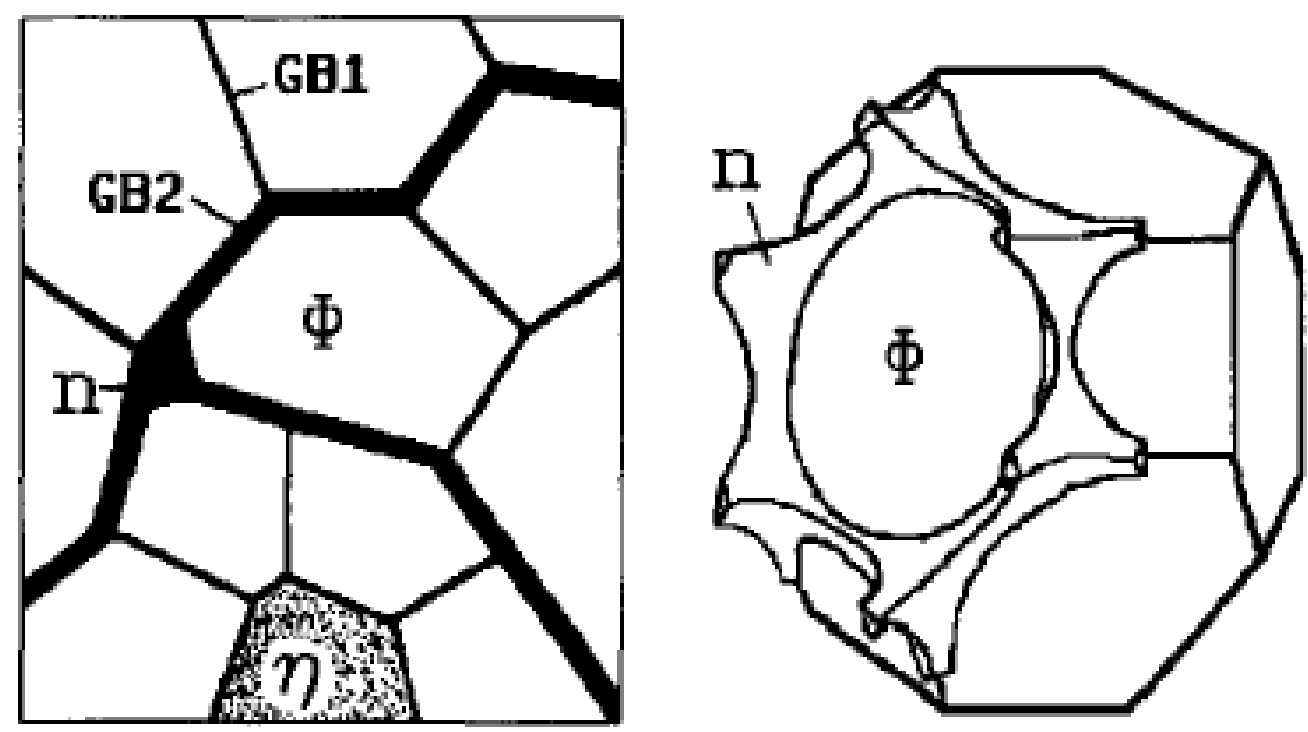

FIGURA 2.12.1 - Esquema mostrando contornos não magnéticos nos ímãs permanentes a base de $\mathrm{Nd}-\mathrm{Fe}-\mathrm{B}$. A fase $(\Phi)$ indica a fase matriz, a fase $(\eta)$ é a fase boreto e a fase $(\mathrm{n})$, rica em Nd. Extraído de Fidler et al. (1989).

Os primeiros trabalhos envolvendo o estudo da microestrutura e a importância do tratamento térmico nesses materiais foram realizados por Hiraga et al. (1985) em ímãs permanentes de $\mathrm{Nd}_{15} \mathrm{Fe}_{77} \mathrm{~B}_{8}$ com auxílio de microscopia eletrônica de transmissão de alta resolução e revelaram contornos com estrutura ccc e com espessura da ordem de $20 \mathrm{~nm}$ entre os grãos magnéticos, pontos triplos de fases ricas em $\mathrm{Nd}$, plaquetas e distorções entre grãos da fase matriz magnética.

Tokunaga et al. (1986), observaram com MET a presença de inúmeras plaquetas com estrutura ccc com $a=0,29 \mathrm{~nm}$, coesas à fase matriz $\mathrm{Nd}{ }_{2} \mathrm{Fe}_{14} \mathrm{~B}$ de ímãs sinterizados a base de Nd Dy Fe B para várias estequiometrias e observaram que após tratamento térmico essas plaquetas desapareciam. Afirmaram, no entanto, que a presença de plaquetas podia não estar relacionada à variação da coercividade.

Fidler et al. (1985) com auxílio de microscopia eletrônica de transmissão relataram a alta densidade de defeitos em regiões de fase não magnética e a formação de contornos de grão com dimensões da ordem de 10nm. Também ressaltaram que a fase rica em $\mathrm{Nd}$ estudada com MET pode ser dividida em pelo 
menos quatro subtipos com diferentes taxas de $\mathrm{Nd}$ :Fe e que o grau de continuidade dessa fase é proporcional a coercividade intrínseca do ímã.

Schrey (1986), em estudos com microscopia eletrônica de transmissão, verificou uma estrutura cfc na região rica em $\mathrm{Nd}$ para o ímã sinterizado de composição nominal $\mathrm{Nd}_{14} \mathrm{Fe}_{78} \mathrm{~B}_{8}$ com substituição de 2 e 6 \%at. de Al, bem como uma superposição de $\operatorname{ccc} \alpha-\mathrm{Fe}$ e hexagonal $\mathrm{Nd}_{2} \mathrm{O}_{3}$ com padrão de difração eletrônica revelando a presença de anéis concêntricos devido a oxidação excessiva naquela região.

Knoch et al. (1992) estudaram os ímãs sinterizados a base de $\mathrm{Nd}-\mathrm{Fe}-\mathrm{B}-\mathrm{Cu}$, produzidos pelo processo HD e com tratamento térmico otimizado e com os recursos da microscopia eletrônica de transmissão e microanálises de EPMA (microanálise por ponta de prova eletrônica) relataram a presença de fases contendo o elemento $\mathrm{Cu}$ nos contornos de grão e nos pontos eutéticos que poderiam explicar os bons valores de coercividade.

Análises feitas por Fidler et al. (1989), com microscopia de transmissão, EDS e padrão de difração em ímãs sinterizados com adição de Al, permitiram a observação de fases distintas nas regiões de fase rica em $\mathrm{Nd}$ que foram substituídas por uma fase $\mathrm{Nd}_{3} \mathrm{Co}$ e pela fase intergranular boreto $(\mathrm{Mo}, \mathrm{Fe})_{3} \mathrm{~B}_{2}$ no ímã sinterizado de composição $\mathrm{Nd}_{15,5} \mathrm{Fe}_{67,5} \mathrm{Co}_{5} \mathrm{~B}_{7} \mathrm{Al}_{2} \mathrm{Mo}_{3}$.

Em outro estudo, Rodewal et al. (1988), realizaram análises com MET e localizaram plaquetas e fases com alta densidade de deslocamentos e estrutura cfc com $\mathrm{a}=0,52 \mathrm{~nm}$. Em outra amostra produzida com $\mathrm{NdFeB}$ e $\mathrm{Al}_{2} \mathrm{O}_{3}$ também identificaram presença de um fase com estrutura hc onde $a=0,39 \mathrm{~nm}$.

Grieb et al. (1989) avaliaram a influência do alumínio adicionado em ímãs sinterizados a base de $\mathrm{Nd}-\mathrm{Fe}-\mathrm{B}$ e constataram com microscopia eletrônica de transmissão a fase $(\mathrm{Fe}, \mathrm{Al})_{2} \mathrm{Nd}$ completamente envolvida pela fase cfc, rica em $\mathrm{Nd}$ no ponto triplo.

Hirosawa et al. (1990), numa investigação da microestrutura de ímãs sinterizados a base de Nd-Fe-B com MET concluíram que os campos de desmagnetização local são as principais fontes na redução da coercividade desses materiais. Mostram um modelo esquemático desenvolvido a partir da análise de micrografias realizadas com MET no contorno entre dois grãos magnéticos antes e após tratamento térmico otimizado. 


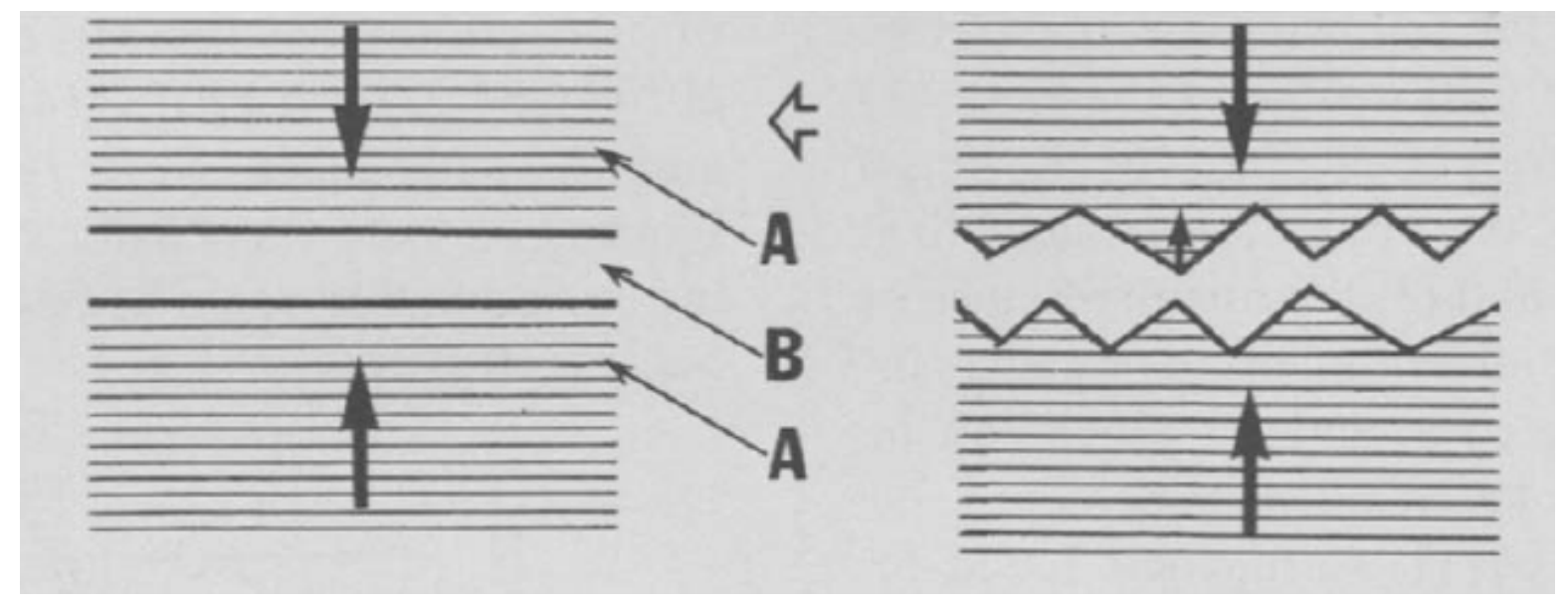

FIGURA 2.12.2 - Possível configuração de magnetização reversa devido a grandes campos de tensão e a situação após tratamento térmico otimizado, onde $A$ representa a fase $(\Phi)$ magnética e $B$ representa a fase do contorno de grão rica em Nd entre dois grãos. (Hirosawa et al.,1990).

A mudança da microestrutura no contorno de grão apontada na Figura 2.12.2 devido ao tratamento térmico está diretamente relacionada ao decréscimo do fator $\mathrm{N}$ da equação (2.7.1) apresentada na secção 2.7.

Yang et al. (1993), discutem a formação de fases identificadas como dhc na região rica em $\mathrm{Nd}$ com auxílio de MET e padrões de difração após ciclos de tratamento térmico seguidos de resfriamento rápido.

Vial et al. (2002) estudaram as transformações metalúrgicas que ocorrem durante o tratamento térmico de ímãs a base de $\mathrm{NdFeB}$ com adições de $\mathrm{Co}, \mathrm{Al}, \mathrm{Cu}$ e investigaram os contornos de grão com auxílio de microscopia eletrônica de varredura (MEV -FEG) e de transmissão de alta resolução (MET- HR) em amostras somente sinterizadas e posteriormente em amostras com tratamento térmico com ciclo otimizado. Confirmaram tanto resultados superiores na coercividade como a visualização de contornos livres de distorções de planos, mais finos e contínuos nas amostras que foram submetidas a tratamento térmico.

Shinba et al. (2005), investigaram os contornos de grãos em ímãs de $\mathrm{Nd}_{15} \mathrm{Fe}_{79} \mathrm{~B}_{6}$ submetidos à tratamento térmico otimizado e registraram imagens com microscopia de transmissão de alta resolução com excelente definição dos contornos. Confirmaram significante mudança na espessura dos contornos e na continuidade dos contornos devido ao tratamento térmico e registraram uma 
transição na estrutura cristalina do contorno de cfc para amorfo conforme a diminuição da espessura.

Wang et al. (2005) estudaram a estabilidade da fase rica em $\mathrm{Nd}$ em ímãs de $\mathrm{Nd}-\mathrm{Fe}-\mathrm{B}$ através de microscopia eletrônica de transmissão com estágio quente (in situ) e observaram a instabilidade da fase identificada como ccc após $300^{\circ} \mathrm{C}$ e finalmente transformada em hc a $400^{\circ} \mathrm{C}$.

Recentemente a necessidade de eliminar-se o uso do Dy, tem levado à crescente utilização de ímãs permanentes à base de NdFeB com a utilização de aditivos de baixo ponto de fusão como $\mathrm{Ga}, \mathrm{Al}, \mathrm{Cu}$ e tratamento térmico otimizado após a sinterização visando à obtenção de um contorno de grão mais suave e regular e conseqüentemente um valor intensificado da coercividade.

Bai et al. (2006) estudaram a influência nas propriedades magnéticas em ímãs de Nd Fe B produzidos com adições de Dy, Ga e Co em ímãs a base de Nd Fe B e verificaram intensificação da coercividade, associada à influencia positiva do Dy na intensificação do campo de anisotropia e à formação de uma fase intergranular contendo Ga com melhor desacoplamento magnético.

Li et al. (2008), também investigaram a influência do tratamento térmico em ímãs a base de $\mathrm{NdFeB}$ contendo $\mathrm{Cu}$ como aditivo e verificaram com microscopia de transmissão de alta resolução, melhor isolação dos grãos magnéticos após o tratamento térmico otimizado.
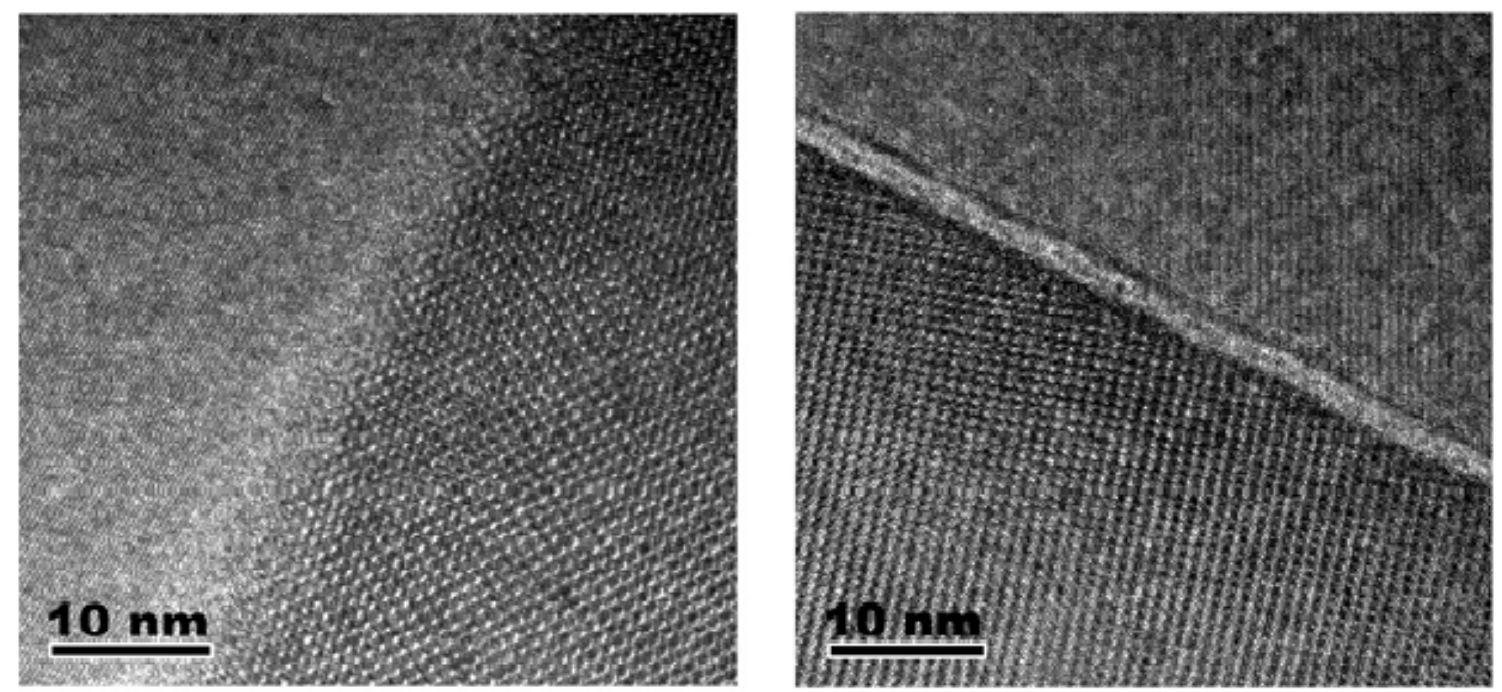

FIGURA 2.12.3 - Microscopia eletrônica de transmissão com alta resolução onde se observa em (a) imagem do contorno em amostra sem tratamento térmico e (b), com tratamento térmico e ciclo otimizado (Li et al., 2008). 


\subsection{3 - A Influência do Oxigênio}

O oxigênio está presente inicialmente nas ligas e no processo de moagem. Nas etapas subseqüentes do processamento, mais oxigênio é adicionado. As propriedades magnéticas, especialmente a coercividade, dependem sensivelmente do conteúdo de oxigênio.

Numa análise com espectrometria Auger, Yin et al. (1993), mostraram que altas concentrações de oxigênio na matriz existem somente na superfície e que devido à alta afinidade do $\mathrm{Nd}$ com o oxigênio, o contorno rico em neodímio forma óxido de neodímio em todo o volume. Corfield et al., (2008) relacionaram a quantidade de oxigênio presentes em ímãs à base de PrFeB com o fator de quadratura. Observaram que o crescimento de grão podia ser minimizado com quantidades adequadas de oxigênio de maneira a melhorar a homogeneidade da microestrutura e gerar fatores de quadratura superiores.

Quantidades adequadas de oxigênio podem promover uma limpeza no contorno de grão e uma inibição do crescimento do tamanho de grão e com isso trazer melhores resultados na coercividade (Kim et al., 1996). Quantidades excessivas de $\mathrm{O}$ por sua vez podem levar ao declínio gradual das propriedades magnéticas. Foi verificado que concentrações superiores a $55 \%$ at. de $\mathrm{O}$ promovem a formação de uma fase rica com estrutura hc que mostraram mal encapsulamento do grão da fase matriz $\mathrm{Nd}_{2} \mathrm{Fe}_{14} \mathrm{~B}$ e que a densidade de sinterização dos ímãs decai quando existe uma grande fração de volume da fase hc (Mo et al., 2008).

Em estudo recente, Mo et al., (2008), analisaram regiões de contornos e pontos triplos ricos em $\mathrm{Nd}$ e associaram as quantidades de oxigênio analisadas com EDS e microscopia eletrônica de transmissão, as estruturas identificadas pelos padrões de difração. Observaram que a concentração de $\mathrm{O}$ varia em cada região e que nos pontos triplos pode-se localizar estruturas, dhc, cfc e hc dependendo da concentração de oxigênio em cada ponto. A FIG. 2.13.1 ilustra a possibilidade de várias fases em relação às quantidades de oxigênio e de $\mathrm{Nd}$. 


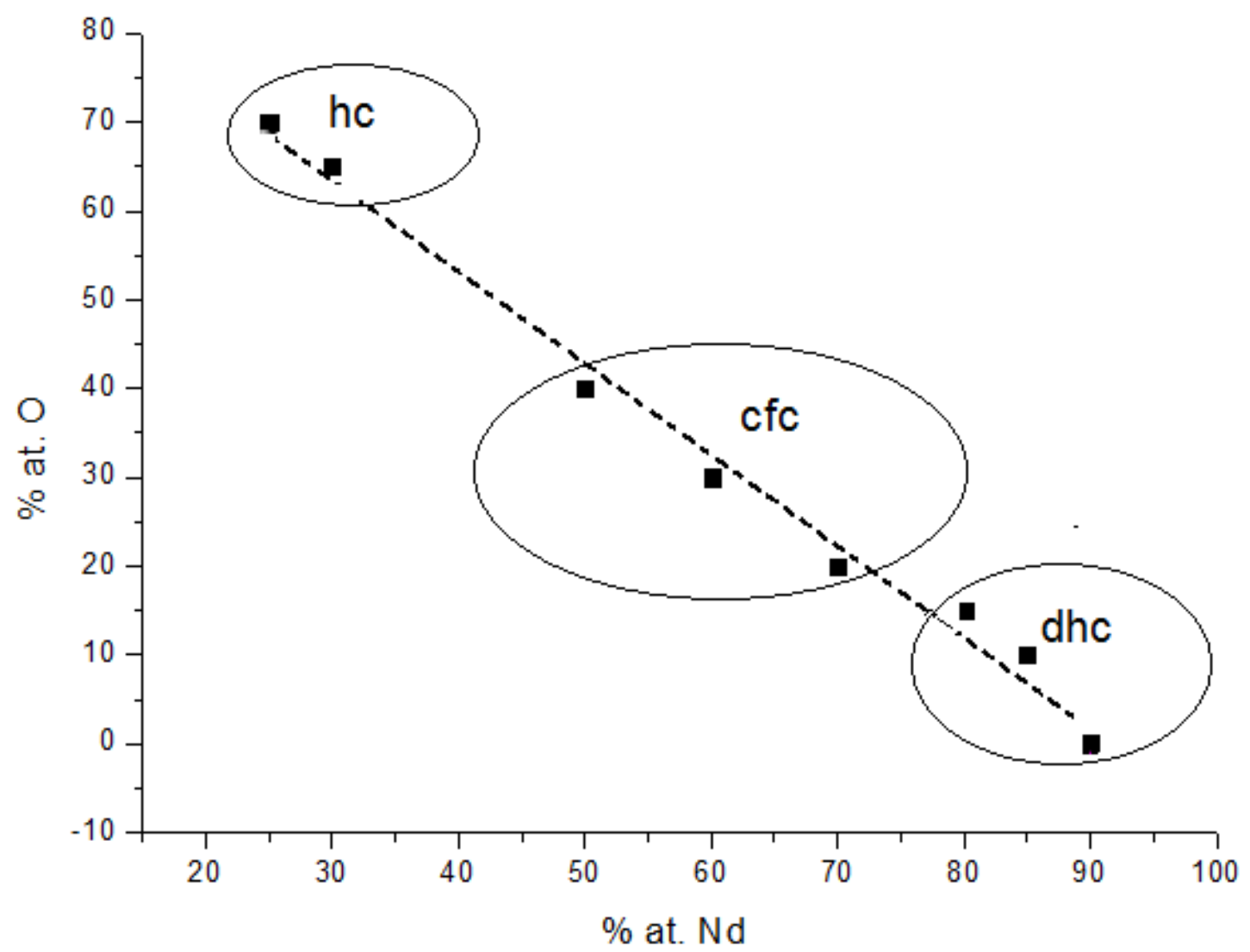

FIGURA 2.13.1 - Fases observadas nos contornos de grão em função da quantidade de oxigênio versus quantidade de Nd (Mo et al., 2008). 


\section{CAPÍTULO 3}

\section{Materiais e Métodos}

Neste capítulo estão descritos inicialmente os procedimentos de fabricação de ímãs permanentes sinterizados a partir de uma mistura de ligas e decrepitação por hidrogênio (processo HD). A seguir discute-se o tratamento metalográfico das amostras para observação em microscópio eletrônico de varredura (MEV) e o método de tratamento computacional e estatístico das micrografias realizadas com elétrons retro-espalhados.

Na segunda etapa, discorre-se sobre a técnica para a preparação de amostras por afinamento iônico para microscopia eletrônica de transmissão (MET) realizada com os microscópios JEOL- JEM 2100 (200kV) e JEM 3010 (300kV), com microanálises de espectrometria de energia dispersiva (EDS) e padrão de difração eletrônica. Essa etapa foi realizada no Laboratório Nacional de Luz Síncrotron (LNLS).

\section{1- Preparações de ímãs HD sinterizados}

A formação de partículas da ordem de 3-7 $\mu \mathrm{m}$ durante a moagem é fundamental para a preparação de ímãs com alto produto de energia. O processo de absorção consiste de dois estágios: o primeiro onde o hidrogênio penetra no contorno de grão e em seguida na fase matriz $\left(\operatorname{Pr}_{2} \mathrm{Fe}_{14} \mathrm{~B}\right)$. A expansão de volume associada à solubilidade do hidrogênio resulta na formação de fraturas com partículas da ordem de $150 \mu \mathrm{m}$. Essas partículas são altamente friáveis devido à micro fissuras e são adequadas ao posterior processo de moagem. O hidrogênio permanece no material durante a moagem e é posteriormente liberado durante a sinterização entre $150-600^{\circ} \mathrm{C}$. A presença do hidrogênio durante o processo também 
é benéfica na redução da contaminação de oxigênio e da remanência da magnetização no compactado verde, facilitando o seu manuseio, (Mottram et al., 1999).

Os ímãs permanentes objetos deste estudo foram preparados a partir de uma liga comercial de composição $\operatorname{Pr}_{16} \mathrm{Fe}_{76} \mathrm{~B}_{8}$ na condição de lingote misturados às ligas de composição $\operatorname{Pr}_{14} \mathrm{Fe}_{\text {bal }} \mathrm{Co}_{16} \mathrm{~B}_{6} \mathrm{Nb}_{0.1} \mathrm{M}_{\mathrm{x}}$ (tratadas termicamente a $1060{ }^{\circ} \mathrm{C}$ por $20 \mathrm{~h}$ ), onde $\mathrm{M}=\mathrm{Al}, \mathrm{Cu}, \mathrm{P}, \mathrm{Si}, \mathrm{Gd}, \mathrm{Ga}$, Dy ou $\mathrm{Tb}$ e $\mathrm{x}=0.1,0.3,0.5$ e $1.0 \%$ em peso.

No processo HD, os fragmentos das duas ligas a serem misturadas foram britados em pedaços de cerca de $10 \mathrm{~mm}$ de diâmetro, misturados em iguais proporções em peso $7,5 \mathrm{~g}$ de cada liga. Os fragmentos das ligas misturadas e devidamente pesadas foram submetidos a um sistema composto de um vaso de aço inox para hidrogenação acoplado a uma bomba de vácuo mecânica, válvula para manobra, um cilindro de hidrogênio e um medidor tipo Pirani.

Inicialmente o sistema foi evacuado a $10^{-1}$ bar durante aproximadamente 1 minuto e em seguida aplicou-se o hidrogênio a uma pressão de 2 bar. Observou-se logo no início do processo um aquecimento no vaso de hidrogenação seguido de uma diminuição da pressão. Introduziu-se mais hidrogênio para que a pressão inicial fosse mantida durante aproximadamente $30 \mathrm{~min}$.

O material hidrogenado foi então transferido ao pote de aço inox contendo esferas do mesmo material com proporção de 10:1 entre a massa dos moedores e massa da amostra em um meio de moagem em um moinho planetário de alta energia por um tempo de 30 minutos. Utilizou-se ciclo-hexano como meio de moagem para evitar-se a oxidação das partículas e a formação de aglomerados.

Após o período de moagem, o pó foi secado com auxílio de bomba de vácuo e posteriormente transferido a um tubo de borracha isostática com $50 \mathrm{~mm}$ de comprimento e $10 \mathrm{~mm}$ de diâmetro e submetido a um campo magnético pulsado de 6T por 3 vezes visando-se alinhar o material particulado e ainda hidrogenado.

A produção de ímãs HD sinterizados em escala laboratorial requer uma atmosfera inerte com quantidades de oxigênio menores que 30 ppm (Kianvash et al., 1999). O sistema proposto por Takiishi et al. (2002), suprime o uso da "glove box" tornando o processo eficiente e de baixo custo. A possibilidade de se prover um fluxo de $\mathrm{N}_{2}$ e evacuar a câmara principal através de uma bomba mecânica, mantém a concentração do oxigênio a níveis satisfatórios. 
A ilustração abaixo mostra o conjunto utilizado para a etapa de transferência contendo o pote de moagem, válvula de manobra e o acoplamento com o tubo de borracha para onde o material será transferido.

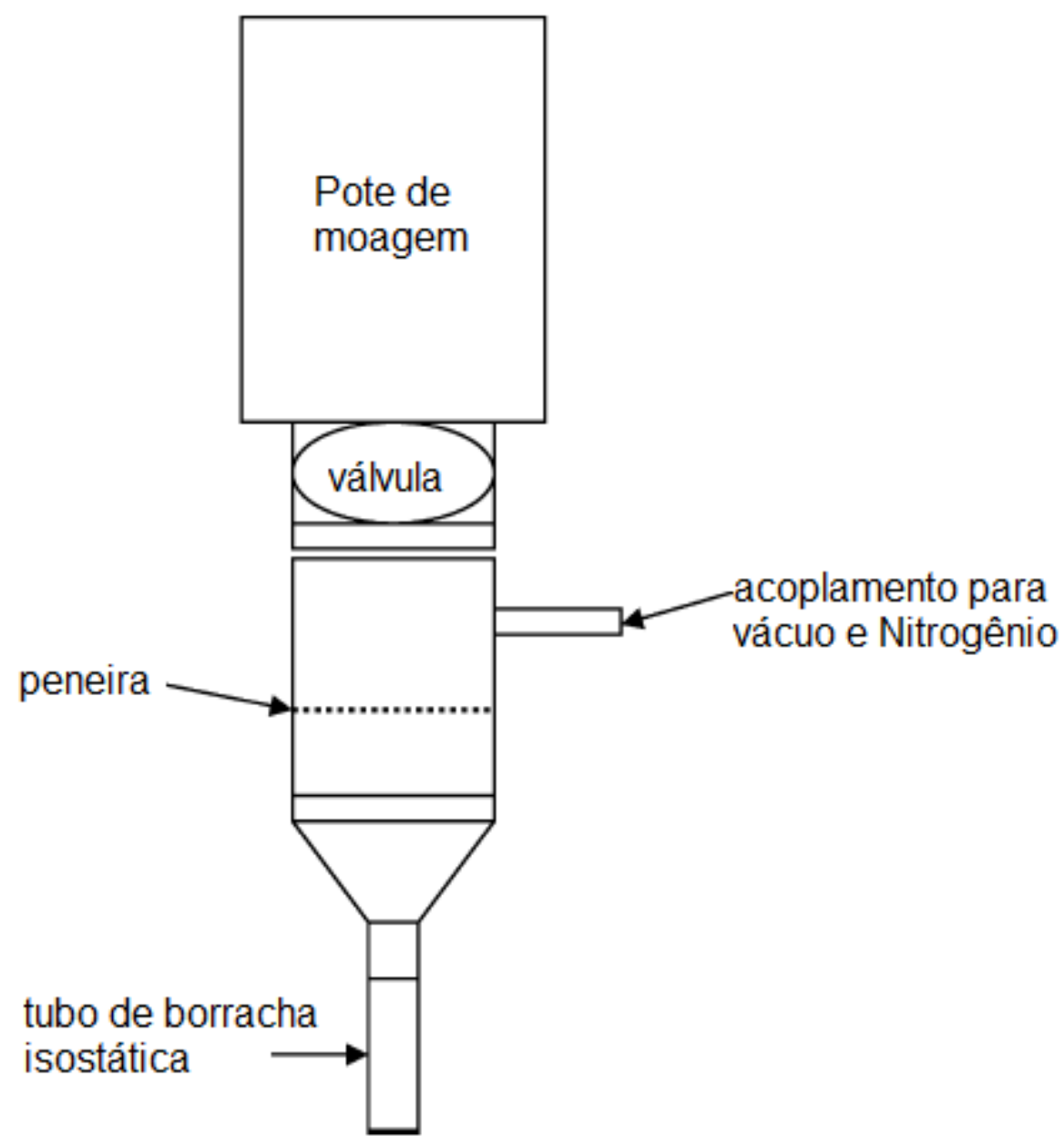

FIGURA 3.1.1 - Sistema de transferência propicia a transferência do material moído para o tubo de borracha que será submetido a campo de 6T em um magnetizador LDJ 450-20C e prensagem isostática. (Takiishi et al., 2002).

A seguir, executou-se a prensagem isostática à $200 \mathrm{MPa}$ e posterior sinterização em forno à vácuo por $1 \mathrm{~h}$ a temperatura de $1050{ }^{\circ} \mathrm{C}$ com resfriamento no próprio forno. 
A curva de sinterização é ilustrada na FIG. 3.1.2 indicando as duas etapas onde ocorrem a dessorção.

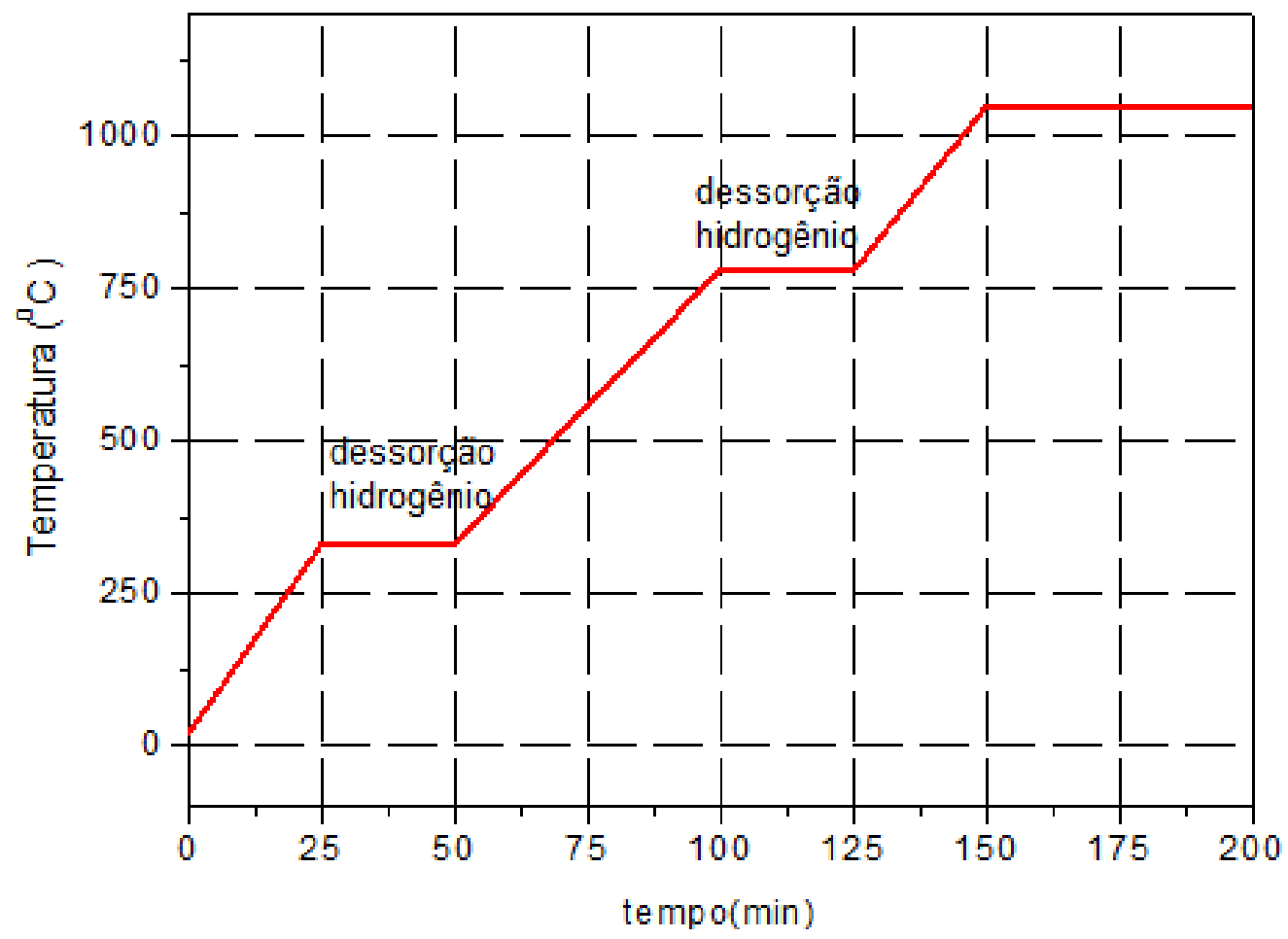

FIGURA 3.1.2 - Curva de sinterização em forno a vácuo com controlador programado.

Após a sinterização, o corpo de prova foi submetido a acabamento superficial para regularização da forma e em seguida procedeu-se a magnetização do mesmo num campo pulsado de intensidade de $6 \mathrm{~T}$ por três vezes. As medidas magnéticas foram executadas em um permeâmetro $\mathrm{BH}-5000$ de onde se extraiu a curva de desmagnetização do segundo quadrante com valores de coercividade e remanência. A determinação dos valores de densidade foi feita pelo método de Archimedes com uma balança digital Toledo AG $204 \mathrm{com}$ as amostras pesadas a seco $\left(\mathrm{m}_{\mathrm{s}}\right)$, parcialmente submersas $\left(m_{i}\right)$ e na forma úmida $\left(m_{u}\right)$ após a submersão em água deionizada em temperatura ambiente.

O valor da densidade foi então calculado pela equação:

$$
\rho=\left(\frac{m_{s}}{m_{u}-m_{i}}\right) \rho_{H_{2} O}
$$




\section{2 - Preparação de amostras - MEV}

As amostras preparadas para observação e análises com microscópio eletrônico de varredura (MEV), foram obtidas a partir de corpos de prova cilíndricos (30 x $10 \mathrm{~mm})$. Com auxílio de serra com disco diamantado cortou-se o corpo de prova transversalmente ao eixo de fácil orientação e realizou-se o embutimento. Posteriormente empregaram-se as técnicas convencionais com lixas \# 400 até \# 2000 e polimento com suspensão diamantada até se obter uma superfície "espelhada" e livre de riscos ou arrancamentos. O controle do acabamento superficial da amostra foi realizado com microscópio ótico com aumento de $100 \mathrm{X}$. Em seguida realizou-se o ataque químico na superfície com uma solução de água destilada, ácido clorídrico e ácido nítrico na proporção 1:2:1 em volume durante aproximadamente 5 segundos para que os grãos ficassem bem revelados. As imagens foram obtidas em um microscópio eletrônico de varredura com elétrons retro espalhados e com aumento de 2000 X. A partir das micrografias obtidas, fez-se o tratamento das imagens com o programa Image Tool 3.0.

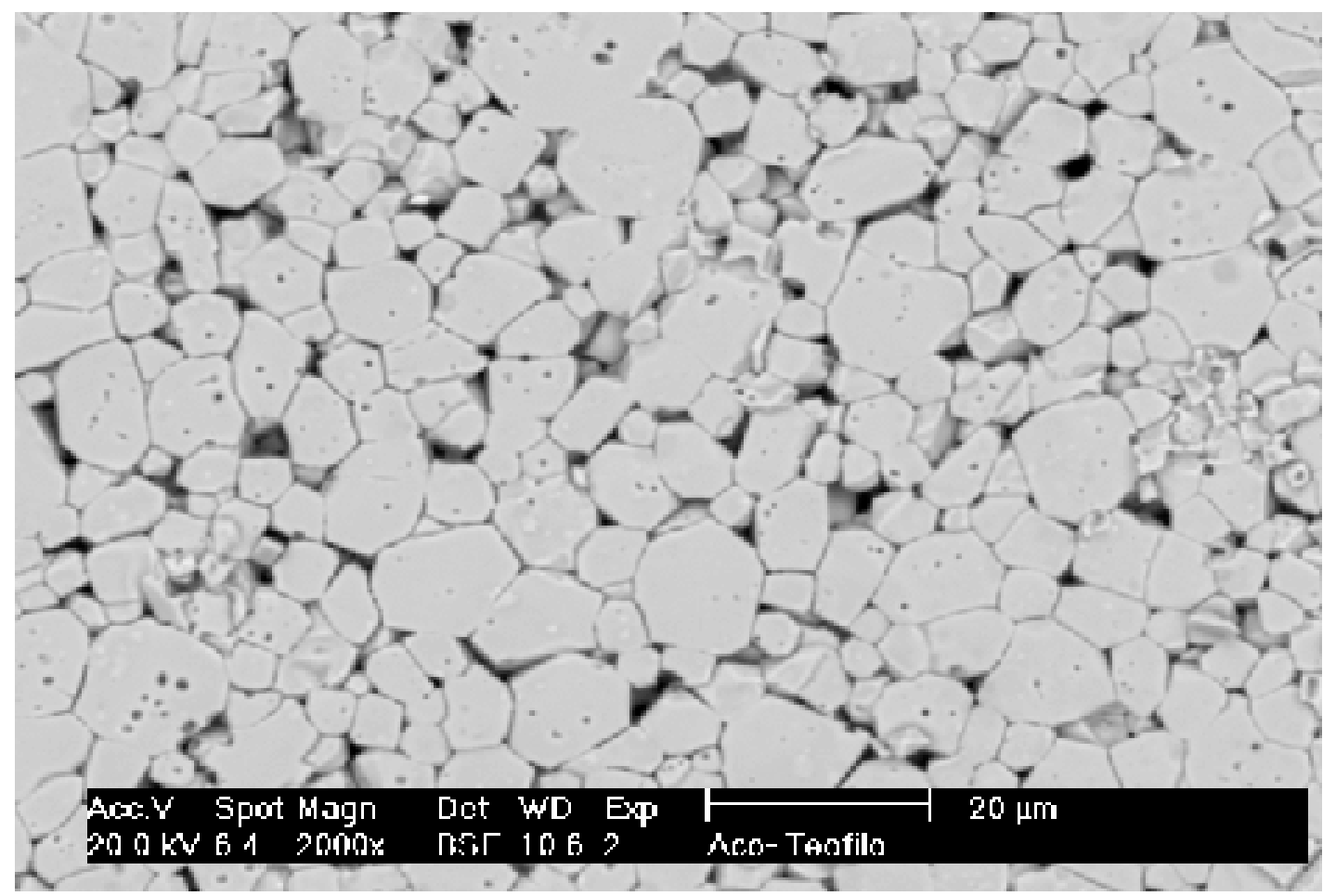

FIGURA 3.2.1 - Micrografia obtida a partir do processo metalográfico acima descrito. 


\section{3 - Tratamento Computacional das Micrografias}

O programa computacional Image Tool 3.0 processa as informações de cada grão magnético a partir da micrografia exemplo mostrado abaixo e gera uma tabela de dados exemplificada na TAB. 3.2.1 utilizada como fonte para a determinação dos parâmetros de tamanho e forma dos grãos da fase matriz.

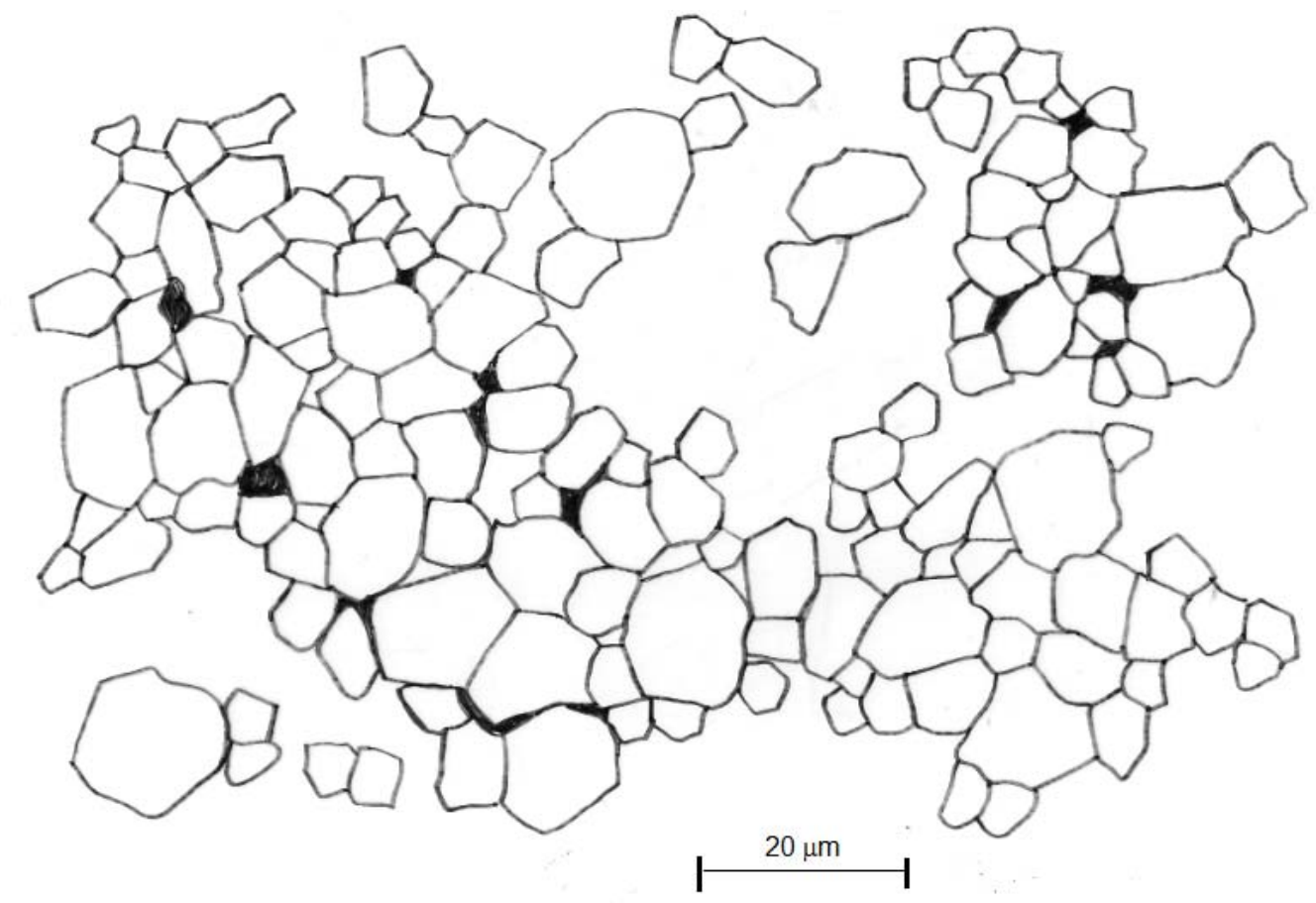

FIGURA 3.2.2 - Imagem digitalizada a partir da micrografia gerada no MEV.

A tabela 3.2.1 abaixo mostra um exemplo do processamento dos dados obtidos com o programa Image Tool 3.0 .

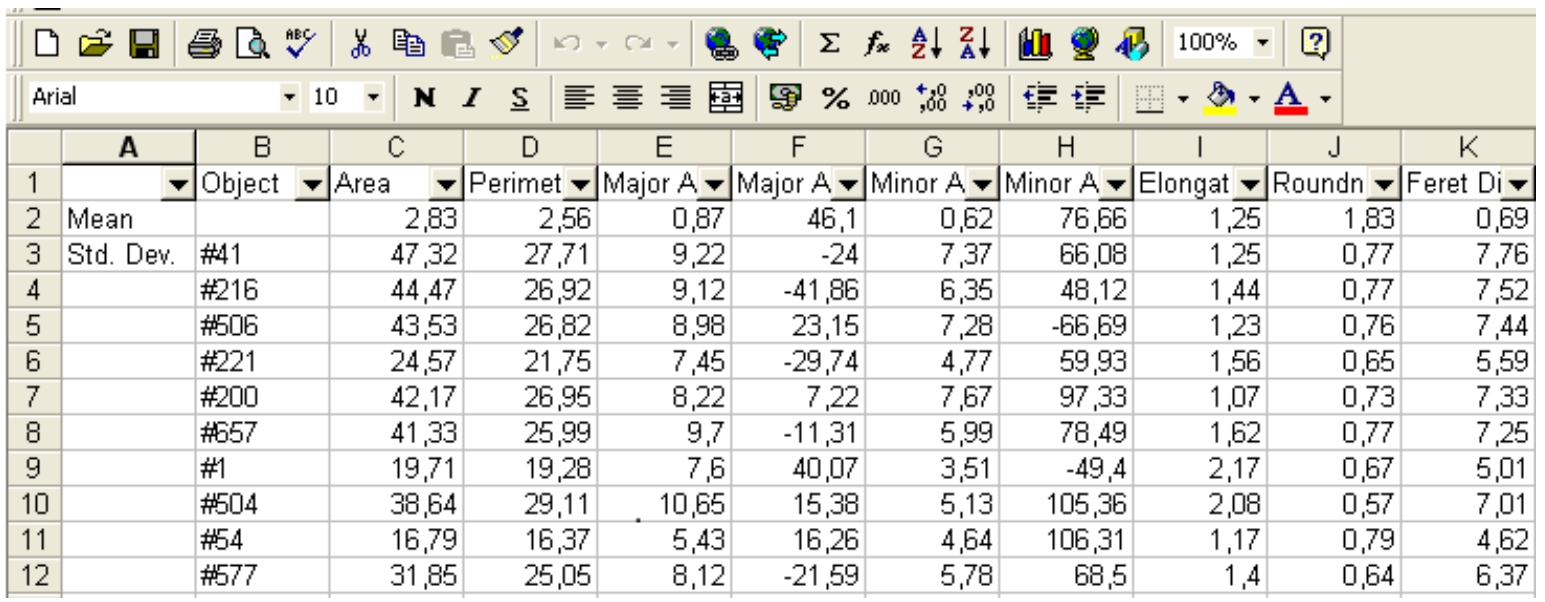


A partir dos dados processados, foi possível quantificar os parâmetros microestruturais, tamanho e formato dos grãos magnéticos, definidos como:
a) $\bar{X}_{T G}$
Tamanho de grão - tamanho médio de grão referente a um espaço amostral de cerca de 500 grãos analisados para cada composição de amostra.
b) $\bar{X}_{E}$
Elongação - a razão entre o comprimento do menor e do maior eixo do grão esquematizado abaixo, considerando que cada eixo deva ser perpendicular ${ }^{33}$.
c) $\quad \bar{X}_{C} \quad$ Circularidade - a razão entre a área de um grão, multiplicada por $4 \pi$, e seu perímetro ao quadrado.

Considerando-se esses parâmetros, foi possível analisar a homogeneidade de tamanho representada pelo tamanho de grão e seu respectivo desvio padrão e a homogeneidade de forma representada pela circularidade e elongação e seus respectivos desvios padrões identificados por $\sigma_{\mathrm{TG}}, \sigma_{\mathrm{E}}$ e $\sigma_{\mathrm{C}}$. A partir dos resultados obtidos para cada amostra, utilizou-se a expressão proposta por Périgo et al. (2007) que relaciona os parâmetros microestruturais e os desvios padrões e permite o cálculo de um fator de homogeneidade $(\mathrm{FH})$ dado pela relação:

$$
F H=1-\left[\frac{\sigma_{T G}}{\overline{\times}_{T G}}\left(\frac{\sigma_{E}}{\overline{\times}_{E}}+\frac{\sigma_{C}}{\overline{\times}_{C}}\right)\right]
$$

Os resultados serão apresentados no capítulo 4 onde os valores calculados a partir dessa correlação foram comparados aos valores do fator de quadratura (FQ) obtidos a partir das curvas de desmagnetização. 


\subsection{Preparações de Amostras - MET}

A preparação de amostras dos ímãs permanentes sinterizados para observação em microscópio eletrônico de transmissão foi realizada por técnica de afinamento comumente utilizada em amostras metálicas, embora os cuidados no tratamento com materiais sinterizados devam ser especiais devido à fragilidade dos mesmos ao serem cortados, lixados e polidos.

A obtenção de boas imagens com microscopia eletrônica de transmissão depende principalmente de áreas suficientemente finas onde o feixe possa ser transmitido. Embora "fina" possa ser um termo relativo, neste caso significa transparência aos elétrons. Para haver transparência eletrônica é necessária a transmissão suficiente de elétrons sobre a tela que possa produzir uma boa imagem a ser registrada e interpretada (Williams et al., 2003).

As amostras podem ser preparadas basicamente de duas maneiras. $\mathrm{Na}$ primeira, denominada auto-suportada, o disco de $3.00 \mathrm{~mm}$ de diâmetro constituído do próprio material a ser analisado é afinado até que se obtenha o furo central e será discutida com detalhes na seção 3.4.1. Na segunda, o material pode ser colocado em diversos tipos e tamanhos de grades de cobre. É importante que a escolha contemple as considerações sobre a estabilidade mecânica do material quando submetidos à radiação e ação do feixe eletrônico. 


\subsection{1 - Corte em serra com disco diamantado}

Inicialmente, os corpos de prova de formato cilíndrico com aproximadamente 30 $\mathrm{mm}$ de comprimento e $10 \mathrm{~mm}$ de diâmetro foram cortados transversalmente ao eixo "C" de fácil magnetização conforme indicado na figura abaixo. Em serra com disco diamantado e refrigeração à água obtiveram-se discos com cerca de $800 \mu m$ de espessura e $10 \mathrm{~mm}$ de diâmetro.

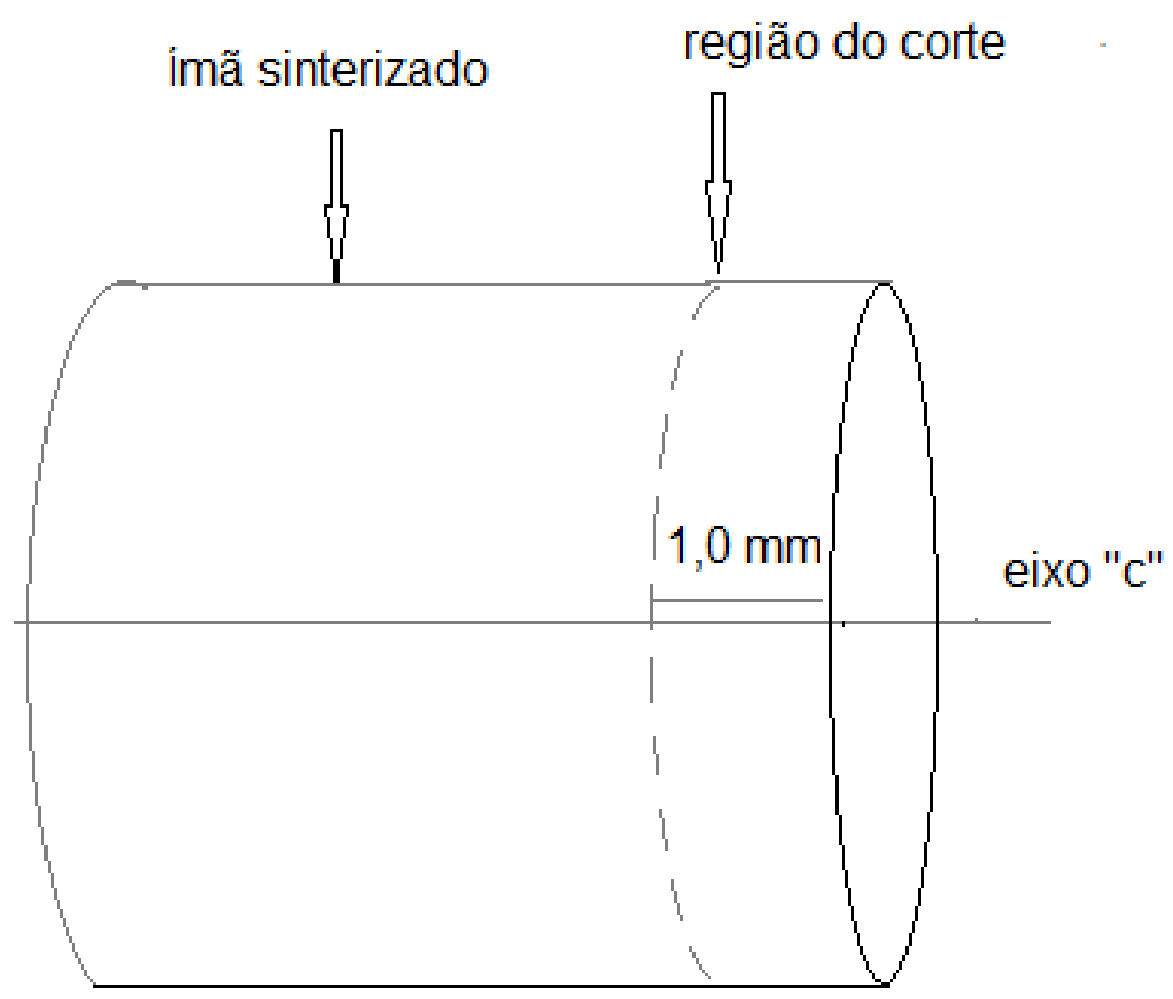

FIGURA 3.4.1.1- Esquemático indicando o sentido do corte do ímã sinterizado na geração de discos com espessura entre 0,8 - 1,0 mm. 


\subsection{2 - Corte em discos de 3,0 mm de diâmetro - Eletroerosão por penetração}

Os discos de $10 \mathrm{~mm}$ de diâmetro e $800 \mu \mathrm{m}$ de espessura foram submetidos a eletroerosão por penetração para se obter discos de 3,0 mm de espessura, padrão dos porta-amostras de microscópios de transmissão. O esquemático abaixo ilustra uma possibilidade otimizada no corte dos discos de $10 \mathrm{~mm}$ de forma a se obter até 3 amostras a partir de um único disco.

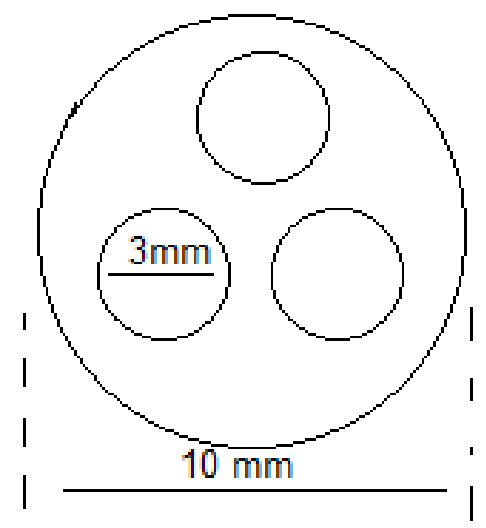

FIGURA 3.4.2.1 - Esquema de corte adotado para obtenção dos discos de 3,0mm a serem afinados.

\subsection{3 - Pré- afinamento dos discos de $3,0 \mathrm{~mm}$}

A partir dos discos de $3,0 \mathrm{~mm}$ de diâmetro e $0,8 \mathrm{~mm}$ de espessura foi executado o pré afinamento da amostra. Inicialmente com lixas \# 400 sobre placas de vidro e água, com a amostra colada com cola "WAX" sobre o "grinder" mostrado na FIG.3.4.3.1 (a) e (b) que permitem bom manuseio e avanço suave da amostra a ser lixada nas duas faces para que a mesma permaneça paralela. Foi verificado que avanços maiores que $0,1 \mathrm{~mm}$ na superfície de lixamento podem trazer arrancamentos indesejados. A espessura e a integridade da amostra foram conferidas a intervalos regulares durante o processo com auxílio de um microscópio ótico de baixo aumento (30 X), equipado com micrômetro comparador digital acoplado à coluna do

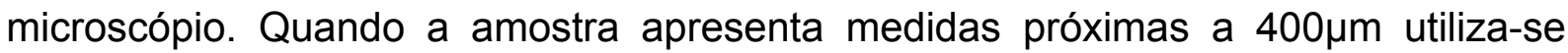
uma seqüência de lixas: \# 800, 1000, 1200 onde a mudança de lixa é determinada pela inexistência de riscos e imperfeições na superfície. O avanço no desbaste com lixas mais grosseiras nessa fase deve ser evitada sob o risco de gerar trincas e 
defeitos na amostra que só serão identificadas nos processos seguintes, podendo tornar a amostra imprópria para o uso.

As FIGS. 3.4.3.1 (a) e (b) mostram os dois tipos de dispositivos utilizados no afinamento inicial.
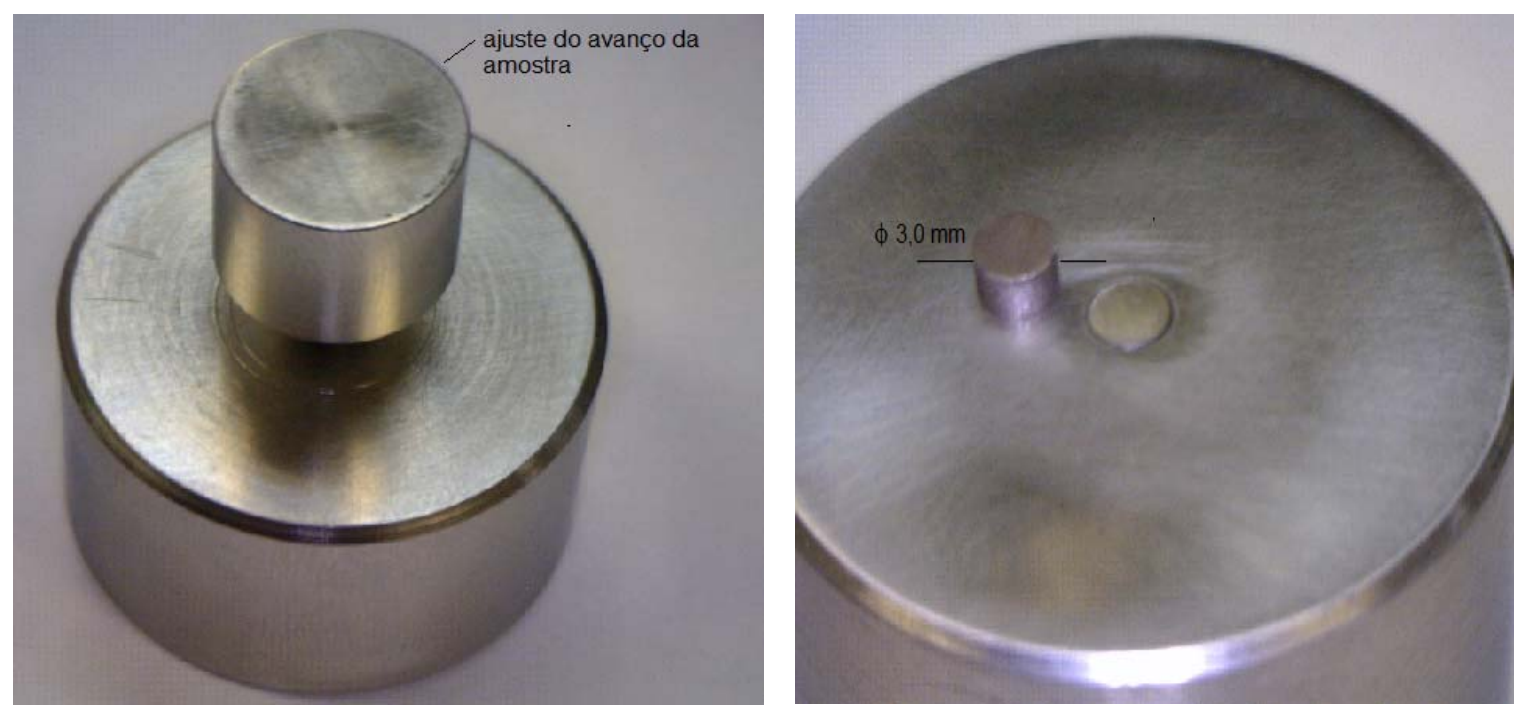

(a)

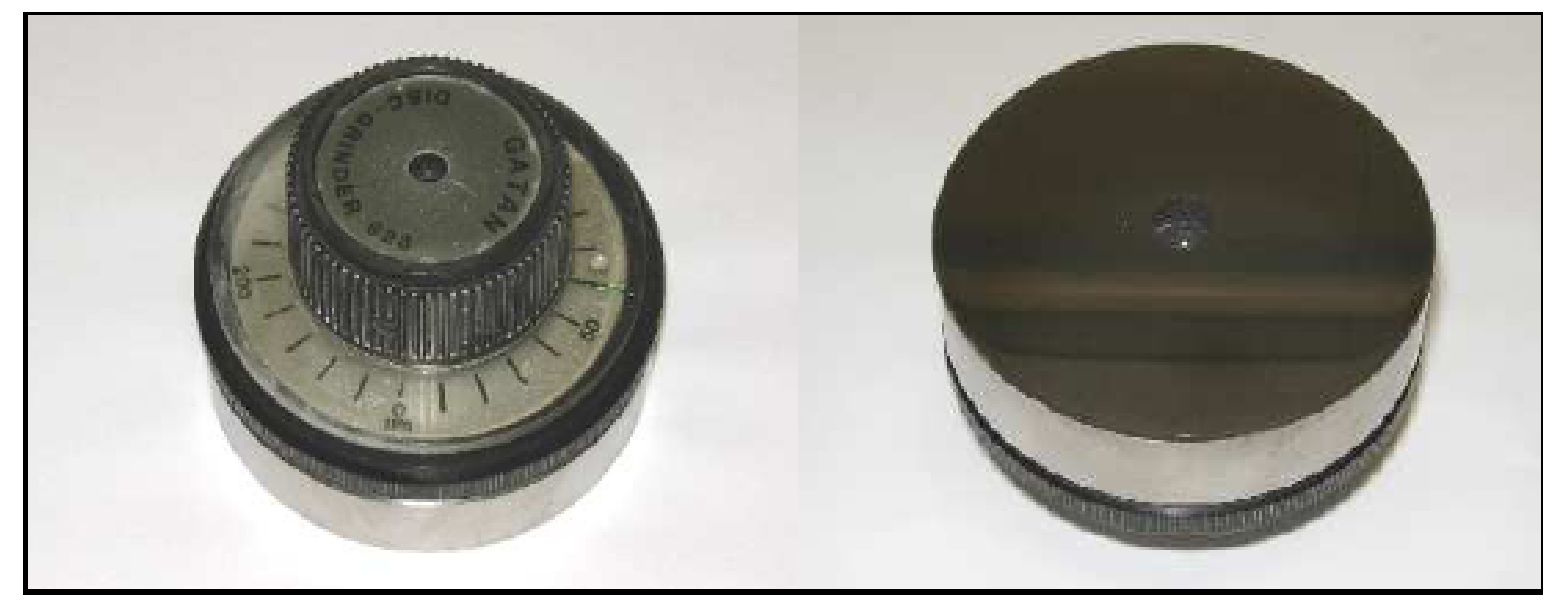

(b)

FIGURA 3.4.3.1 - (a), grinder desenvolvido para pré-afinamento na faixa de 0,8 $\mathrm{mm}$ 0,3 mm e (b), Grinder Gattan 628 para espessuras da ordem de 80-100 $\mathrm{mm}$. 
Quando existirem áreas com arrancamentos significativos ou trincas de extensão considerável, essa amostra deverá ser desconsiderada. Finalmente, é feito um polimento com feltro sobre placa de vidro e com uma solução de $\mathrm{Al}_{2} \mathrm{O}_{3}$ obtendose finalmente uma amostra paralela e com espessura entre $80-100 \mu \mathrm{m}$. Foram feitas tentativas de diminuição na espessura final para uma faixa entre $60-70 \mu \mathrm{m}$, porém, como nessa faixa de afinamento o material se mostrou muito frágil, regrediu-se para a faixa atual. Concluído o processo de pré-afinamento faz-se uma medida final na espessura da amostra no microscópio ótico e micrômetro acoplado fazendo-se a média de três medidas consecutivas.

A FIG.3.4.3.2 mostra a seqüência de afinamento com os tipos de lixas a serem utilizadas e as correspondentes espessuras nas amostras.
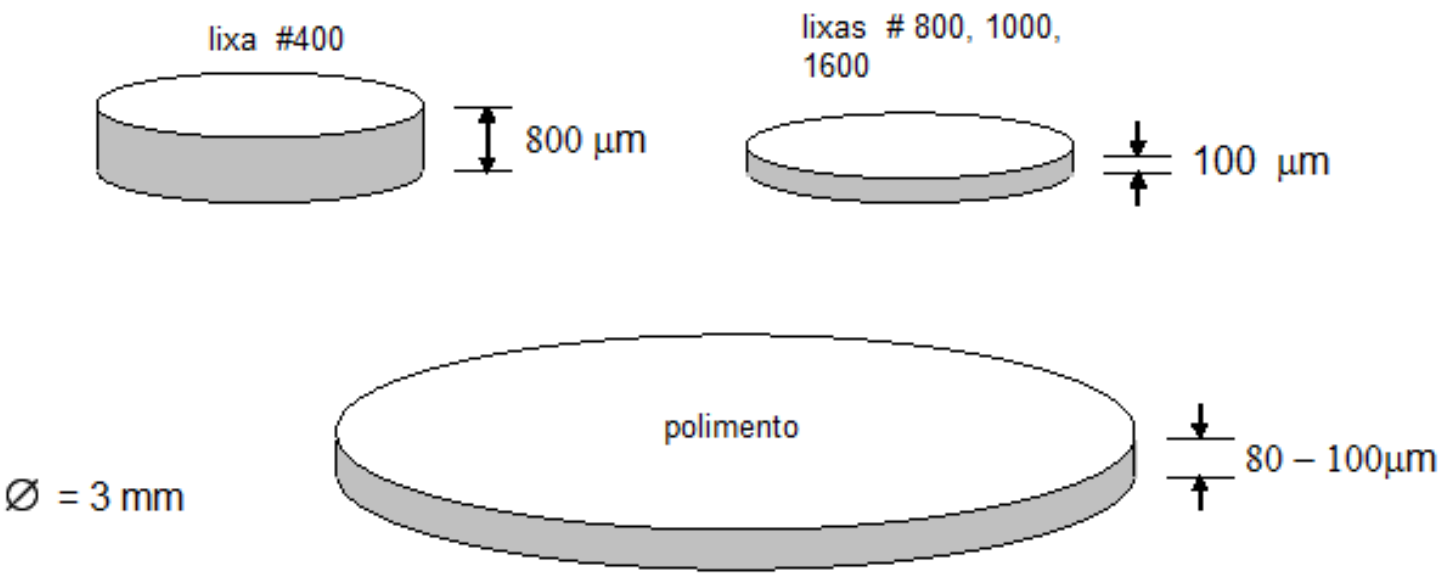

FIGURA 3.4.3.2 - Discos de 3,0mm em processo de afinamento sucessivo com lixamento e polimento paralelo. (Conrado et al., 2009).

\subsection{4 - "Dimpler" dos discos pré-afinados}

O passo seguinte ao pré-afinamento compreende o desbaste central da amostra com auxílio de um equipamento composto de uma base magnética rotativa na qual a amostra é fixada com uma cola especial, de baixo ponto de fusão (WAX), 
utilizando-se uma chapa aquecedora. O disco de cobre de desbaste é fixado no eixo rotativo conforme indicado na FIG. 3.4.1.4, com velocidade ajustada em $50 \%$ e um contrapeso para que se possa ajustar a pressão do disco sobre a amostra. $O$ avanço do disco sobre a amostra é monitorado por um micrômetro comparador e é possível programar a medida a ser desbastada através do botão de ajuste de desbaste identificado na FIG. 3.4.4.1. A determinação da medida de desbaste deve considerar que a espessura da amostra foi bem determinada na etapa anterior, sob o risco de furarmos a amostra no "dimpler" e inutilizarmos a mesma. Durante todo o processo de afinamento com o "dimpler" é necessária a utilização de água introduzida através de uma seringa de pequeno volume para que se possa gotejar a água sobre a amostra evitando o aquecimento excessivo ou arrancamento de fases de interesse. Foi utilizado como meio de desbaste sobre a amostra uma pequena quantidade de pasta diamantada de granulometria \# $2 \mu \mathrm{m}$ e ao final do processo quando a espessura do menisco já estava próximo dos $20 \mu \mathrm{m}$ utiliza-se uma solução de alumina $\left(\mathrm{Al}_{2} \mathrm{O}_{3}\right)$ para um polimento final.

A FIG. 3.4.4.1 mostra o equipamento utilizado na realização da concavidade da amostra

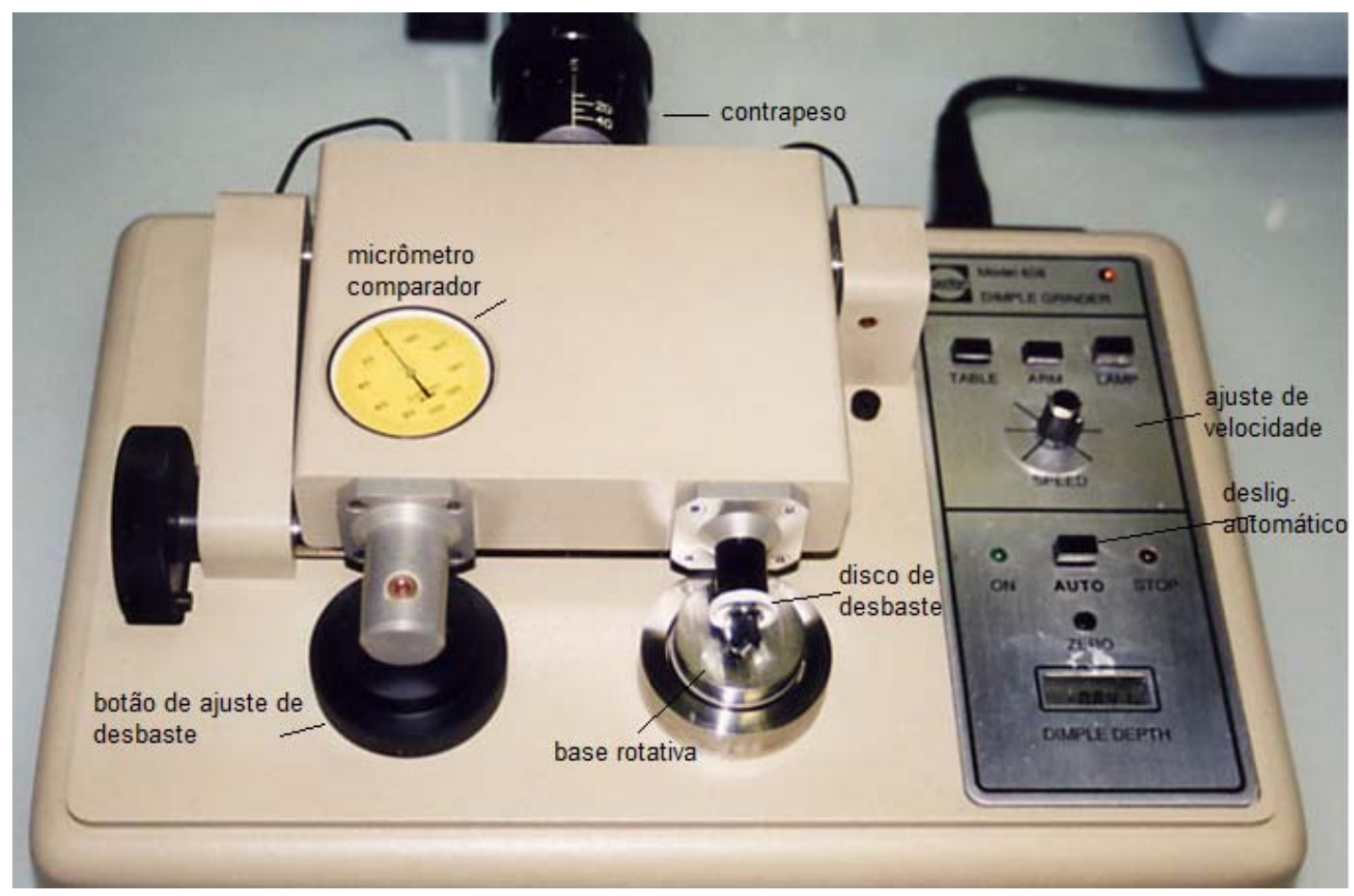

FIGURA 3.4.4.1 "Dimpler" Gattan utilizado na preparação da amostra pré- afinada. 
Após o polimento da amostra com $\mathrm{Al}_{2} \mathrm{O}_{3}$ retira-se a base rotativa, que é magnética, e leva-se ao microscópio de baixo aumento para uma conferência da dimensão ao centro que deverá ser de aproximadamente $20 \mu \mathrm{m}$. Essa inspeção também visa um exame minucioso em toda a superfície da amostra para que se possam identificar trincas ou arrancamentos de grandes proporções e da mesma forma que se considerou no item 3.4.3, faz-se uma análise do risco dessa amostra perder a integridade mecânica e eventualmente ser "sugada" na próxima etapa do polimento iônico. Caso haja trincas de grandes proporções, a amostra é descartada. Finalmente a amostra é descolada da base através de imersão em acetona pura durante alguns minutos. Deve-se evitar a utilização de aquecimento nessa etapa, pois devido à espessura reduzida no centro da amostra poderá haver danos que impossibilitem a utilização da mesma. A Figura 3.4.4.2 ilustra um esquemático de uma amostra em corte onde se destaca a espessura desejada ao centro.

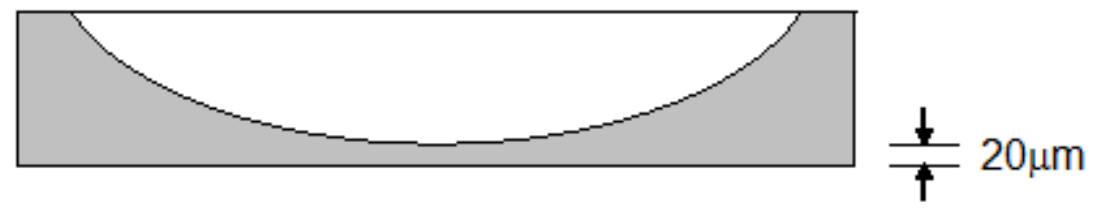

FIGURA 3.4.4.2 - Vista em corte do esquemático de uma amostra após a realização da concavidade executada com o "dimpler".

Concluída a fase do afinamento por "Dimpler" executa-se a última etapa de preparação com o polimento iônico de argônio descrito a seguir.

\subsection{5 - Sistema de Polimento lônico de Precisão}

A amostra é finalmente submetida ao equipamento PIPS (Polimento iônico de precisão - GATAN 691). Inicialmente deve-se fixar a amostra utilizando-se um dos dois sistemas ilustrados na FIG. 3.4.5.1. As amostras devem ser sempre manipuladas com auxílio de canetas á vácuo e montadas no sistema de fixação com o auxílio do dispositivo da FIG. 3.4.5.2. Após a montagem da amostra no sistema de 
fixação da FIG 3.4.5.1 com auxílio do dispositivo da FIG.3.4.5.2 procede-se o polimento sob feixe iônico de argônio.

A FIG. 3.4.5.1 mostra duas possibilidades para a fixação de amostras que serão submetidas ao polimento iônico. Geralmente utiliza-se o sistema com pinça para amostra de materiais metálicos e o sistema com cola para materiais cerâmicos. No nosso caso foi utilizado o sistema com pinça, onde o dispositivo mostrado na FIG. 3.4.5.2 é indispensável.
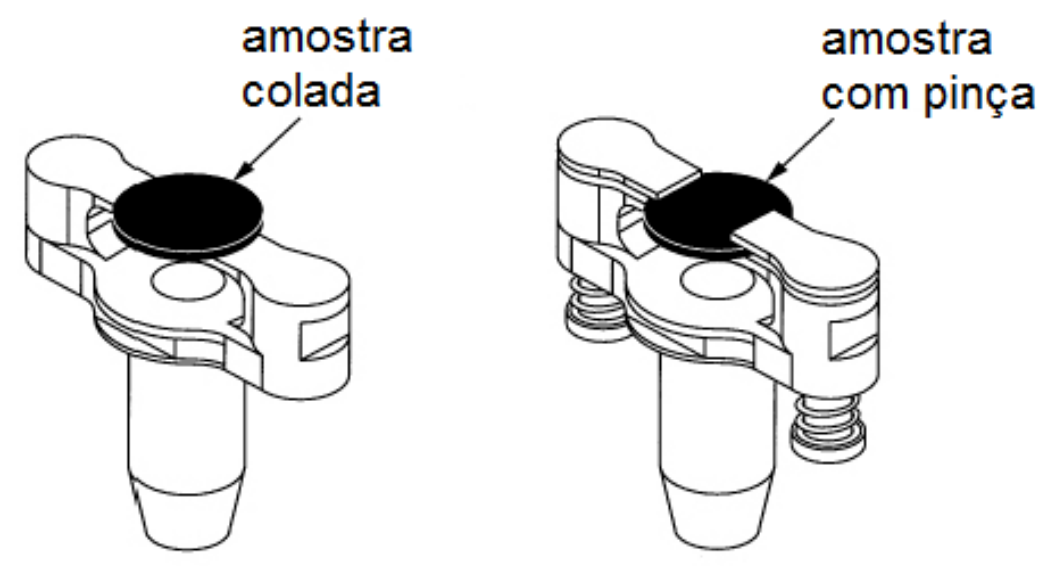

FIGURA 3.4.5.1 - Sistemas de fixação disponíveis no equipamento de polimento iônico Gattan 691. (Conrado et al., 2009).

A FIG. 3.4.5.2 mostra o dispositivo necessário para o manuseio da amostra a ser polida juntamente com o sistema de fixacão mostrado na FIG 3.4.5.1.

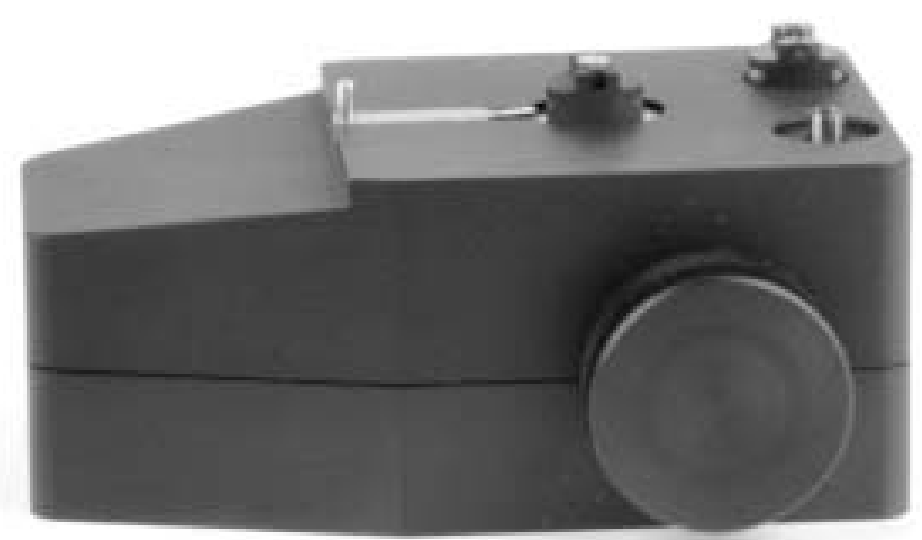

FIGURA 3.4.5.2 - Dispositivo para montagem da amostra no sistema de fixação. 
Após a inserção da amostra no equipamento da FIG. 3.4.5.3, em atmosfera controlada (sob vácuo), são direcionados dois canhões com feixe iônico de Argônio, intensidade (4-6 keV) e ângulos de ataque (5-10²), um com incidência superior e outro inferior a amostra conforme ilustrado na FIG. 3.4.5.5. Foram ajustados períodos 20 minutos e através do microscópio acoplado foi acompanhada a evolução do polimento. O tempo médio para que as amostras revelassem o furo central ficou em torno de 1- 2 horas e é variável conforme o afinamento conseguido no "dimpler". A corrente do feixe de cada canhão pode ser ajustada durante o processo e deve permanecer no máximo valor possível (em torno de $20 \mu \mathrm{A}$ ). O polimento iônico pode ser considerado finalizado quando se visualiza no microscópio de baixo aumento um pequeno furo identificado pela passagem de luz presente sob a amostra. Um polimento final é executado com baixo ângulo de ataque $\left(<5^{0}\right)$ e uma tensão de 3,0 $\mathrm{kV}$, durante 5 minutos, a uma rotação de 3,0 rpm para que a borda da área fina fique livre de depósitos de materiais arrancados no polimento.

A FIG. 3.4.5.3 mostra o esquemático do equipamento Gattan 691, utilizado no polimento das amostras com os respectivos comandos e indicadores disponíveis

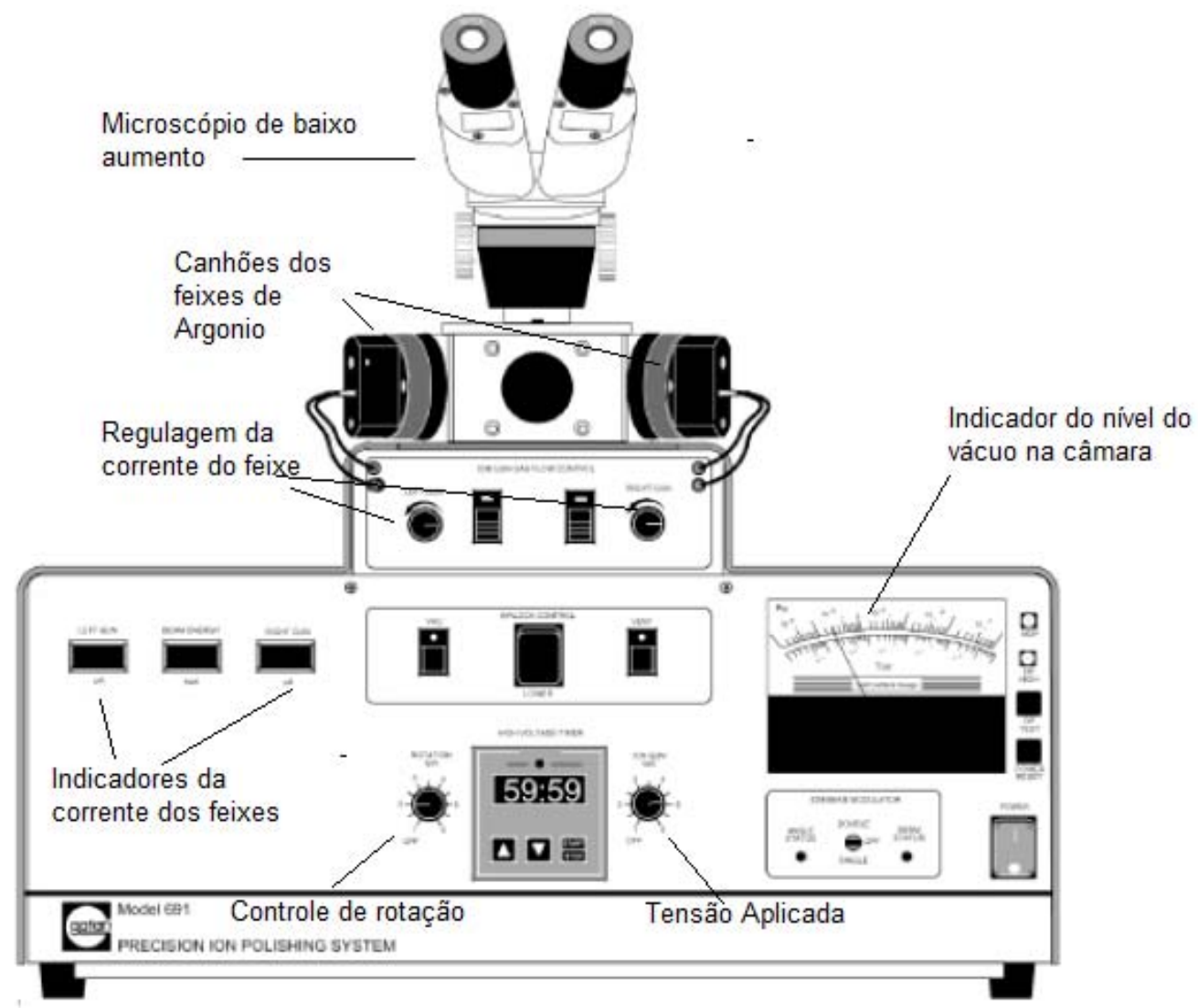

FIGURA 3.4.5.3 - Vista frontal do equipamento Gattan 691 utilizado no polimento iônico das amostras. 
A FIG. 3.4.5.4 ilustra com detalhes como o sistema de canhões de íons bombardeia a amostra girando através de um sistema moto- redutor acoplado na câmara evacuada.

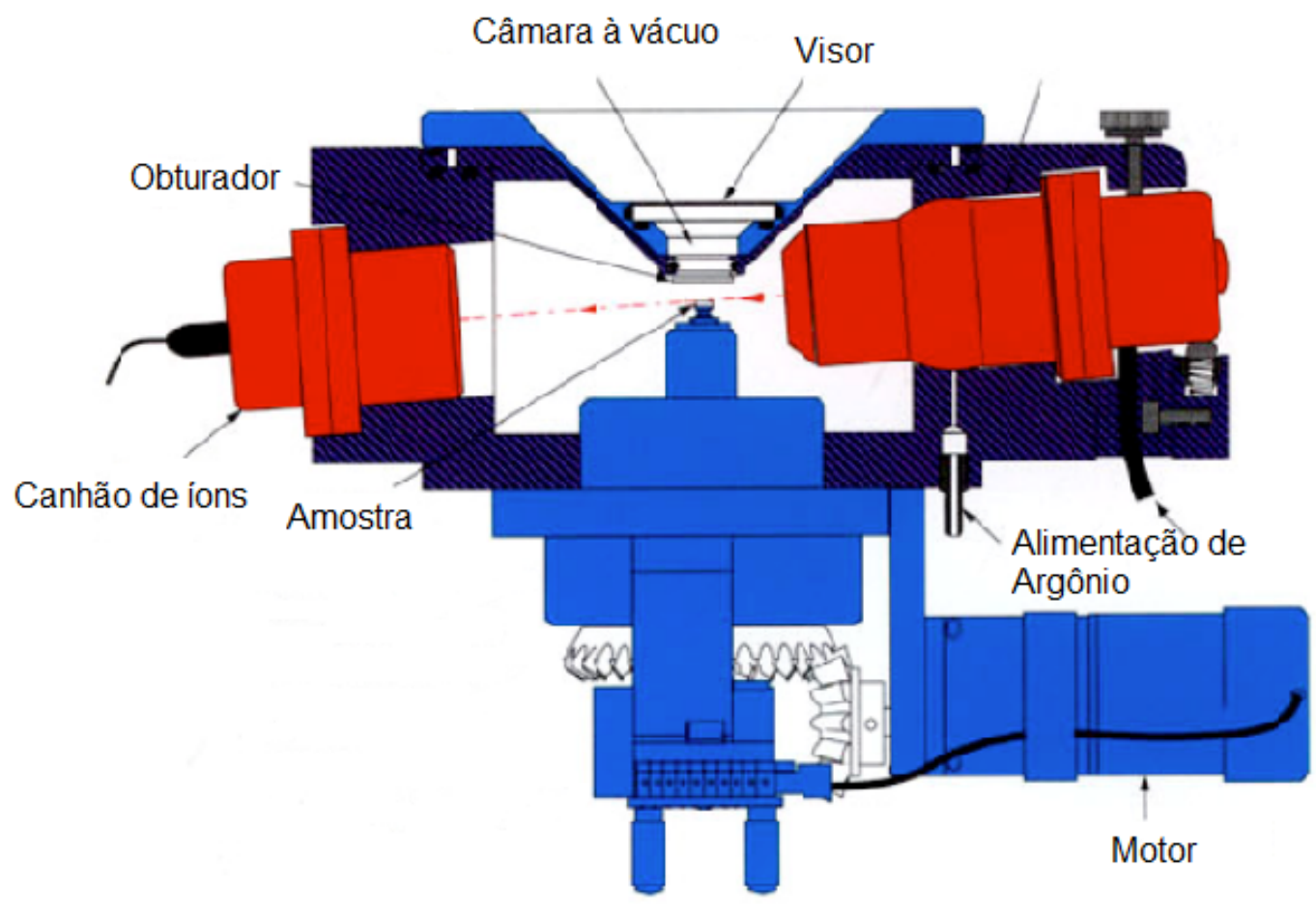

FIGURA 3.4.5.4 - Esquemático do sistema de canhões de íons que executam o polimento da amostra em um "íon milling". (www.gattan.com, 2009).

A FIG 3.4.5.5 mostra o bombardeamento do feixe de $\mathrm{Ar}$ com a finalidade de gerar áreas finas $(<100 \mathrm{~nm})$ ao centro da amostra.

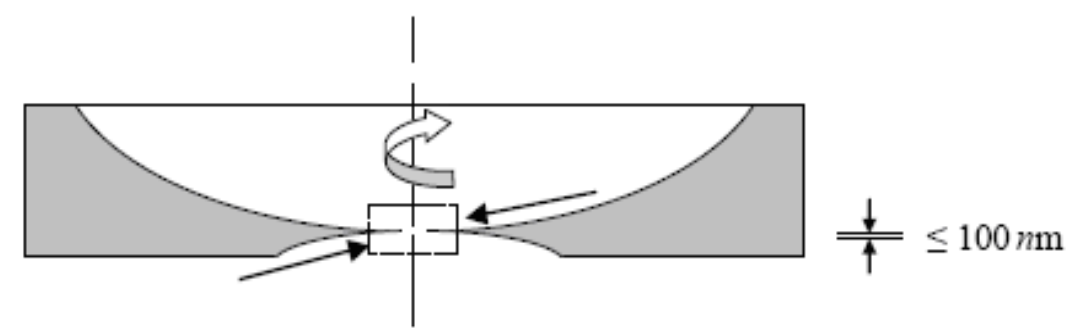

FIGURA 3.4.5.5 - Esquemático do feixe iônico incidindo sobre a amostra na obtenção da área fina. 
A FIG. 3.4.5.6 (a), mostra uma imagem da amostra ao final do processo de afinamento com aumento de $20 \mathrm{X}$, onde se destaca a região de área fina na borda do furo e em (b) uma grade de cobre de mesmo diâmetro colada sobre a amostra.

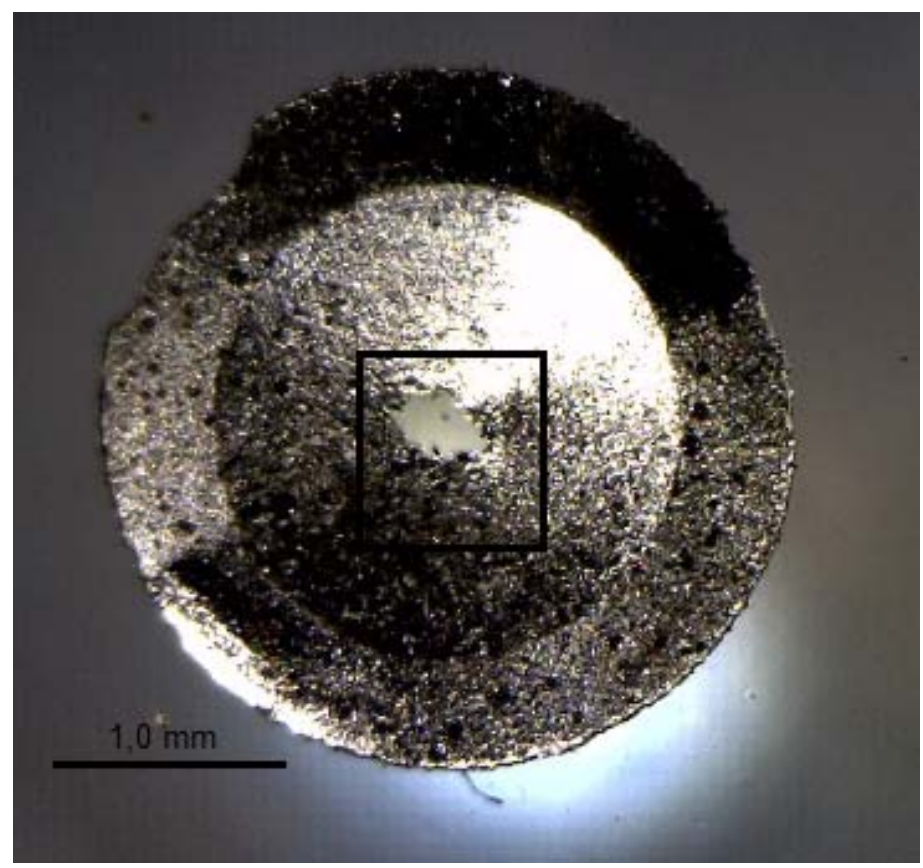

(a)

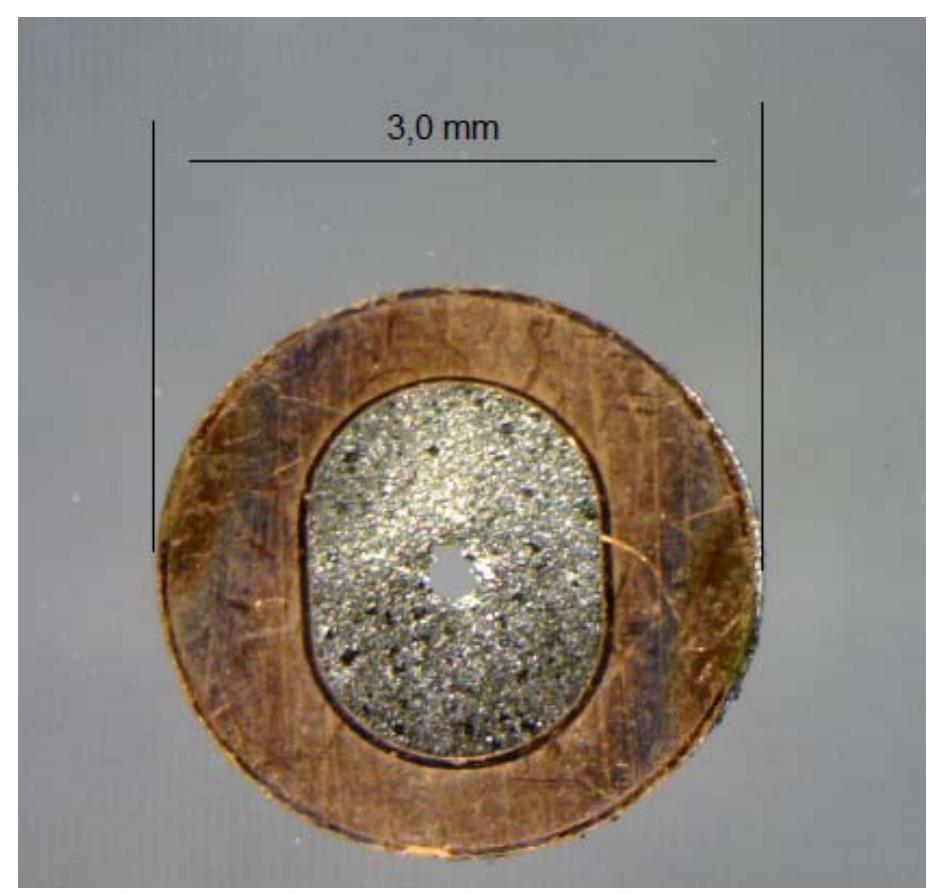

(b)

FIGURA 3.4.5.6 - Em (a) a amostra já polida e em (b) colada sob uma grade de Cu visando melhor resistência mecânica. 
Amostras de materiais magnéticos sinterizados tornam-se frágeis após o processo de afinamentos sucessivos com posterior polimento iônico e geralmente apresentam trincas ou quebras nas bordas. Durante a observação no MET, com feixe eletrônico de 200-300 kV interagindo na amostra poderá haver desprendimento de material no interior da coluna do microscópio, causando sérios danos ao equipamento. Uma grade de Cu padrão $\left(\Phi_{\mathrm{e}}=3,0 \mathrm{~mm}\right)$ pode ser colada sobre a mesma, garantindo dessa forma uma situação mecânica mais favorável e segura conforme ilustrado na FIG. 3.4.5.6 (b).

Durante o processo de polimento iônico é possível observar-se as condições da amostra através do microscópio ótico indicado no esquemático da FIG. 3.4.5.3 onde algumas vezes são constatadas trincas que conforme a extensão torna a amostra imprópria para uso ilustrado na FIG 3.4.5.7.

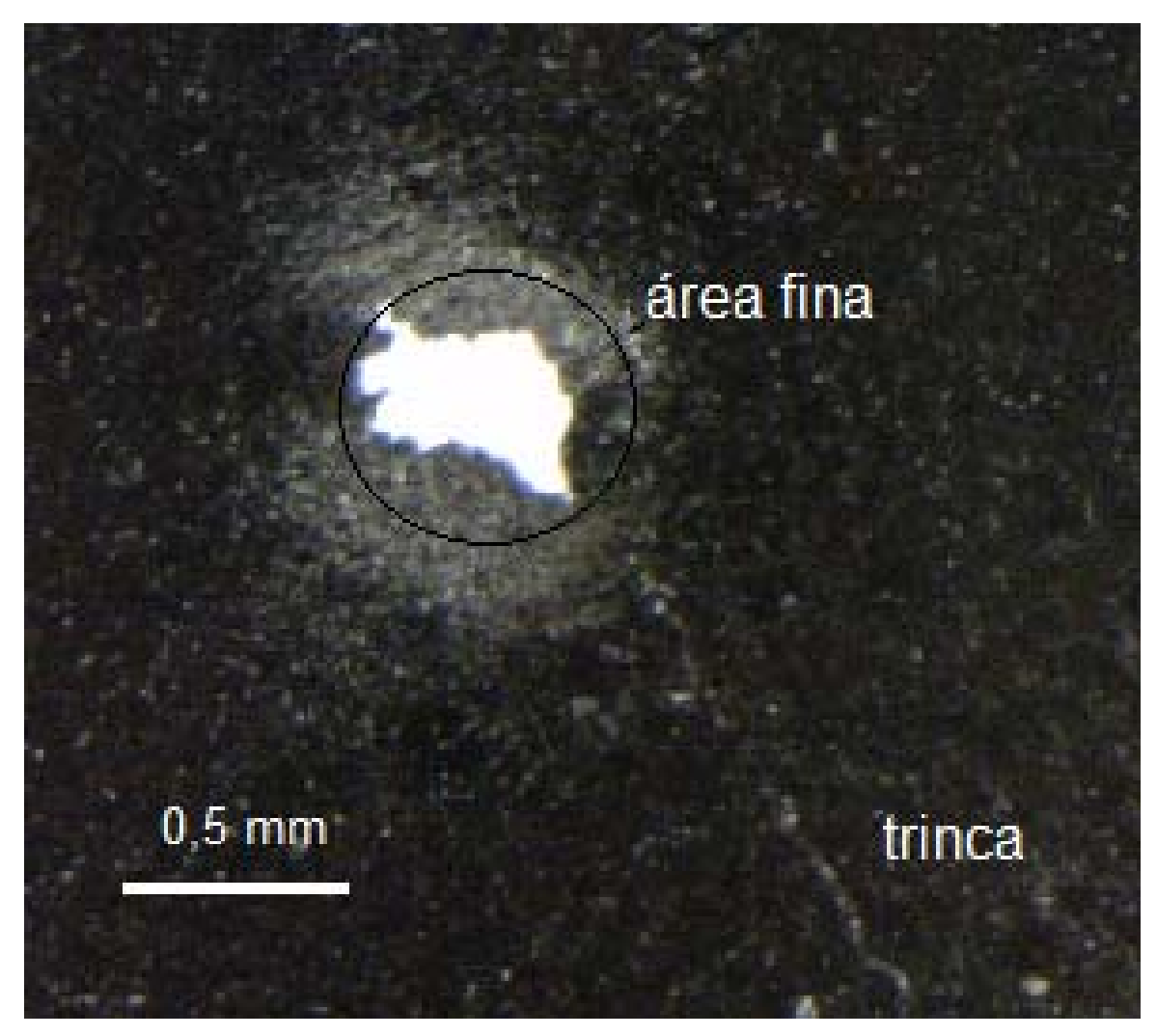

FIGURA 3.4.5.7 - Amostra de ímã sinterizado PrFeB após preparação em "íon milling" onde se constatou trinca com extensão indesejável.

O recurso do polimento iônico na preparação de amostras para microscopia de transmissão foi utilizado desde o início das pesquisas com materiais sinterizados a base de $\mathrm{Nd}-\mathrm{Fe}-\mathrm{B}$. Permite a obtenção de regiões suficientemente finas para 
observação, más também pode gerar alguns inconvenientes já comentados anteriormente na literatura. Tsubokawa et al. (1988) relataram num estudo investigando o contorno de grão, que a oxidação e o bombardeamento de íons causam aquecimento local durante o processo de preparação de amostras e modificam a estrutura cristalográfica numa faixa de $\sim 20 \mathrm{~nm}$ junto a fase matriz.

A micrografia de alta resolução do ímã sinterizado a base de PrFeB abaixo, ilustra uma região modificada próxima ao contorno do grão da fase magnética, provavelmente devido ao tempo e intensidade de exposição ao bombardeamento iônico.

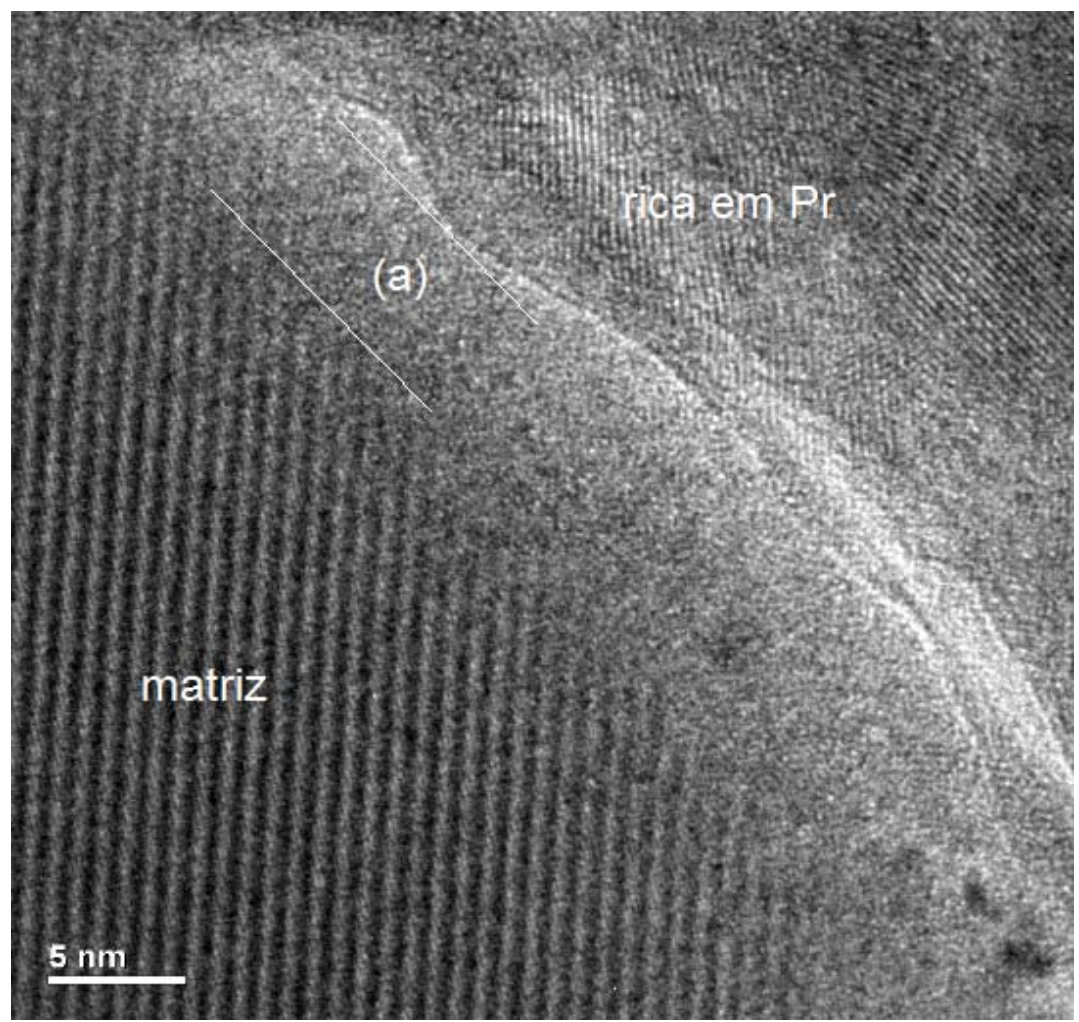

FIGURA 3.4.5.8 - Imagem em alta resolução da região de interface entre um grão da fase matriz e a fase rica em Pr. Pode ser observar a modificação causada pelo bombardeamento iônico na fase matriz indicada na região (a).

Futuras preparações de amostras com materiais dessa natureza poderão ser executadas à temperatura de nitrogênio líquido, visando minimizar o aumento da temperatura local durante o bombardeamento. A utilização de FIB (feixe iônico focado), na seleção da região de interesse seguido de observação com ponta de prova atômica assistida a laser, constitui uma alternativa mais promissora na investigação desses materiais e tem sido apresentada em trabalhos recentes. 


\section{CAPÍTULO 4}

\section{Resultados e Discussão}

Os resultados obtidos com as amostras dos ímãs sinterizados com adições de elementos de liga estão apresentados obedecendo-se a metodologia descrita no capítulo 3.

Inicialmente são apresentados os resultados extraídos das curvas de desmagnetização com os valores da coercividade intrínseca, remanência, produto de energia, fator de quadratura e densidade do ímã adotado como padrão $\operatorname{Pr}_{15} \mathrm{Fe}_{\text {bal }} \mathrm{Co}_{8} \mathrm{~B}_{7} \mathrm{Nb}_{0,05}$ e nos demais com adições de Al, Si, P, Cu, Ga, Gd, Tb e Dy nas concentrações indicadas.

As curvas de desmagnetização das amostras com desempenho superior ao ímã padrão $\operatorname{Pr}_{15} \mathrm{Fe}_{\text {bal }} \mathrm{Co}_{8} \mathrm{~B}_{7} \mathrm{Nb}_{0,05}$, foram analisadas considerando-se o melhor resultado obtido para a coercividade e fator de quadratura. As micrografias realizadas com MEV foram processadas com o programa Image Tool 3.0 gerando as características de forma e tamanho dos grãos. Os fatores de quadratura extraídos das curvas de desmagnetização e aqueles calculados a partir da equação (3.2.1) também são apresentados.

A verificação de valores superiores para a coercividade nos ímãs com adições de $\mathrm{Ga}$, mesmo com tamanho de grão superior, levaram a investigações com microscopia eletrônica de transmissão (MET) visando à observação das modificações na microestrutura, que possam explicar tais resultados.

As investigações da microestrutura com microscopia eletrônica de transmissão em ímãs permanentes à base de PrFeB com adições de elementos de liga, constituem o ineditismo dessa pesquisa. 


\section{1- Resultados Obtidos - Curvas de Desmagnetização no Segundo Quadrante}

A TAB. 4.1.1 mostra os resultados das propriedades magnéticas obtidos a partir das curvas de desmagnetização no segundo quadrante para os ímãs sinterizados à base de $\operatorname{Pr}_{15} \mathrm{Fe}_{\text {bal }} \mathrm{Co}_{8} \mathrm{~B}_{7} \mathrm{Nb}_{0,05}$ adotado como padrão, e os demais com aditivos $\left(\mathbf{M}_{\mathbf{x}}\right)$ adicionados nas concentrações indicadas. A densidade $(\rho)$ foi calculada pelo método de Archimedes descrito no capítulo 3, equação (3.1.1).

TABELA 4.1.1 - Propriedades magnéticas dos ímãs sinterizados $\operatorname{Pr}_{15} \mathrm{Fe}_{\mathrm{bal}} \mathrm{Co}_{8} \mathrm{~B}_{7} \mathrm{Nb}_{0,05} \mathrm{M}_{\mathrm{x}}$.

\begin{tabular}{|c|c|c|c|c|c|}
\hline$M_{x}$ & $\begin{array}{c}\mathrm{B}_{\mathrm{r}}(\mathrm{mT}) \\
( \pm 2 \%)\end{array}$ & $\begin{array}{c}\mu_{0 i} \mathrm{H}_{c} \\
(\mathrm{mT}) \\
( \pm 2 \%)\end{array}$ & $\begin{array}{c}\mathrm{BH}_{(\max )}\left(\mathrm{kJm}^{-3}\right) \\
( \pm 2 \%)\end{array}$ & $\begin{array}{c}F Q \\
( \pm 2 \%)\end{array}$ & $\begin{array}{l}\rho\left(\mathrm{g} / \mathrm{cm}^{3}\right) \\
( \pm 0.5 \%)\end{array}$ \\
\hline Padrão & 1150 & 1000 & 247 & 0,84 & 7,41 \\
\hline $\mathrm{Al}_{0,05}$ & 1120 & 910 & 230 & 0,78 & 7,48 \\
\hline $\mathrm{Al}_{0,15}$ & 1080 & 950 & 210 & 0,71 & 7,43 \\
\hline $\mathrm{Al}_{0,25}$ & 1140 & 970 & 242 & 0,80 & 7,43 \\
\hline $\mathrm{Si}_{0,05}$ & 1120 & 800 & 230 & 0,85 & 7,55 \\
\hline $\mathrm{Si}_{0,15}$ & 1100 & 850 & 218 & 0,81 & 7,53 \\
\hline $\mathrm{Si}_{0,25}$ & 1140 & 1000 & 242 & 0,86 & 7,41 \\
\hline$P_{0,05}$ & 1080 & 900 & 214 & 0,81 & 7,38 \\
\hline$P_{0,15}$ & 1140 & 720 & 242 & 0,85 & 7,39 \\
\hline$P_{0,25}$ & 1170 & 880 & 254 & 0,89 & 7,48 \\
\hline $\mathrm{Cu}_{0,05}$ & 1070 & 1040 & 215 & 0,77 & 7,47 \\
\hline $\mathrm{Cu}_{0,15}$ & 1140 & 970 & 240 & 0,81 & 7,42 \\
\hline $\mathrm{Cu}_{0,50}$ & 1080 & 940 & 224 & 0,79 & 7,40 \\
\hline $\mathrm{Ga}_{0,05}$ & 1090 & 1000 & 223 & 0,79 & 7,41 \\
\hline $\mathrm{Ga}_{0,15}$ & 1150 & 1050 & 246 & 0,86 & 7,38 \\
\hline $\mathbf{G a}_{0,25}$ & 1060 & 1100 & 208 & 0,77 & 7,42 \\
\hline $\mathrm{Gd}_{0,05}$ & 1050 & 850 & 216 & 0,87 & 7,46 \\
\hline $\mathrm{Gd}_{0,15}$ & 1050 & 790 & 208 & 0,86 & 7,44 \\
\hline $\mathrm{Gd}_{0,25}$ & 1120 & 690 & 225 & 0,86 & 7,48 \\
\hline $\mathrm{Tb}_{0,15}$ & 1090 & 920 & 215 & 0,86 & 7,48 \\
\hline $\mathrm{Dy}_{0,15}$ & 1050 & 910 & 207 & 0,82 & 7,48 \\
\hline
\end{tabular}


Após a caracterização dos ímãs e a obtenção dos valores das propriedades magnéticas e da densidade, realizou-se um estudo com MEV buscando-se informações sobre o tamanho de grão, elongação e circularidade denominado fator de homogeneidade (FH) por Périgo et al. (2008) e sua correlação com o fator de quadratura (FQ), extraído das curvas de desmagnetização.

A visualização dos valores extremos da coercividade através das curvas do segundo quadrante está apresentada na FIG. 4.1.1, onde foi possível compara o padrão $\operatorname{Pr}_{15} \mathrm{Fe}_{\text {bal }} \mathrm{Co}_{8} \mathrm{~B}_{7} \mathrm{Nb}_{0,05}$ aos ímãs com adição de $\mathrm{P}$ e $\mathrm{Ga}$ (0,25\%at.).

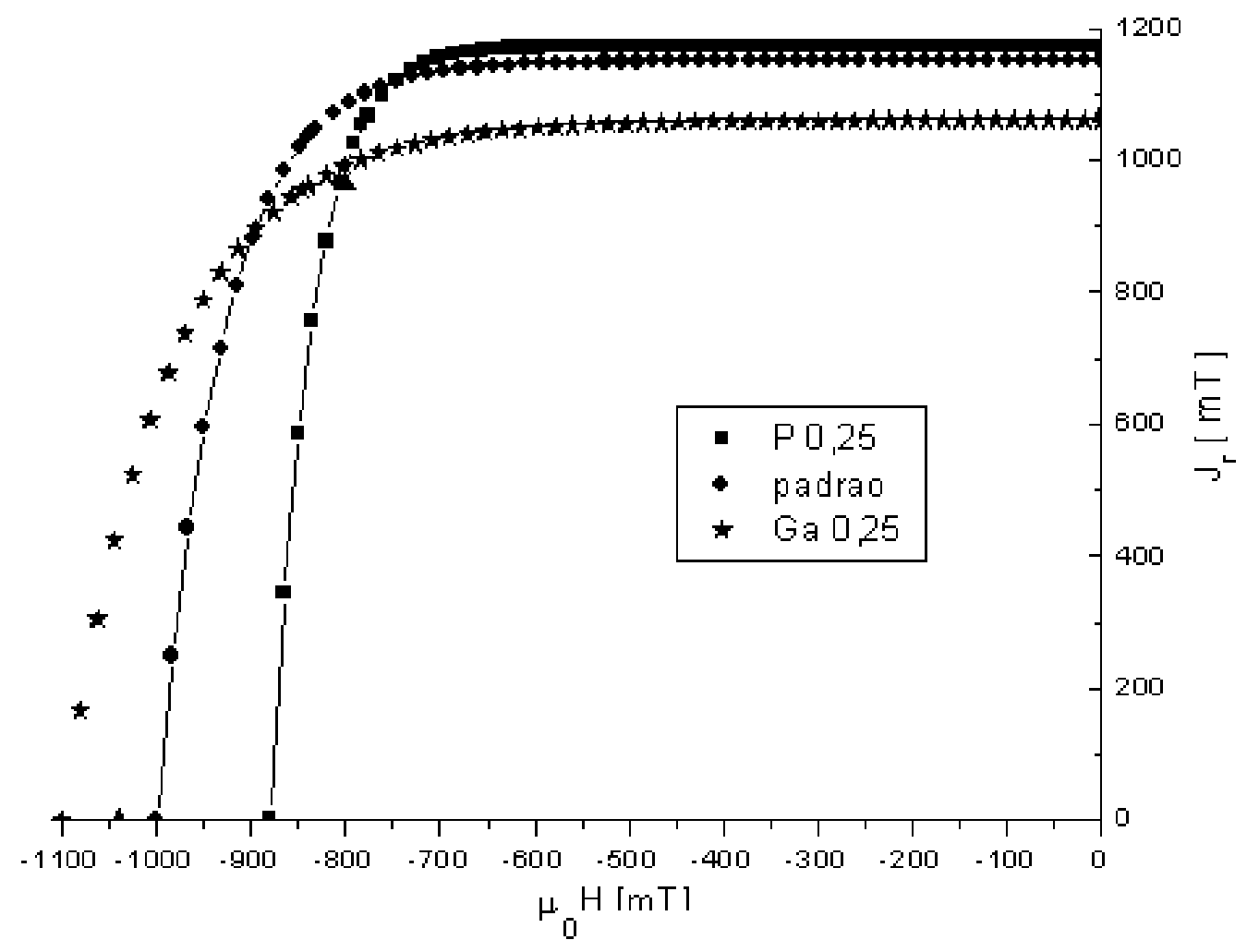

FIGURA 4.1.1 - Curvas de desmagnetização do segundo quadrante para os ímãs padrão e com adições de $\mathrm{P}$ e $\mathrm{Ga}(0,25 \%$ at.). 


\section{2- Análises com Microscopia Eletrônica de Varredura}

As micrografias apresentadas a seguir foram obtidas com Microscopia Eletrônica de Varredura em amostras produzidas com magnificação 1000 X, elétrons retroespalhados, $20 \mathrm{keV}$, para amostras com composição padrão $\operatorname{Pr}_{15} \mathrm{Fe}_{\text {bal }} \mathrm{Co}_{8} \mathrm{~B}_{7} \mathrm{Nb}_{0,05} \mathrm{e}$ com adições de $\mathrm{Al}_{0,25}, \mathrm{Si}_{0,25}, \mathrm{P}_{0,25}, \mathrm{Cu}_{0,05}, \mathrm{Ga}_{0,25}, \mathrm{Gd}_{0,15}, \mathrm{~Tb}_{0,15}$ e $\mathrm{Dy}_{0,15}$ nas composições indicadas nas figuras 4.2.1 a 4.2.9.

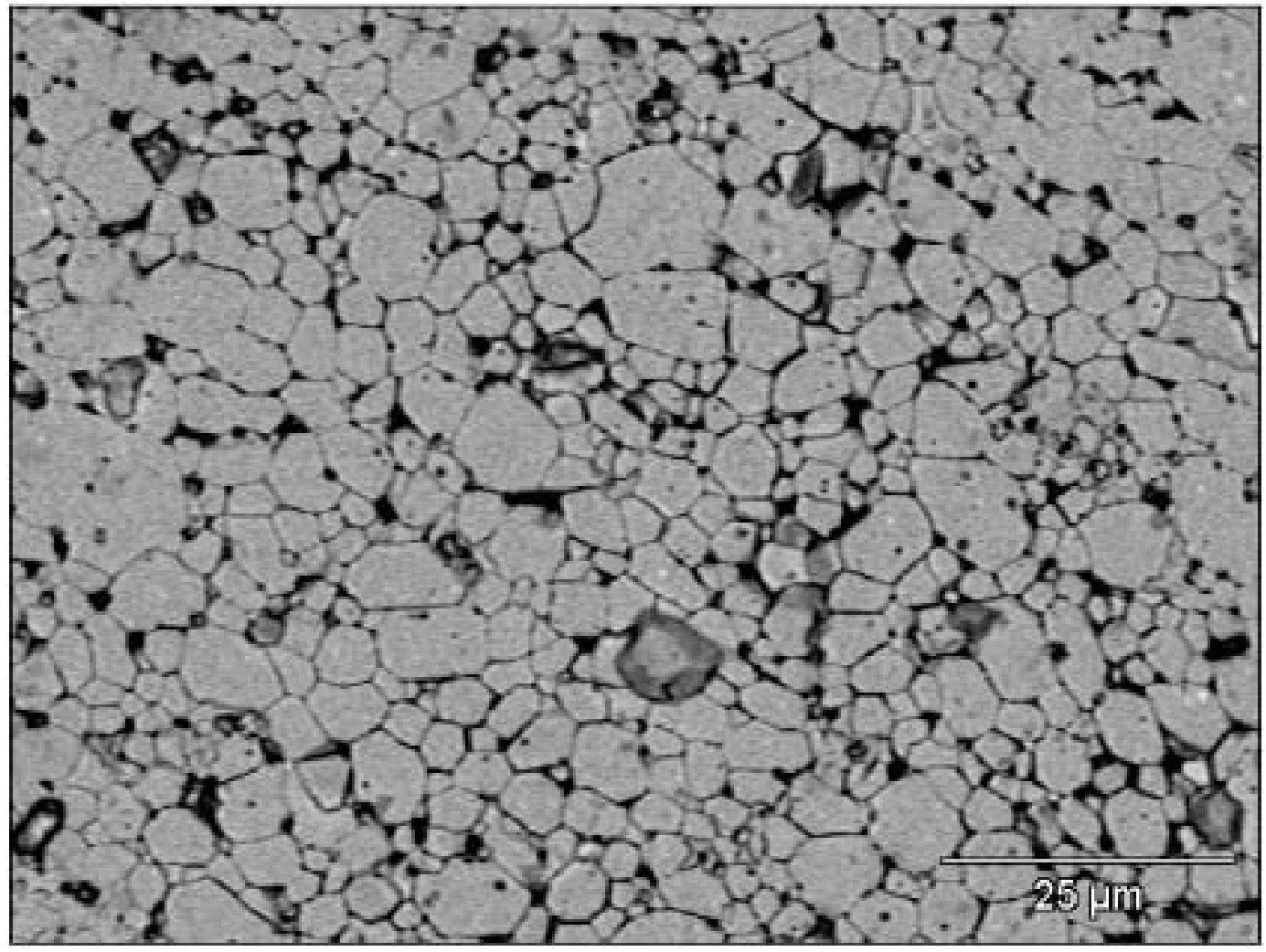

FIGURA 4.2.1 - Micrografia obtida com MEV, 1000 X, elétrons retro-espalhados para o ímã sinterizado adotado como padrão $\mathrm{Pr}_{15} \mathrm{Fe}_{\text {bal }} \mathrm{Co}_{8} \mathrm{~B}_{7} \mathrm{Nb}_{0,05}$. 


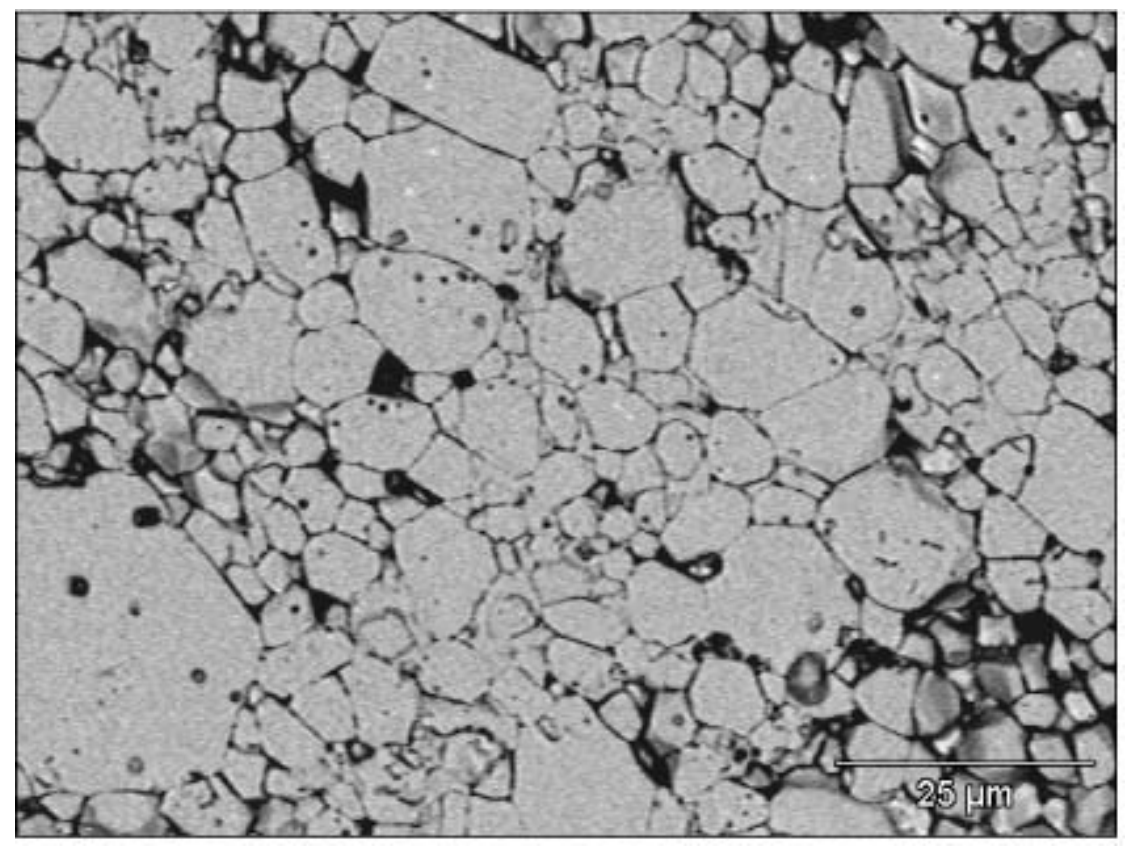

FIGURA 4.2.2 - Micrografias obtidas com MEV, $1000 \mathrm{X}$, elétrons retro-espalhados para o ímã $\operatorname{Pr}_{15} \mathrm{Fe}_{\text {bal }} \mathrm{Co}_{8} \mathrm{~B}_{7} \mathrm{Nb}_{0,05} \mathrm{Al}_{0,25}$.

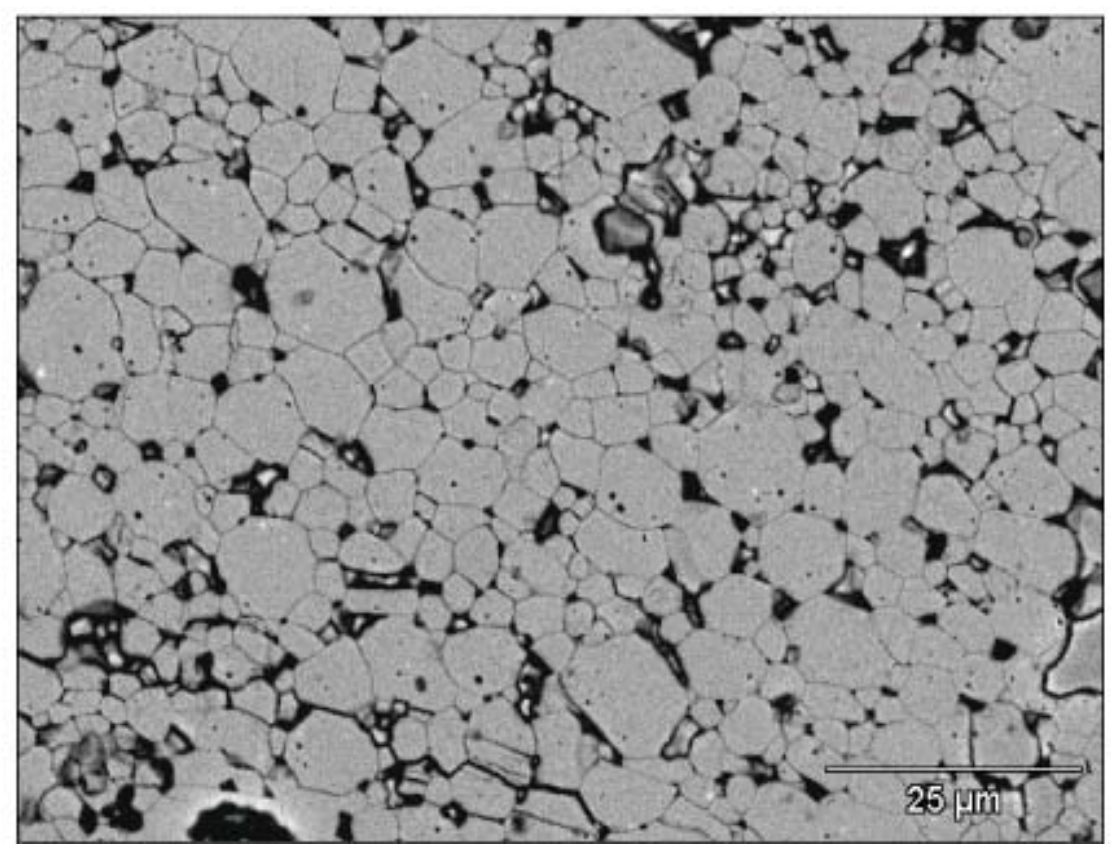

FIGURA 4.2.3 - Micrografia obtida com MEV, 1000 X, elétrons retro-espalhados para o ímã $\operatorname{Pr}_{15} \mathrm{Fe}_{\text {bal }} \mathrm{Co}_{8} \mathrm{~B}_{7} \mathrm{Nb}_{0,05} \mathrm{Si}_{0,25}$. 


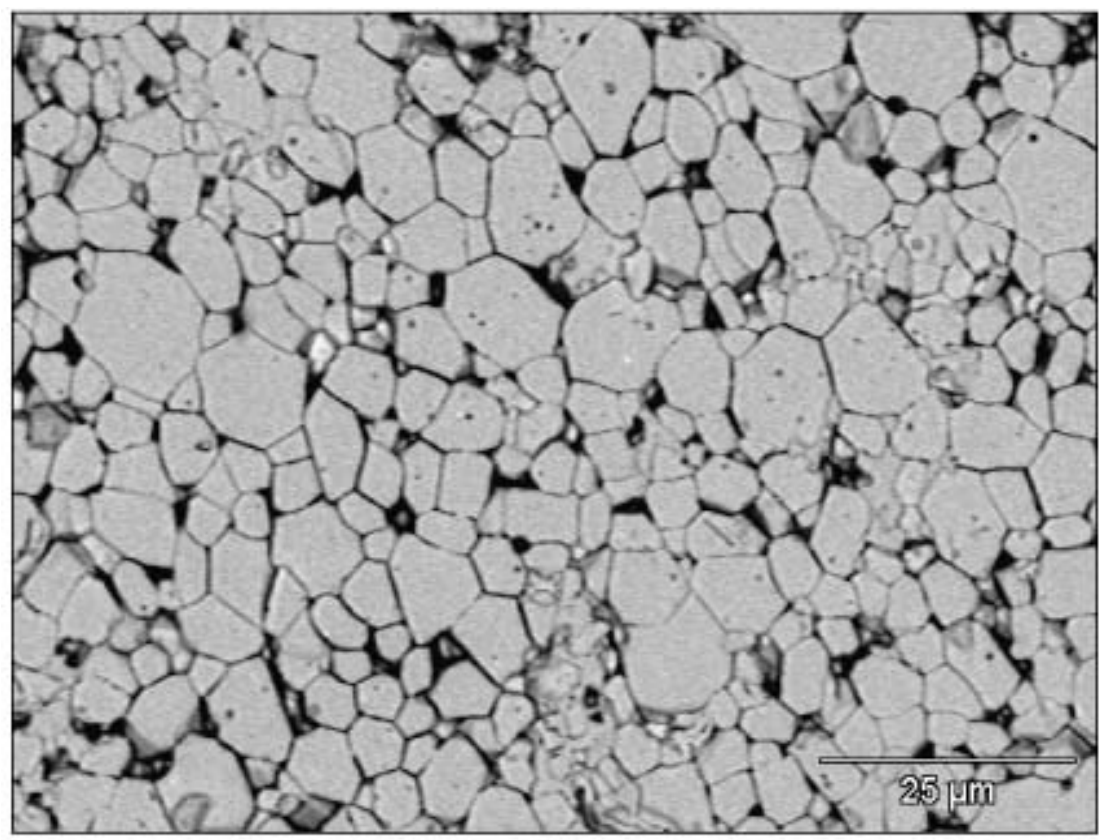

FIGURA 4.2.4 - Micrografias obtidas com MEV, 1000 X, elétrons retro-espalhados para o ímã $\operatorname{Pr}_{15} \mathrm{Fe}_{\text {bal }} \mathrm{Co}_{8} \mathrm{~B}_{7} \mathrm{Nb}_{0,05} \mathrm{Cu}_{0,05}$.

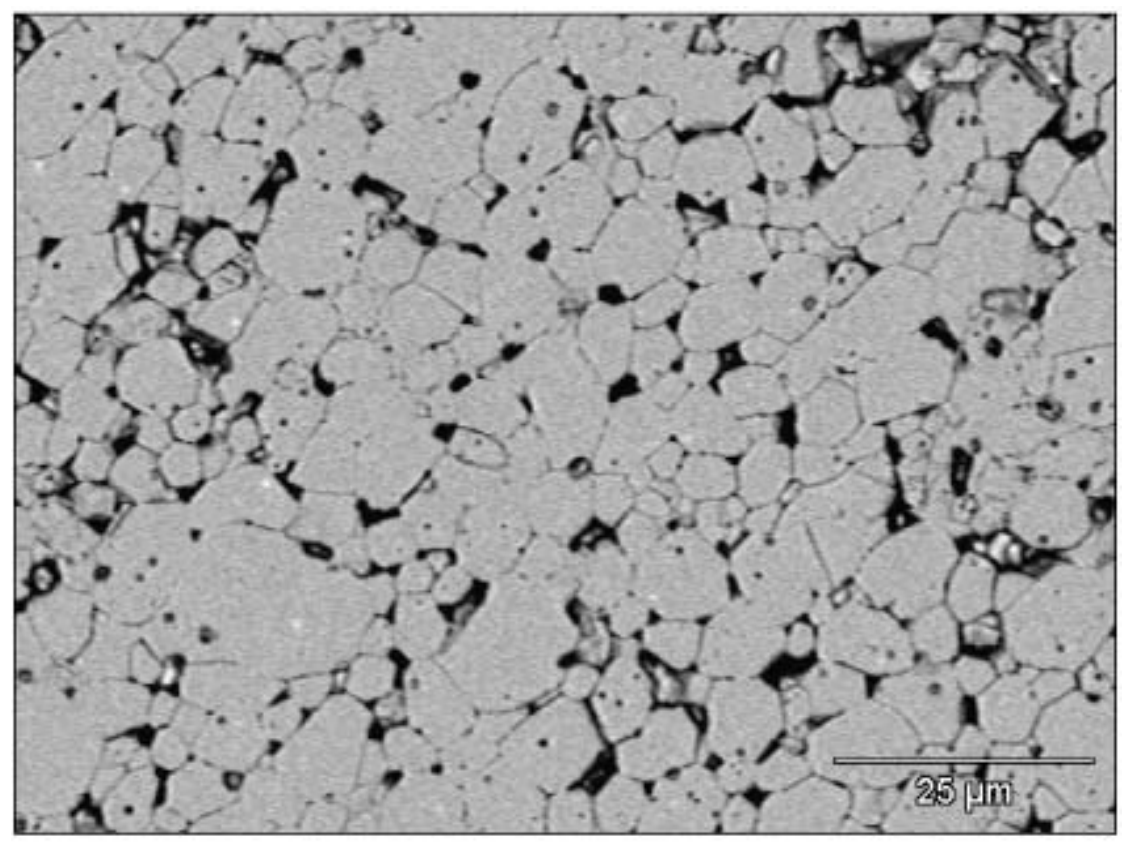

FIGURA 4.2.5 - Micrografias obtidas com MEV, $1000 \mathrm{X}$, elétrons retro-espalhados para o ímã $\mathrm{Pr}_{15} \mathrm{Fe}_{\text {bal }} \mathrm{Co}_{8} \mathrm{~B}_{7} \mathrm{Nb}_{0,05} \mathrm{P}_{0,25}$. 


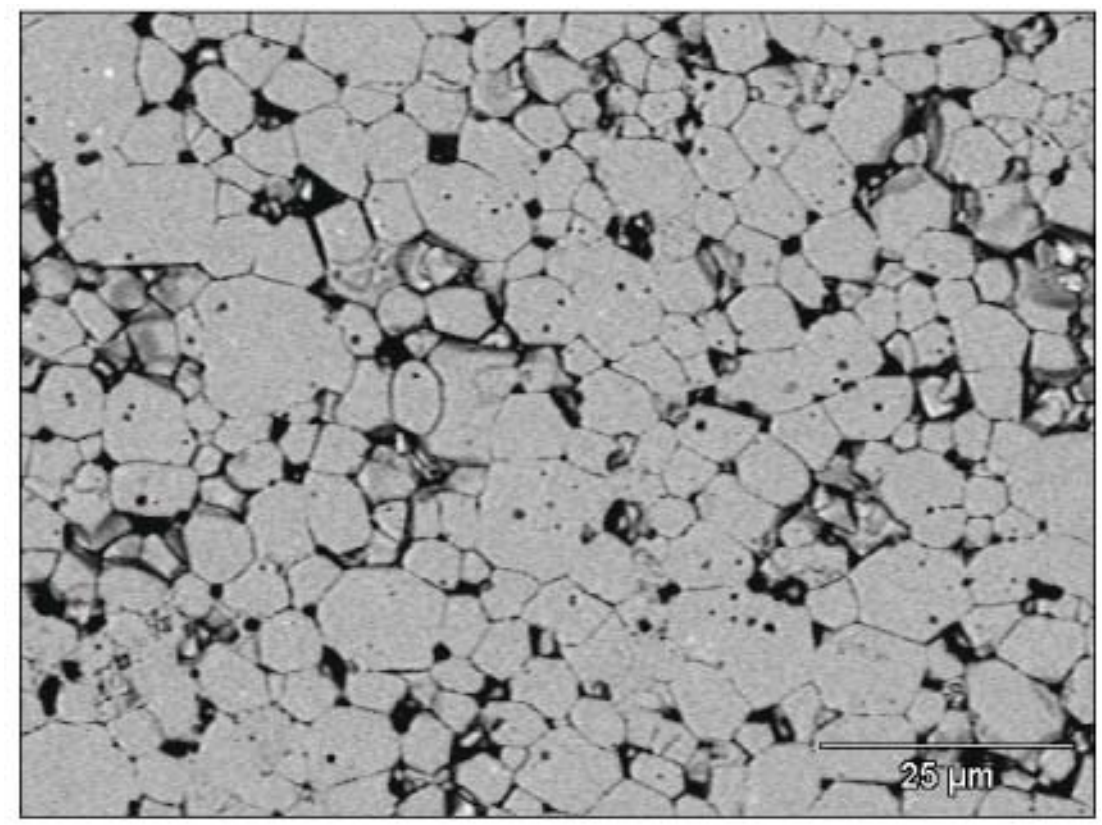

FIGURA 4.2.6 - Micrografia obtida com MEV, 1000 X, elétrons retro-espalhados para o ímã sinterizado $\operatorname{Pr}_{15} \mathrm{Fe}_{\text {bal }} \mathrm{Co}_{8} \mathrm{~B}_{7} \mathrm{Nb}_{0,05} \mathrm{Ga}_{0,25}$.

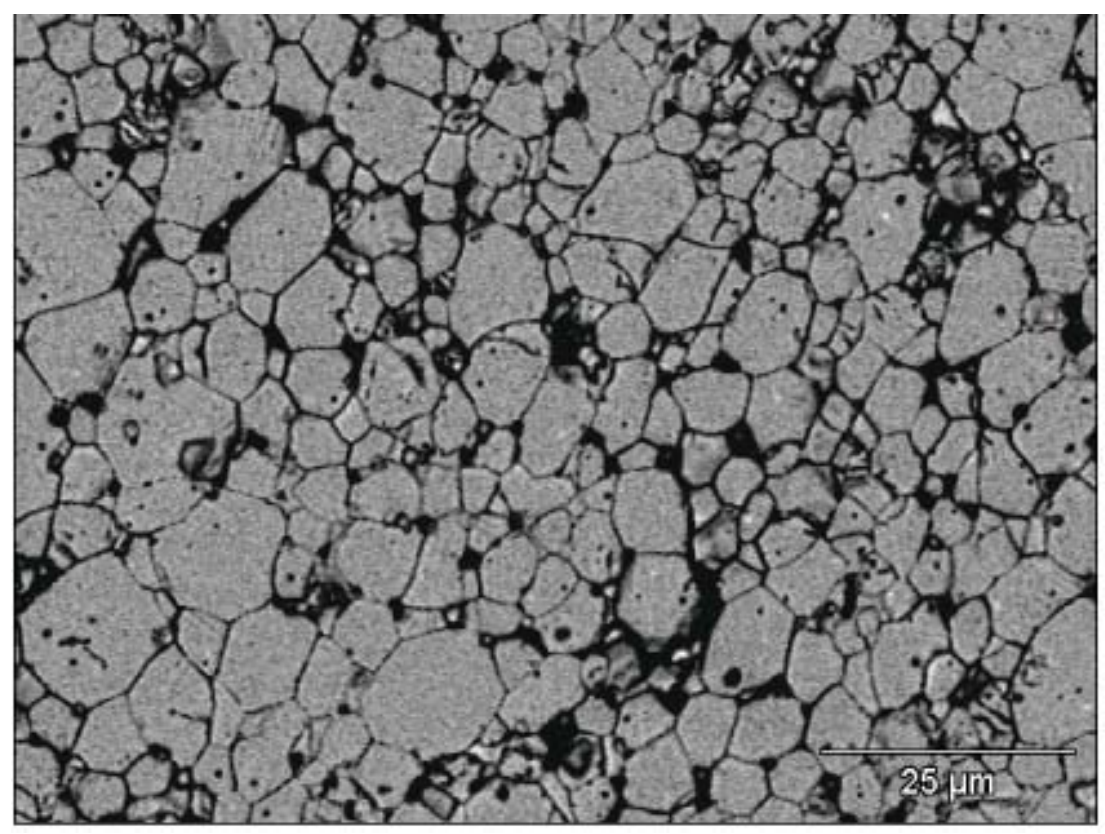

FIGURA 4.2.7 - Micrografia obtida com MEV, 1000 X, elétrons retro-espalhados para o ímã sinterizado $\operatorname{Pr}_{15} \mathrm{Fe}_{\text {bal }} \mathrm{Co}_{8} \mathrm{~B}_{7} \mathrm{Nb}_{0,05} \mathrm{Gd}_{0,15}$. 


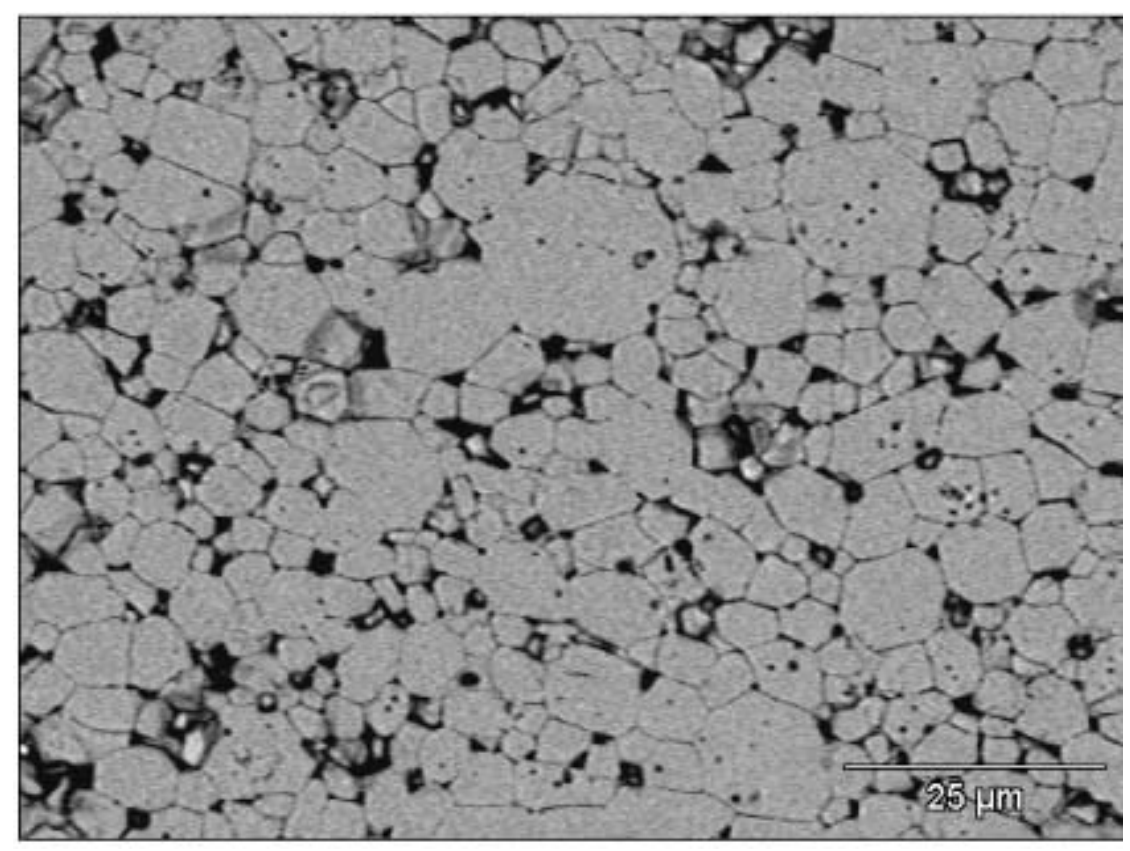

FIGURA 4.2.8 - Micrografia obtida com MEV, 1000 X, elétrons retro-espalhados para o ímã sinterizado $\operatorname{Pr}_{15} \mathrm{Fe}_{\text {bal }} \mathrm{Co}_{8} \mathrm{~B}_{7} \mathrm{Nb}_{0,05} \mathrm{~Tb}_{0,15}$.

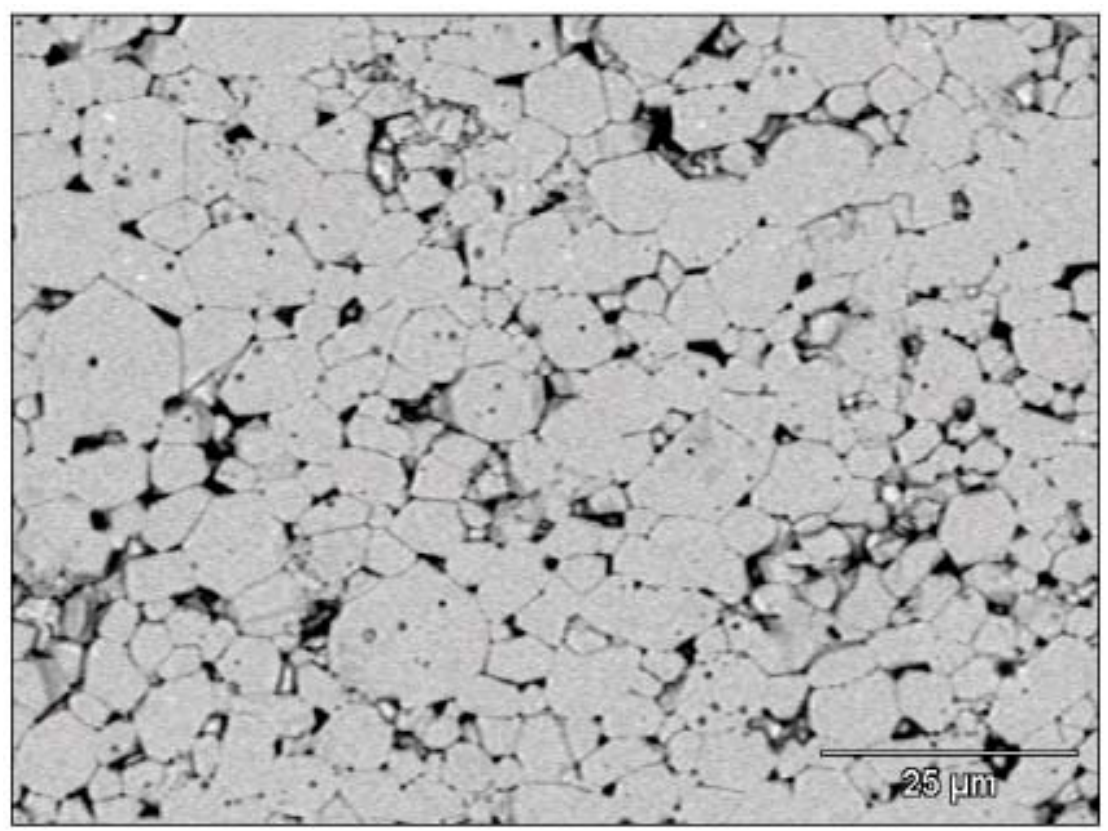

FIGURA 4.2.9 - Micrografia obtida com MEV, $1000 \mathrm{X}$, elétrons retro-espalhados para o ímã sinterizado $\operatorname{Pr}_{15} \mathrm{Fe}_{\mathrm{bal}} \mathrm{Co}_{8} \mathrm{~B}_{7} \mathrm{Nb}_{0,05} \mathrm{Dy}_{0,15}$. 
Foram processadas em média 5 micrografias de cada composição totalizando cerca de 500 grãos e com a utilização do programa Image Tool 3.0, foram gerados os resultados apresentados na TAB. 4.2.1.

TABELA 4.2.1 - Tamanho de Grão (TG), Elongação (E), Circularidade (C), Fator de Quadratura (FQ) medido e fator de homogeneidade $(\mathrm{FH})$ calculado.

\begin{tabular}{|c|c|c|c|c|c|}
\hline$M_{x}$ & $\begin{array}{l}\bar{X}_{\mathrm{TG}} \pm \sigma_{\mathrm{GS}} \\
(\mu \mathrm{m})\end{array}$ & $\begin{array}{l}\bar{X}_{E} \pm \sigma_{E} \\
(\mu \mathrm{m})\end{array}$ & $\begin{array}{c}-\bar{X}_{C} \pm \sigma_{R} \\
(\mu \mathrm{m})\end{array}$ & $\begin{array}{r}F Q \\
( \pm 2 \%)\end{array}$ & $\mathbf{F H}$ \\
\hline Padrão & $4,61 \pm 1,70$ & $1,51 \pm 0,39$ & $0,57 \pm 0,13$ & 0,84 & 0,82 \\
\hline $\mathrm{Al}_{0,05}$ & $5,52 \pm 1,94$ & $1,46 \pm 0,60$ & $0,70 \pm 0,13$ & 0,78 & 0,86 \\
\hline $\mathrm{Al}_{0,15}$ & $5,80 \pm 2,61$ & $1,44 \pm 0,73$ & $0,68 \pm 0,15$ & 0,71 & 0,67 \\
\hline $\mathrm{Al}_{0,25}$ & $5,49 \pm 2,56$ & $1,47 \pm 0,47$ & $0,69 \pm 0,18$ & 0,80 & 0,89 \\
\hline $\mathrm{Al}_{0,50}$ & $5,88 \pm 2,41$ & $1,46 \pm 0,59$ & $0,67 \pm 0,08$ & 0,77 & 0,78 \\
\hline $\mathrm{Si}_{0,05}$ & $4,52 \pm 1,80$ & $1,55 \pm 0,43$ & $0,67 \pm 0,18$ & 0,85 & 0,78 \\
\hline$S i_{0,15}$ & $4,65 \pm 1,90$ & $1,48 \pm 0,36$ & $0,68 \pm 0,17$ & 0,81 & 0,79 \\
\hline $\mathrm{Si}_{0,25}$ & $4,54 \pm 1,89$ & $1,44 \pm 0,71$ & $0,62 \pm 0,11$ & 0,86 & 0,83 \\
\hline$P_{0,05}$ & $5,80 \pm 2,76$ & $1,45 \pm 0,32$ & $0,67 \pm 0,15$ & 0,81 & 0,78 \\
\hline$P_{0,15}$ & $4,73 \pm 1,93$ & $1,43 \pm 0,28$ & $0,68 \pm 0,15$ & 0,85 & 0,82 \\
\hline$P_{0,25}$ & $5,65 \pm 2,07$ & $1,41 \pm 0,25$ & $0,69 \pm 0,08$ & 0,89 & 0,89 \\
\hline $\mathrm{Cu}_{0,05}$ & $5,78 \pm 2,93$ & $1,38 \pm 0,36$ & $0,71 \pm 0,17$ & 0,77 & 0,74 \\
\hline $\mathrm{Cu}_{0,15}$ & $6,11 \pm 2,90$ & $1,47 \pm 0,51$ & $0,65 \pm 0,09$ & 0,81 & 0,76 \\
\hline $\mathrm{Cu}_{0,25}$ & $5,22 \pm 2,31$ & $1,44 \pm 0,29$ & $0,69 \pm 0,20$ & 0,67 & 0,77 \\
\hline $\mathrm{Cu}_{0,50}$ & $5,57 \pm 2,47$ & $1,47 \pm 0,33$ & $0,68 \pm 0,19$ & 0,79 & 0,77 \\
\hline $\mathrm{Ga}_{0,05}$ & $6,43 \pm 2,76$ & $1,39 \pm 0,28$ & $0,68 \pm 0,08$ & 0,79 & 0,85 \\
\hline $\mathrm{Ga}_{0,15}$ & $6,08 \pm 2,74$ & $1,40 \pm 0,31$ & $0,67 \pm 0,11$ & 0,86 & 0,82 \\
\hline $\mathrm{Ga}_{0,25}$ & $5,42 \pm 2,37$ & $1,48 \pm 0,46$ & $0,66 \pm 0,09$ & 0,77 & 0,79 \\
\hline $\mathrm{Gd}_{0,05}$ & $5,30 \pm 1,85$ & $1,46 \pm 0,34$ & $0,56 \pm 0,11$ & 0,87 & 0,84 \\
\hline $\mathrm{Gd}_{0,15}$ & $5,29 \pm 1,94$ & $1,45 \pm 0,33$ & $0,66 \pm 0,09$ & 0,86 & 0,87 \\
\hline $\mathrm{Gd}_{0,25}$ & $5,61 \pm 2,25$ & $1,49 \pm 0,33$ & $0,63 \pm 0,14$ & 0,86 & 0,81 \\
\hline $\mathrm{Tb}_{0,15}$ & $5,69 \pm 2,40$ & $1,43 \pm 0,33$ & $0,68 \pm 0,14$ & 0,86 & 0,80 \\
\hline $\mathrm{Dy}_{0,15}$ & $5,49 \pm 2,16$ & $1,47 \pm 0,32$ & $0,67 \pm 0,09$ & 0,82 & 0,85 \\
\hline
\end{tabular}


Analisando-se os resultados referentes aos ímãs com adições, comparados ao ímã padrão, foi possível observar que as amostras com adições apresentaram crescimento de grão em torno de $20 \%$ com exceção do elemento Si.

O ímã com adição de P (0,25\%at.) apresentou o maior fator de quadratura comparado ao padrão, porém com o menor valor para a coercividade. Foi investigada com microscopia eletrônica de transmissão (MET) a composição de elementos na área selecionada de ponto triplo, buscando-se a localização do elemento $P$. Os resultados estão apresentados na secção 4.4 .1 referente aos resultados com MET.

Dos resultados apresentados na TAB. 4.2.1 também foi possível a comparação com os valores dos fatores de quadratura (FQ) oriundos das curvas de desmagnetização e aqueles calculados com a equação (3.2.1), identificados como fator de homogeneidade (FH). O comparativo dos dois fatores apresentados mostrou boa concordância e indicam que a equação (3.2.1) pode ser utilizada na estimativa do fator de quadratura a partir das informações dos grãos da matriz.

Comparando-se os dados em negrito da TAB. 4.1.1 com os resultados referentes aos tamanhos de grão apresentados na TAB. 4.1.2 foi possível verificar que o ímã padrão $\operatorname{Pr}_{15} \mathrm{Fe}_{\text {bal }} \mathrm{Co}_{8} \mathrm{~B}_{7} \mathrm{Nb}_{0,05}$ apresentou um tamanho médio de grão de $4,61 \mu \mathrm{m}$ contra $5,42 \mu \mathrm{m}$ para o ímã com adição de $\mathrm{Ga}$ a $0,25 \%$ at. Isso pode indicar a influência do $\mathrm{Ga}$ nos contornos, refletido no resultado $10 \%$ superior para a coercividade, mesmo com um tamanho de grão 20 \% superior ao padrão.

As investigações da microestrutura nos pontos triplos e nos contornos de grãos entre os ímãs padrão e com adição de $\mathrm{Ga} 0,25 \%$ at. foi feita com microscopia eletrônica de transmissão (MET), padrões de difração e EDS que estão apresentados na secção 4.4 . 


\section{3 - Distribuição dos tamanhos de grãos}

Segundo Ramesh et al., $(1988,1990)$ a distribuição dos tamanhos de grãos segue uma distribuição logarítima normal com uma tendência positiva, ou seja, existem mais grãos menores do que maiores. A curva de distribuição fornece a informação do tamanho médio dos grãos $\left(\bar{X}_{T G}\right)$.

As FIG 4.3.2.1 e 4.3.2.2 mostram as informações extraídas do processamento das micrografias do padrão $\operatorname{Pr}_{15} \mathrm{Fe}_{\text {bal }} \mathrm{Co}_{8} \mathrm{~B}_{7} \mathrm{Nb}_{0,05}$, e $\operatorname{Pr}_{15} \mathrm{Fe}_{\text {bal }} \mathrm{Co}_{8} \mathrm{~B}_{7} \mathrm{Nb}_{0,05} \mathrm{Ga}_{0,25}$, e confirmam a tendência log - normal das distribuições dos tamanhos de grãos.

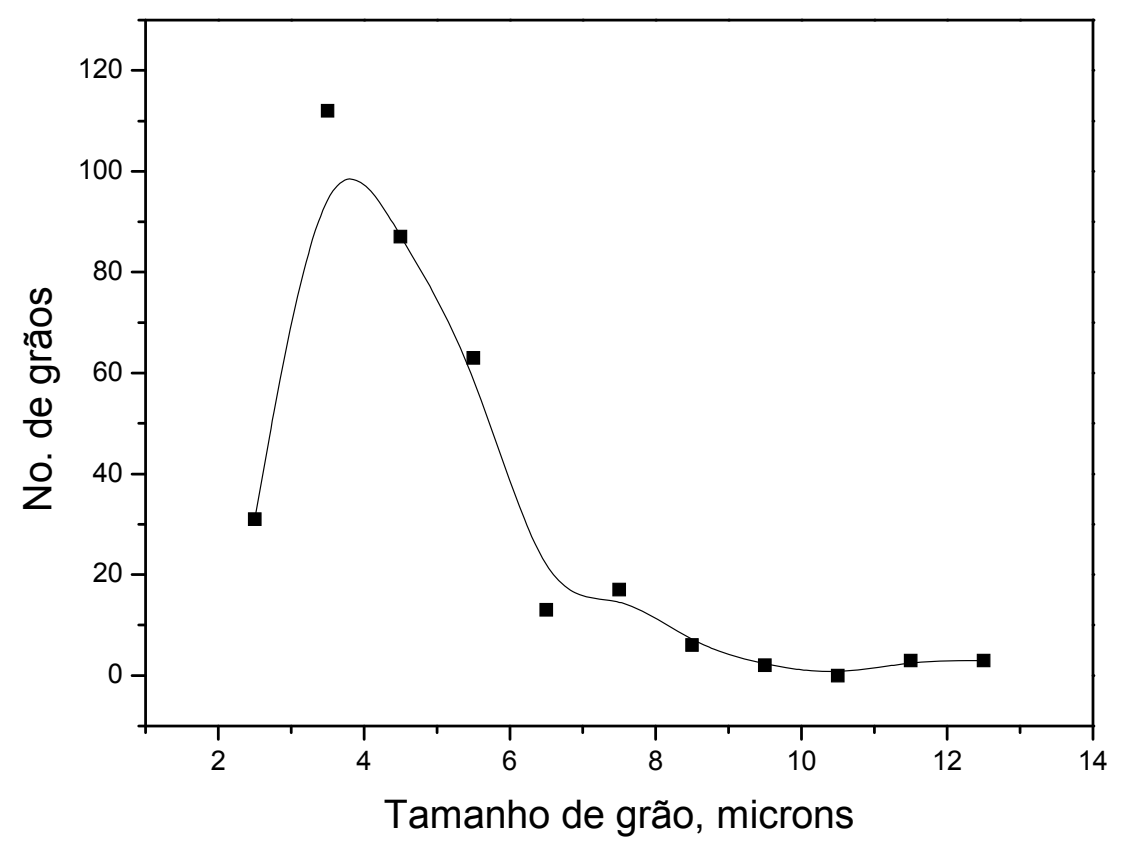

FIGURA 4.3.2.1 - Distribuição dos tamanhos de grãos do ímã, $\operatorname{Pr}_{15} \mathrm{Fe}_{\text {bal }} \mathrm{Co}_{8} \mathrm{~B}_{7} \mathrm{Nb}_{0,05}$. 


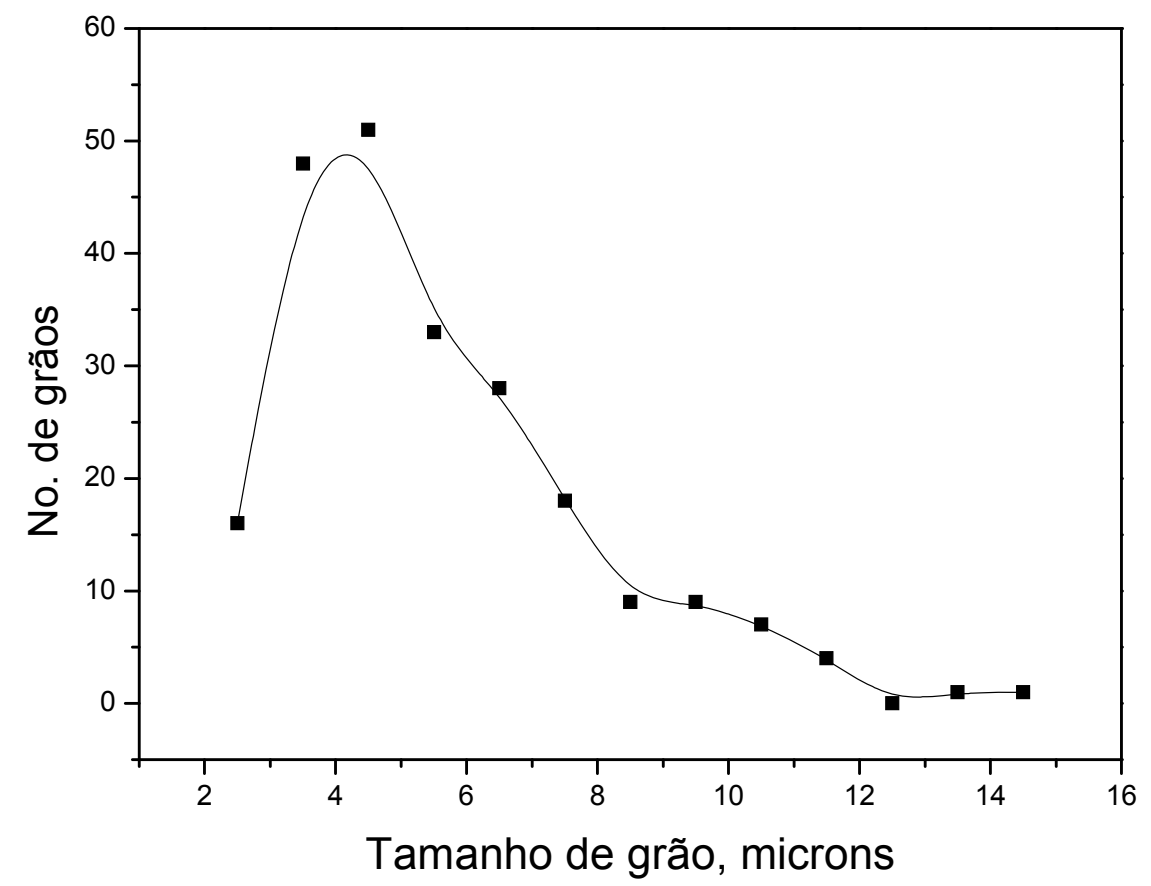

FIGURA 4.3.2.2 - Distribuição dos tamanhos de grãos do ímã $\mathrm{Pr}_{15} \mathrm{Fe}_{\mathrm{bal}} \mathrm{Co}_{8} \mathrm{~B}_{7} \mathrm{Nb}_{0,05} \mathrm{Ga}_{0,25}$.

\section{4 - Investigações com Microscopia Eletrônica de Transmissão (MET)}

As investigações com microscopia eletrônica de transmissão (MET) resultaram em uma série de micrografias com imagens em campo claro, padrões de difração, análises com EDS, e imagens de alta resolução.

Também foi registrada a presença de precipitados e defeitos na fase matriz. Defeitos podem comprometer a coercividade desses ímãs devido à formação de campos de nucleação reversa. Buscou-se analisar as regiões de ponto triplo com as devidas composições identificadas com auxílio de EDS. Para o ímã com adição de fósforo é apresentado um mapa de elementos na região do ponto triplo.

As investigações na microestrutura com microscopia de transmissão nos ímãs sinterizados $\mathrm{Pr}_{15} \mathrm{Fe}_{\mathrm{bal}} \mathrm{Co}_{8} \mathrm{~B}_{7} \mathrm{Nb}_{0,05}$ e com adição de $\mathrm{Ga}$ foram realizadas inicialmente nas regiões de fases ricas em TR e $\mathrm{B}$, e posteriormente, nos contornos de grãos utilizando-se microscopia eletrônica de transmissão de alta resolução (HRTEM). 


\subsection{1 - Investigações nos pontos triplos - Ímãs com adições de Ga e P}

A partir da investigação da imagem em campo claro no ponto triplo do ímã com adição de Ga 0,25\%at., utilizou-se o recurso da difração de pontos, (JEM 2100 200kV), focando-se os pontos identificados na FIG. 4.4.1.1 e identificou-se as fases presentes por comparações com fichas cristalográficas (Swanson et al.,1956, Tian et al.,1987). Confirmaram-se as fases matriz $\mathrm{Pr}_{2} \mathrm{Fe}_{14} \mathrm{~B}$, tetragonal e a fase rica em praseodímio comparada com a ficha cristalográfica do $\mathrm{Nd}$. As comparações das distâncias interplanares do $\mathrm{Pr}_{2} \mathrm{O}_{3}$ confirmaram similaridade com as do óxido de neodímio $\mathrm{Nd}_{2} \mathrm{O}_{3}$, com estrutura hexagonal compacta (hc). Os valores identificados nas fichas cristalográficas em comparação com os valores das distâncias medidas com o programa computacional acoplado ao microscópio estão mostrados na TAB. 4.4.1.1.

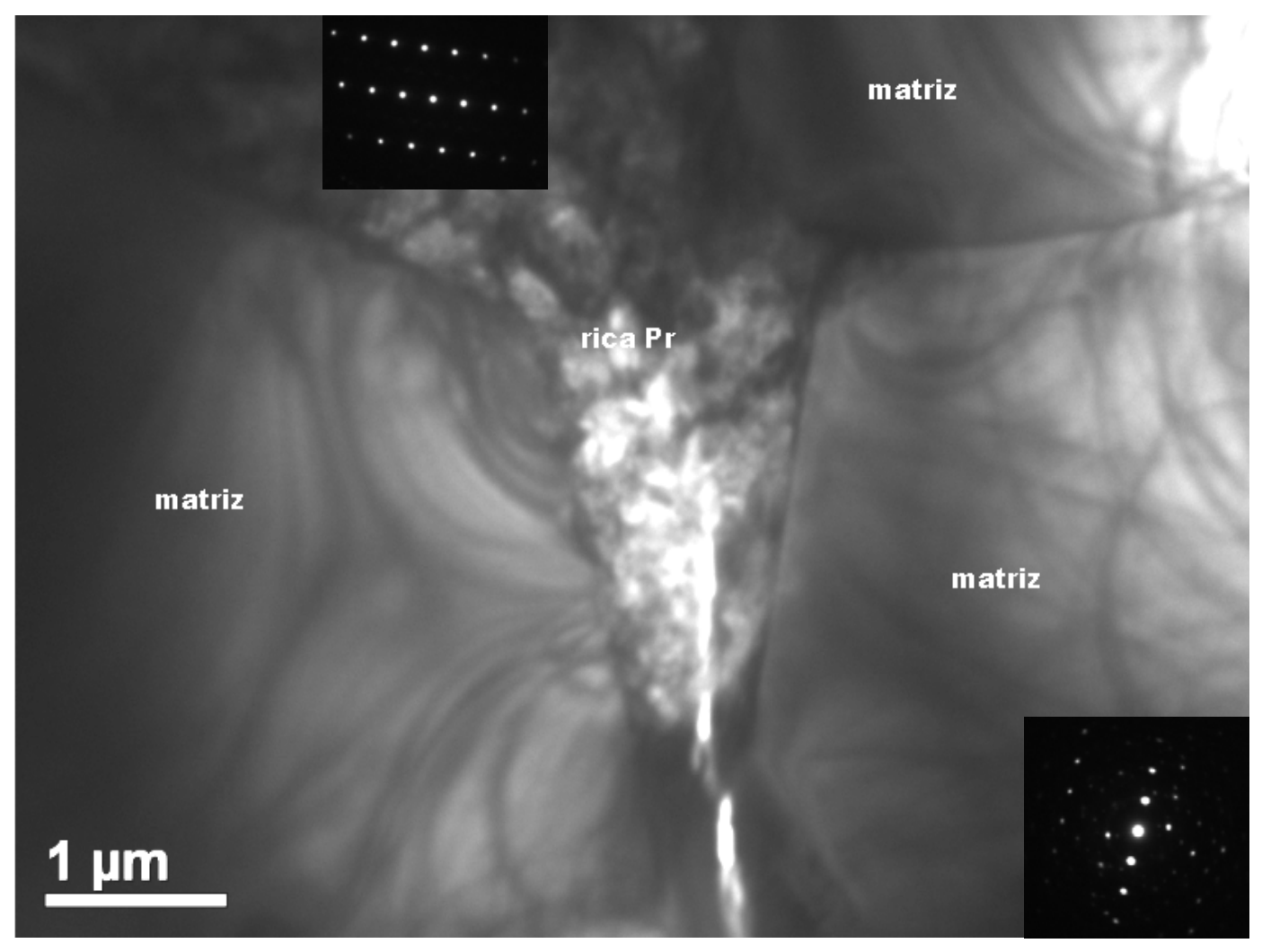

FIGURA 4.4.1.1 - Imagem em campo claro do ímã $\operatorname{Pr}_{15} \mathrm{Fe}_{\text {bal }} \mathrm{Co}_{8} \mathrm{~B}_{7} \mathrm{Nb}_{0,05} \mathrm{Ga}_{0,25}$, no ponto triplo contendo a fase rica em Pr envolvida por grãos magnéticos da fase matriz, com padrões de difração nas áreas selecionadas. 
TABELA 4.4.1.1 - Distâncias interplanares medidas a partir dos padrões de difração obtidos nas regiões exploradas na área selecionada da FIG. 4.4.1.1 e comparadas com as fichas cristalográficas (Swanson et al.,1956, e Tian et al.,1987).

\begin{tabular}{|c|c|c|c|c|}
\hline \multirow[t]{2}{*}{$\begin{array}{l}\text { Planos } \\
\text { (hkl) }\end{array}$} & \multicolumn{2}{|c|}{$\begin{array}{l}\text { Fase Matriz ( } \Phi) \\
\qquad \operatorname{Pr}_{2} \mathrm{Fe}_{14} \mathrm{~B}\end{array}$} & \multicolumn{2}{|c|}{$\begin{array}{l}\text { Fase Rica em } P r \\
\text { (hcp) }-\mathrm{Pr}_{2} \mathrm{O}_{3}\end{array}$} \\
\hline & $d_{\text {medido }}(\AA)$ & $d_{\text {ficha }}(\AA)$ & $d_{\text {medido }}(\AA)$ & $d_{\text {ficha }(N d)}(\AA)$ \\
\hline 002 & 6,110 & 6,122 & 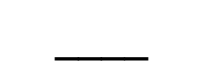 & 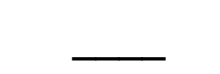 \\
\hline 110 & 6,146 & 6,192 & $\bar{L}$ & $\bar{L}$ \\
\hline 004 & 3,062 & 3,061 & 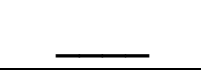 & 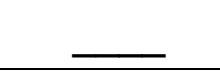 \\
\hline 101 & 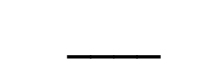 & 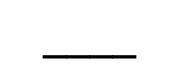 & 2,883 & 2,902 \\
\hline 103 & - & - & 1,704 & 1,713 \\
\hline 203 & 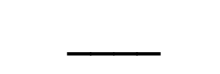 & 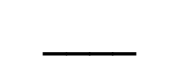 & 1,286 & 1,276 \\
\hline
\end{tabular}

Vários padrões de difração podem ser obtidos na região do ponto triplo da FIG 4.4.1.1. que dependem da orientação dos cristais, da composição local ou mesmo de regiões policristalinas. A FiG. 4.4.1.2 mostra um padrão composto de pontos e anéis concêntricos típicos de regiões policristalinas.

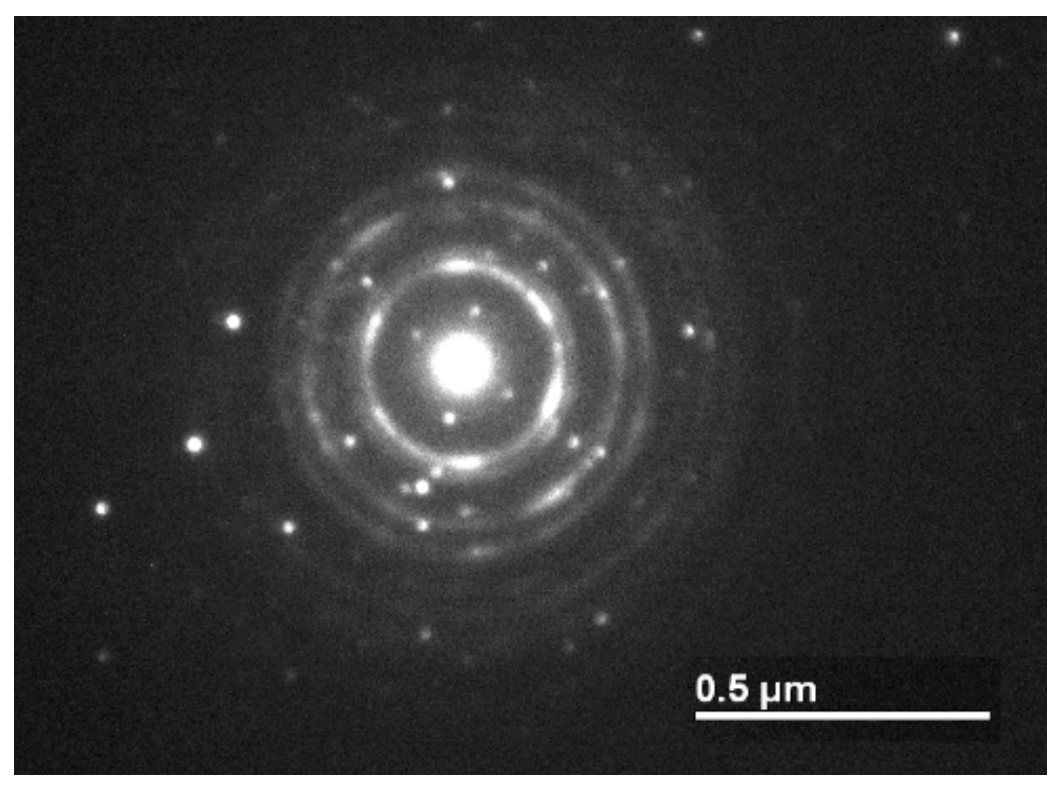

FIGURA 4.4.1.2 - Padrão de difração na região de fase rica onde pontos juntamente com anéis concêntricos indicam estrutura policristalina. 
A FIG. 4.4.1.3 mostra a imagem em campo claro na região de ponto triplo do ímã $\mathrm{Pr}_{15} \mathrm{Fe}_{\text {ball }} \mathrm{Co}_{8} \mathrm{~B}_{7} \mathrm{Nb}_{0,05} \mathrm{Ga}_{0,25}$ com fase rica em $\mathrm{Pr}$, matriz e plaqueta identificadas com EDS.

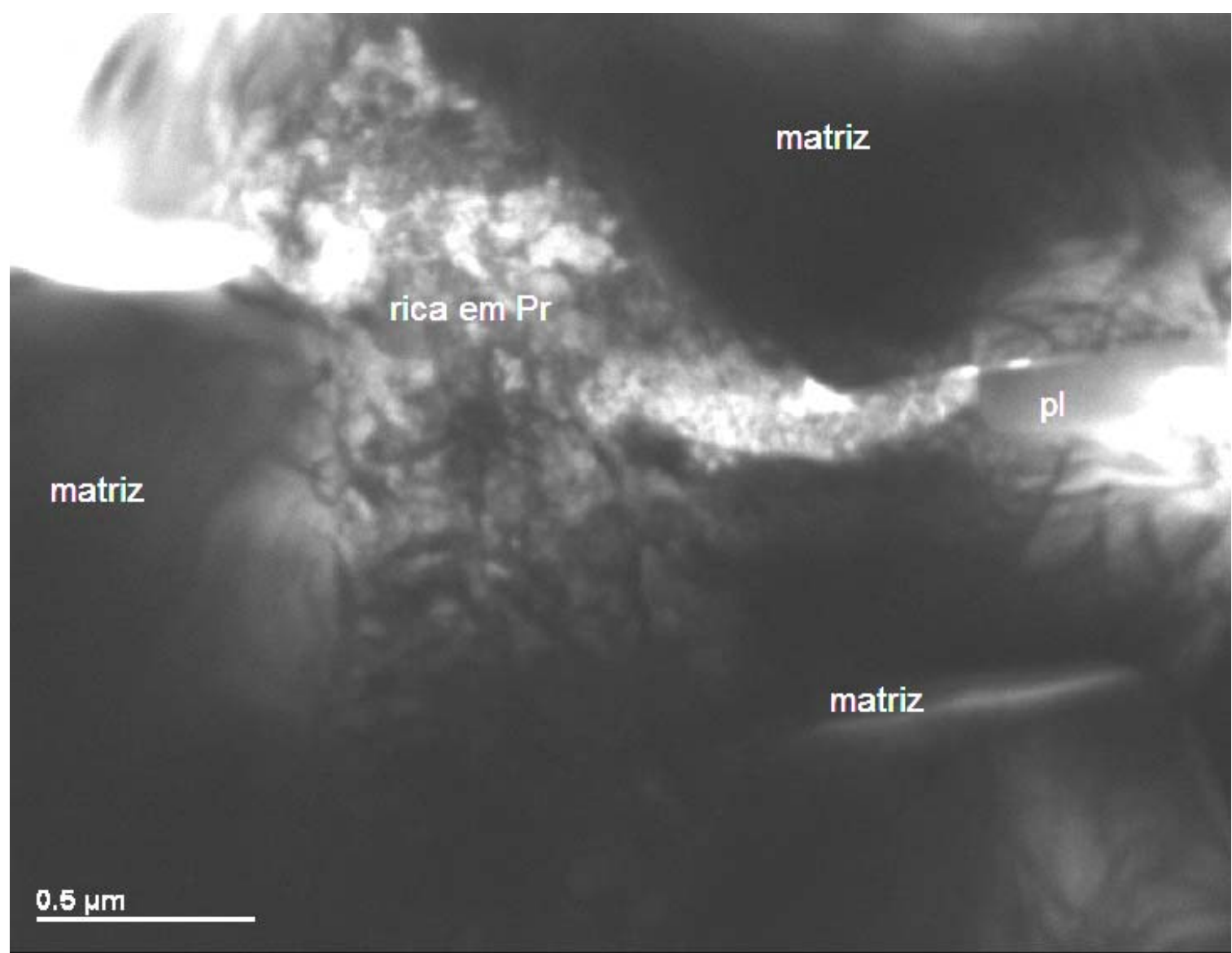

FIGURA 4.4.1.3 - Imagem em campo claro na região de ponto triplo do ímã $\operatorname{Pr}_{15} \mathrm{Fe}_{\text {bal }}$ $\mathrm{Co}_{8} \mathrm{~B}_{7} \mathrm{Nb}_{0,05} \mathrm{Ga}_{0,25}$ com fase rica em $\mathrm{Pr}$, matriz e plaqueta identificadas com EDS.

A partir da região de ponto triplo identificada na FIG 4.4.1.3, com imagem em campo claro, foi possível a observação de uma fase com contraste diferenciado da fase rica em Pr. A composição obtida com EDS e comparada com estudos anteriores em ímãs com $\mathrm{Nd}$, mostrou tratar-se de uma fase já identificada como plaqueta $(\mathrm{pl})$. Prosseguindo-se na seqüência do contorno, foi localizada uma região contendo altos teores de boro identificadas como B1, B2 e B3, cuja análise indica que tanto B1, B2, B3 quanto (pl) pertencem a mesma fase (boreto). As composições estão apresentadas na TAB. 4.4.1.2. 
Na FIG. 4.4.1.4 estão mostradas as fases identificadas por $\Phi, B 1, B 2$, B3 e pl para o ímã $\mathrm{Pr}_{15} \mathrm{Fe}_{\text {bal }} \mathrm{Co}_{8} \mathrm{~B}_{7} \mathrm{Nb}_{0,05} \mathrm{Ga}_{0,25}$

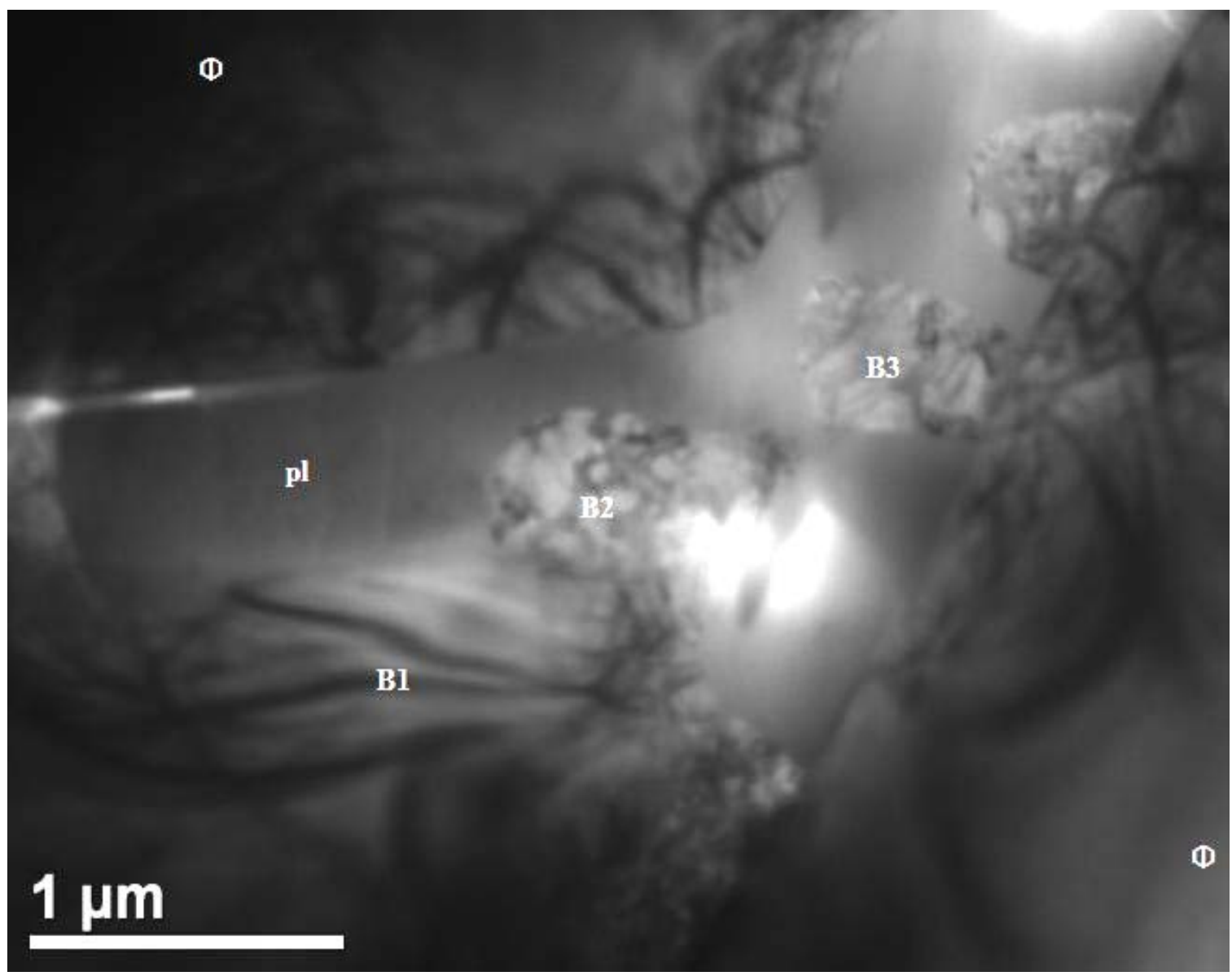

FIGURA 4.4.1.4 - Imagem em campo claro do ímã $\mathrm{Pr}_{15} \mathrm{Fe}_{\mathrm{bal}} \mathrm{Co}_{8} \mathrm{~B}_{7} \mathrm{Nb}_{0,05} \mathrm{Ga}_{0,25}$ mostra uma região com matriz, fases ricas em boro e oxigênio.

A TAB. 4.4.1.2 ilustra os resultados das análises das fases determinadas com EDS pontual ao centro das regiões selecionadas indicadas nas FIGS. 4.4.1.1, 4.4.1.2 e 4.4.1.3. 
TABELA 4.4.1.2 - Composição das fases identificadas nas FIGS. 4.4.1.1, 4.4.1.2 e 4.4.1.3.

\begin{tabular}{|c|c|c|c|c|c|c|}
\hline İmãs/Fases & $\begin{array}{l}\mathrm{Pr} \\
\text { (\%at.) } \\
( \pm 2 \%) \\
\end{array}$ & $\begin{array}{l}\mathrm{Fe} \\
(\% \text { at.) } \\
( \pm 2 \%)\end{array}$ & $\begin{array}{l}\text { Co } \\
\text { (\%at.) } \\
( \pm 2 \%) \\
\end{array}$ & $\begin{array}{l}\text { B } \\
\text { (\%at.) } \\
( \pm 5 \%)\end{array}$ & $\begin{array}{l}\text { O } \\
\text { (\%at.) } \\
( \pm 5 \%)\end{array}$ & $\begin{array}{l}\text { Ga } \\
\text { (\%at.) } \\
( \pm 4 \%)\end{array}$ \\
\hline \multicolumn{7}{|l|}{ PrFeCoBNbGa $a_{0,25}$} \\
\hline Matriz (Ф) & 13,60 & 77,70 & 8,50 & - & & 0,20 \\
\hline Rica em $\operatorname{Pr}(n)$ & 48,82 & 7,59 & 14,90 & - & 18,33 & 10,35 \\
\hline Plaqueta (pl) & 27,35 & 4,25 & 8,35 & 45,89 & 8,36 & 5,80 \\
\hline Boreto (B1) & 25,96 & 1,18 & 0,38 & 52,99 & 19,50 & - \\
\hline Boreto (B2) & 22,87 & 1,57 & 7,20 & 47,92 & 15,49 & 4,94 \\
\hline Boreto (B3) & 32,96 & . & 5,32 & 43,20 & 18,47 & 0,04 \\
\hline
\end{tabular}

Inicialmente, confirmou-se a fase matriz $(\Phi)$ com $77,7 \%$ de $\mathrm{Fe}, 8,5 \%$ de Co e $13,6 \%$ de $\operatorname{Pr}$. Na região rica em $\operatorname{Pr}(\mathrm{n})$, identificou-se a presença de Ga com 10,35\% indicando que o mesmo também pode estar presente nos contornos de grãos. A plaqueta ( $\mathrm{pl}$ ) e as regiões identificadas por B1, B2 e B3 mostram um teor elevado para o B e provavelmente se tratam da mesma fase (boreto). As regiões pl e B2 apresentaram alto teor de $\mathrm{Ga}$ (5,80 e 4,94\% at.) respectivamente e indicam a migração de Ga para os contornos. Na revisão realizada por Faria et al. (2002), foram apresentadas análises da fase rica em boro em ligas e ímãs permanentes à base de NdFeB realizadas com EDS e WDS que revelaram quantidades de boro similares àquelas detectadas nesse trabalho.

A presença de oxigênio em regiões de fase rica em $\operatorname{Pr}$ e $B$ também foram observadas, embora a sua quantificação realizada com EDS é considerada semiquantitativa. Mo et al., (2008) investigaram o teor de $\mathrm{O}$ na fase rica em $\mathrm{Nd}$ em ímãs sinterizados de Nd-Fe-B de forma semelhante com MET e EDS e observaram que 0 teor de $\mathrm{Fe}$ foi de $3-10 \%$, enquanto o teor de $\mathrm{Nd}$ e $\mathrm{O}$ variou muito.

Dessa forma pode-se afirmar que as regiões de fases ricas em terras raras para esse tipo de material são bastante complexas. Para investigarmos essa região foi utilizado EDS de linha (MET modo varredura) na região de fronteira selecionada e obteve-se o espectro de elementos.

Na FIG. 4.4.1.5 (a) e (b), foi realizada a investigação com EDS em linha no ímã com adição de $\mathrm{Ga}$ a $0,25 \%$ at., numa região entre grãos da fase matriz mostrada em 
(a). Em (b) observa-se o espectro de elementos com a presença de picos de Co ao longo da linha na fase matriz indicando precipitados de Co.

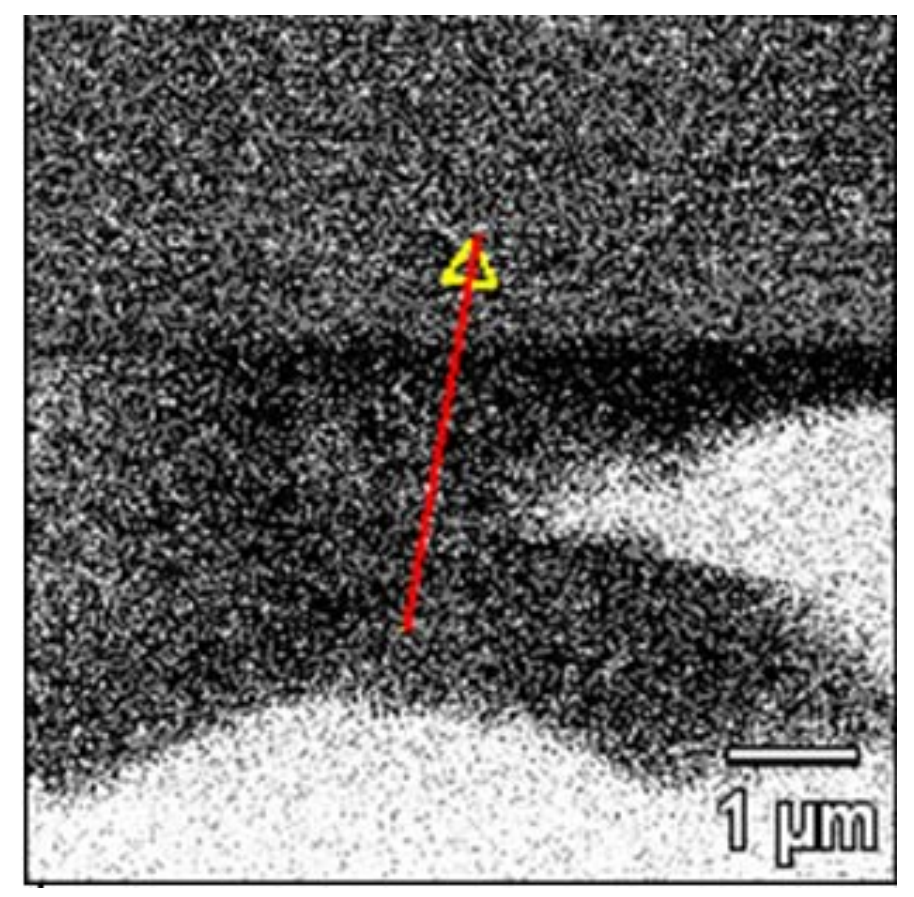

(a)

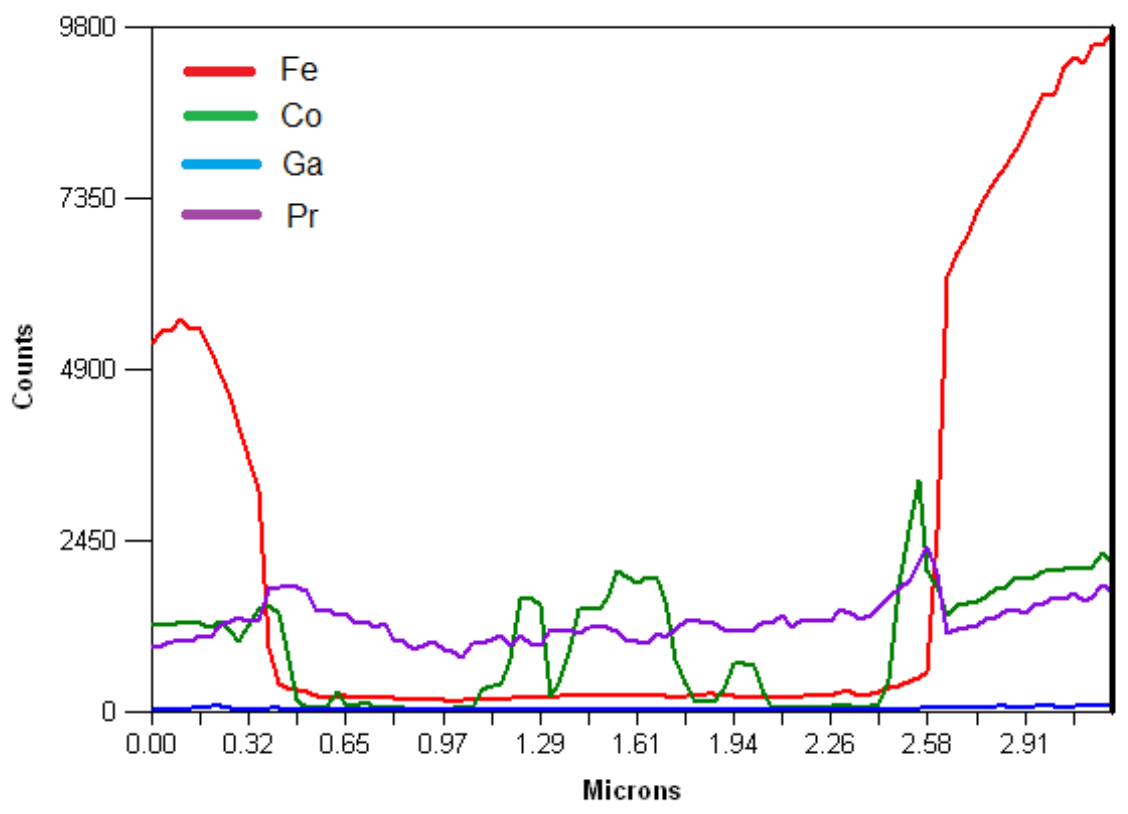

(b)

FIGURA 4.4.1.5 - EDS, modo STEM na linha indicada em (a),região de contorno de grão magnético no ímã com adição de $\mathrm{Ga} 0,25 \%$ at. e (b) espectro de elementos 
$\mathrm{Na}$ investigação do ímã com adição de fósforo $\mathrm{Pr}_{15} \mathrm{Fe}_{\text {bal }} \mathrm{Co}_{8} \mathrm{~B}_{7} \mathrm{Nb}_{0,05} \mathrm{P}_{0,25}$, foi utilizado o recurso de mapa de elementos buscando identificar a localização do elemento de adição $(P)$.

A FIG. 4.4.1.6 apresenta a imagem em campo claro do ímã $\mathrm{Pr}_{15} \mathrm{Fe}_{\text {bal }} \mathrm{Co}_{8} \mathrm{~B}_{7} \mathrm{Nb}_{0,05} \mathrm{P}_{0,25}$, na região do ponto triplo entre grãos da fase matriz onde foi realizada a análise com mapa de elementos.

\section{P-025 6 (6)}

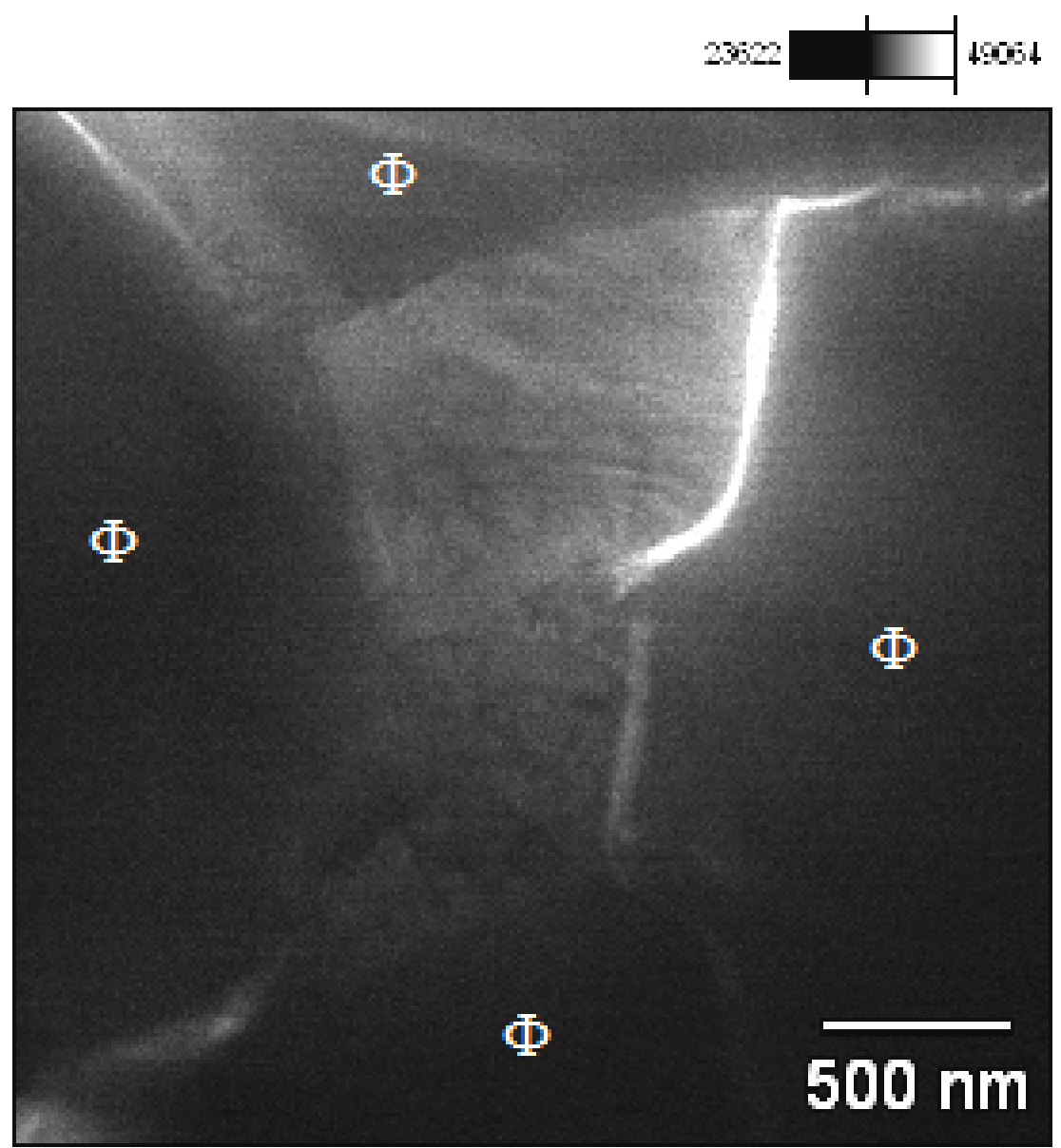

FIGURA 4.4.1.6 - Imagem em campo claro da região entre grãos da fase matriz do ímã $\mathrm{Pr}_{15} \mathrm{Fe}_{\mathrm{bal}} \mathrm{Co}_{8} \mathrm{~B}_{7} \mathrm{Nb}_{0,05} \mathrm{P}_{0,25}$. 
Com o MET na forma varredura e EDS acoplado foi possível obter-se o mapa dos elementos identificados na Figura 4.4.1.7 (a), (b) e (c). As imagens apresentadas no mapa dos elementos $\mathrm{Fe}, \operatorname{Pr}$ e $\mathrm{P}$ respectivamente, foram identificados individualmente com o programa computacional "Digital Image Processing" (Baxes, 1994).
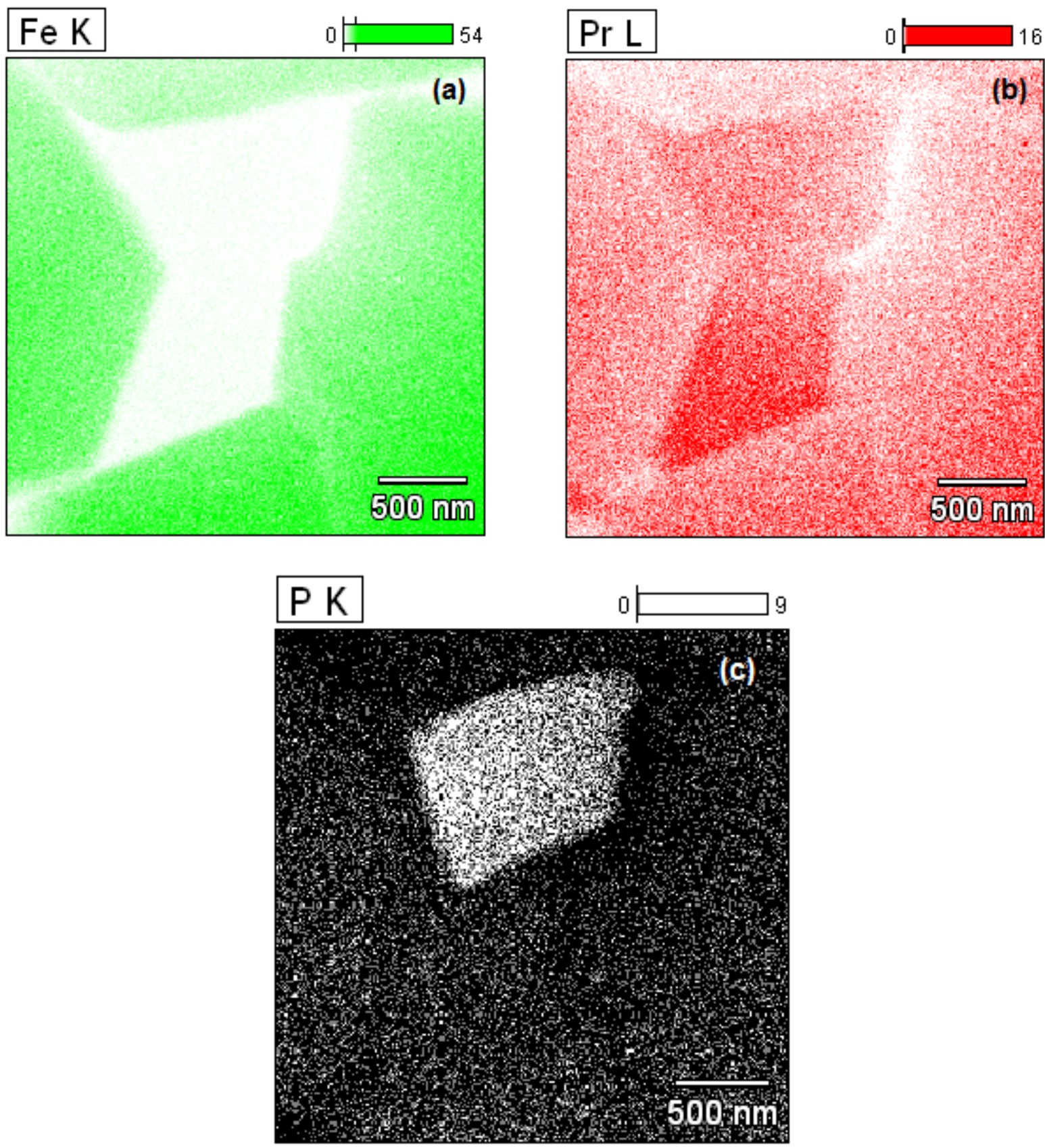

FIGURA 4.4.1.7 - Mapa de elementos para o ponto triplo identificado na imagem em campo claro, da FIG. 4.4.1.6 para o ímã $\operatorname{Pr}_{15} \mathrm{Fe}_{\text {bal }} \mathrm{Co}_{8} \mathrm{~B}_{7} \mathrm{Nb}_{0,05} \mathrm{P}_{0,25}$ onde se observam as regiões com concentrações dos elementos (a)Fe, (b)Pr e (c)P. 


\subsection{2 - Imagens de alta resolução para o ímã com Ga}

As investigações na fase matriz e no ponto triplo para $o$ ímã $\operatorname{Pr}_{15} \mathrm{Fe}_{\text {bal }} \mathrm{Co}_{8} \mathrm{~B}_{7} \mathrm{Nb}_{0,05} \mathrm{Ga}_{0,25}$ com microscópio de alta resolução (300 kV), revelaram espaçamentos interplanares bem definidos na fase matriz magnética $(\Phi)$ e nano cristais na região da fase rica em Pr. A fase rica em $\mathrm{Pr}$ é visivelmente muito heterogênea, ao contrário da fase matriz, sempre com planos bem orientados e com poucos defeitos.

A FIG. 4.4.2.1 mostra a fase rica para o ímã $\mathrm{Pr}_{15} \mathrm{Fe}_{\text {bal }} \mathrm{Co}_{8} \mathrm{~B}_{7} \mathrm{Nb}_{0,05} \mathrm{Ga}_{0,25}$ com nano cristais distribuídos aleatoriamente.

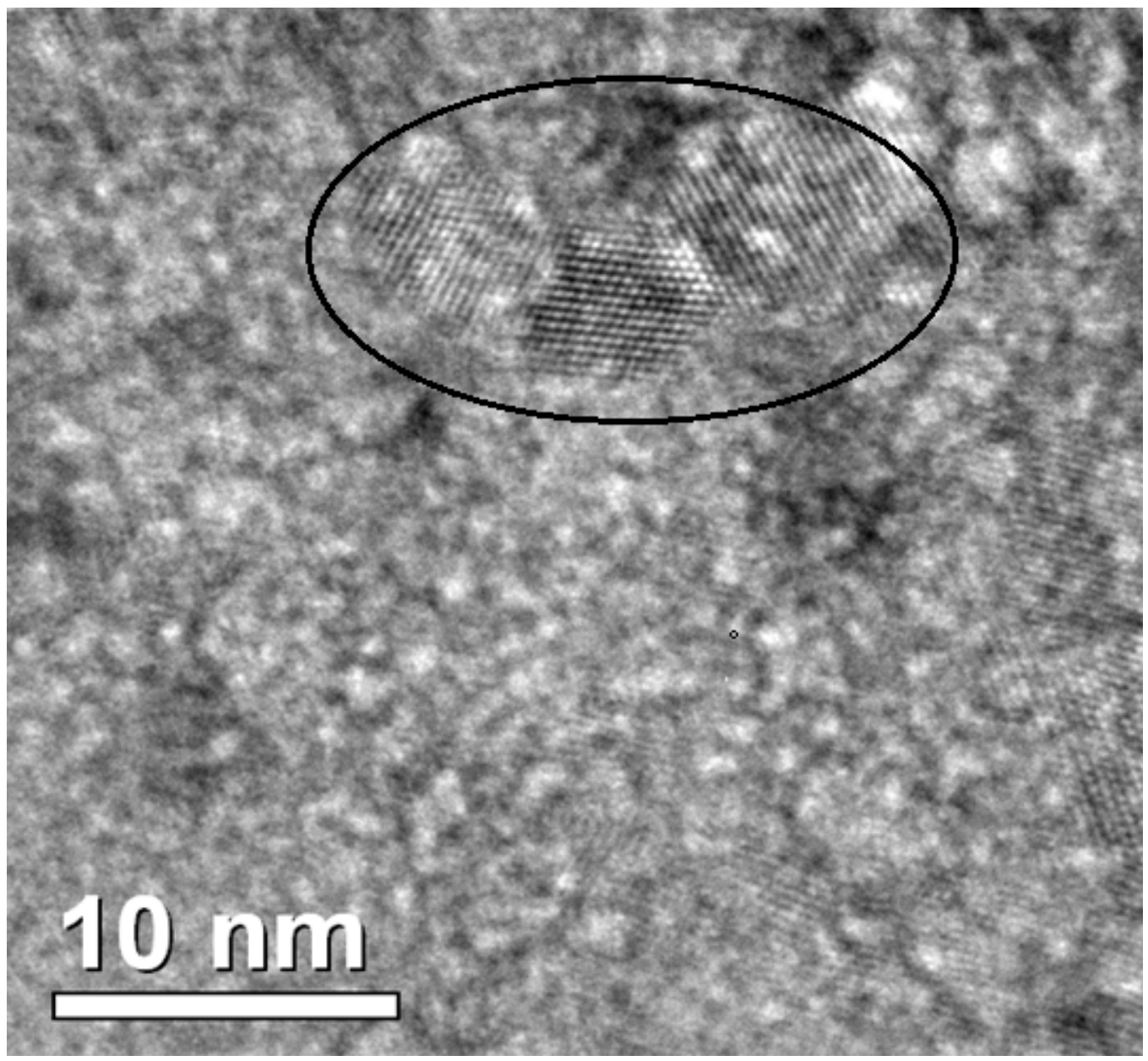

FIGURA 4.4.2.1 - Imagem em alta resolução na região de fase rica em Pr para o ímã $\operatorname{Pr}_{15} \mathrm{Fe}_{\text {bal }} \mathrm{Co}_{8} \mathrm{~B}_{7} \mathrm{Nb}_{0,05} \mathrm{Ga}_{0,25}$ onde se observam irregularidades e nano-cristais distribuídos aleatoriamente. 
A FIG 4.4.2.2 mostra a imagem em alta resolução da fase matriz $(\Phi)$ do ímã com adição de $\mathrm{Ga}$, e revelou distância interplanar $\mathrm{d}_{\mathrm{hkl}}=0,88 \mathrm{~nm}$ determinada com recurso de medição por histograma (“Digital Image Processing”, Baxes, 1994), onde se observam estruturas regulares e livres de defeitos. Não foi possível a identificação de planos e direções devido à inexistência de fichas cristalográficas com as composições dos ímãs aqui estudados.

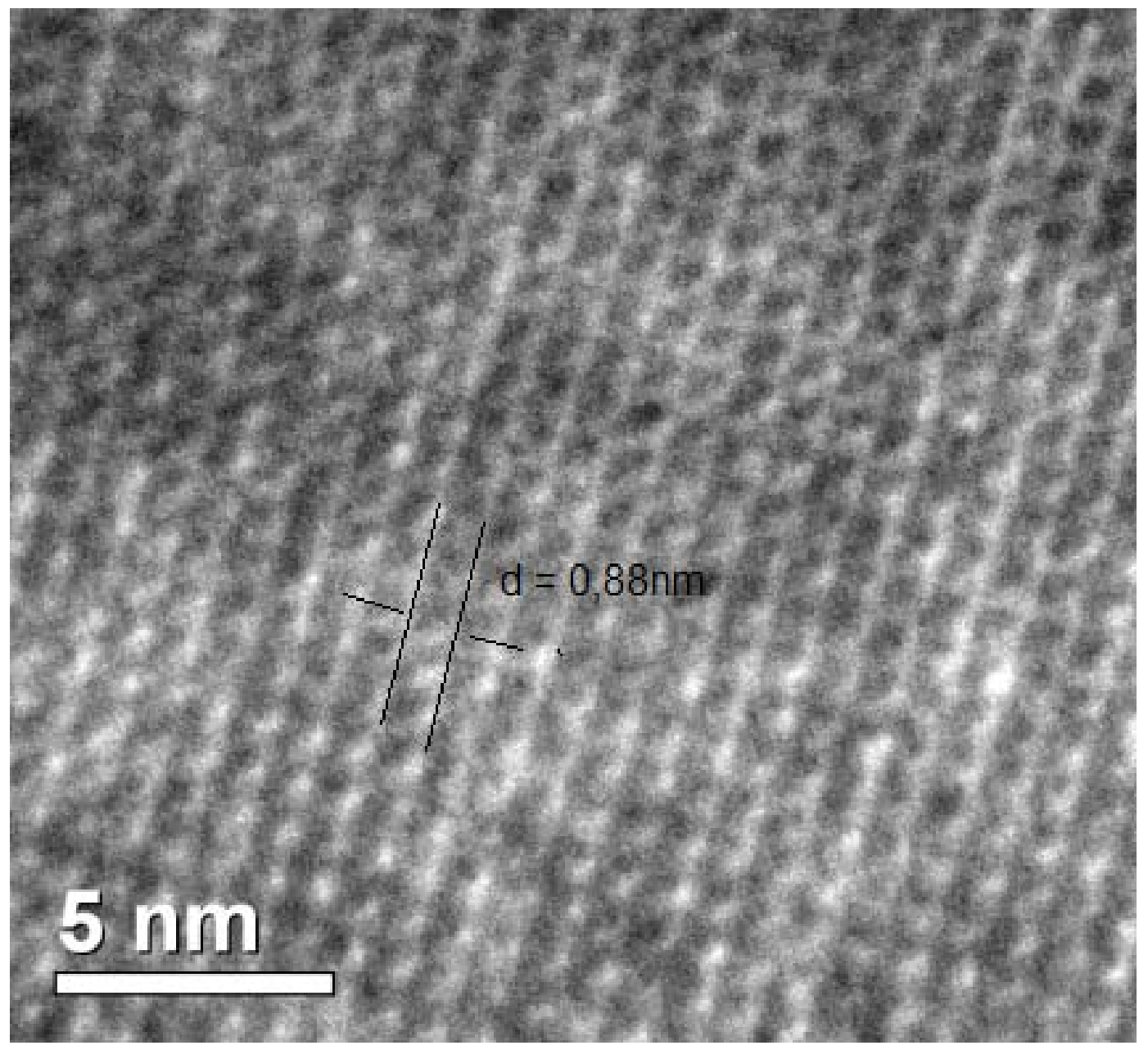

FIGURA 4.4.2.2 - Imagem de alta resolução do ímã $\operatorname{Pr}_{15} \mathrm{Fe}_{\text {bal }} \mathrm{Co}_{8} \mathrm{~B}_{7} \mathrm{Nb}_{0,05} \mathrm{Ga}_{0,25}$, com distância interplanar de $0,88 \mathrm{~nm}$ medido com programa analisador de imagens através de histograma. 


\subsection{3 - Estudo dos Contornos de Grãos}

As amostras com a composição adotada como padrão $\left(\operatorname{Pr}_{15} \mathrm{Fe}_{\text {bal }} \mathrm{Co}_{8} \mathrm{~B}_{7} \mathrm{Nb}_{0,05}\right)$ e a amostra do ímã que apresentou o melhor resultado de coercividade com adição de Ga (0,25\%at.), foram analisadas nos contornos de grãos com imagens de alta resolução no microscópio eletrônico de transmissão (JEM-3010-300 kV). O contraste gerado nas imagens com baixa magnificação indica a presença de uma camada de isolação entre os grãos conforme ilustra a FIG. 4.4.3.1.

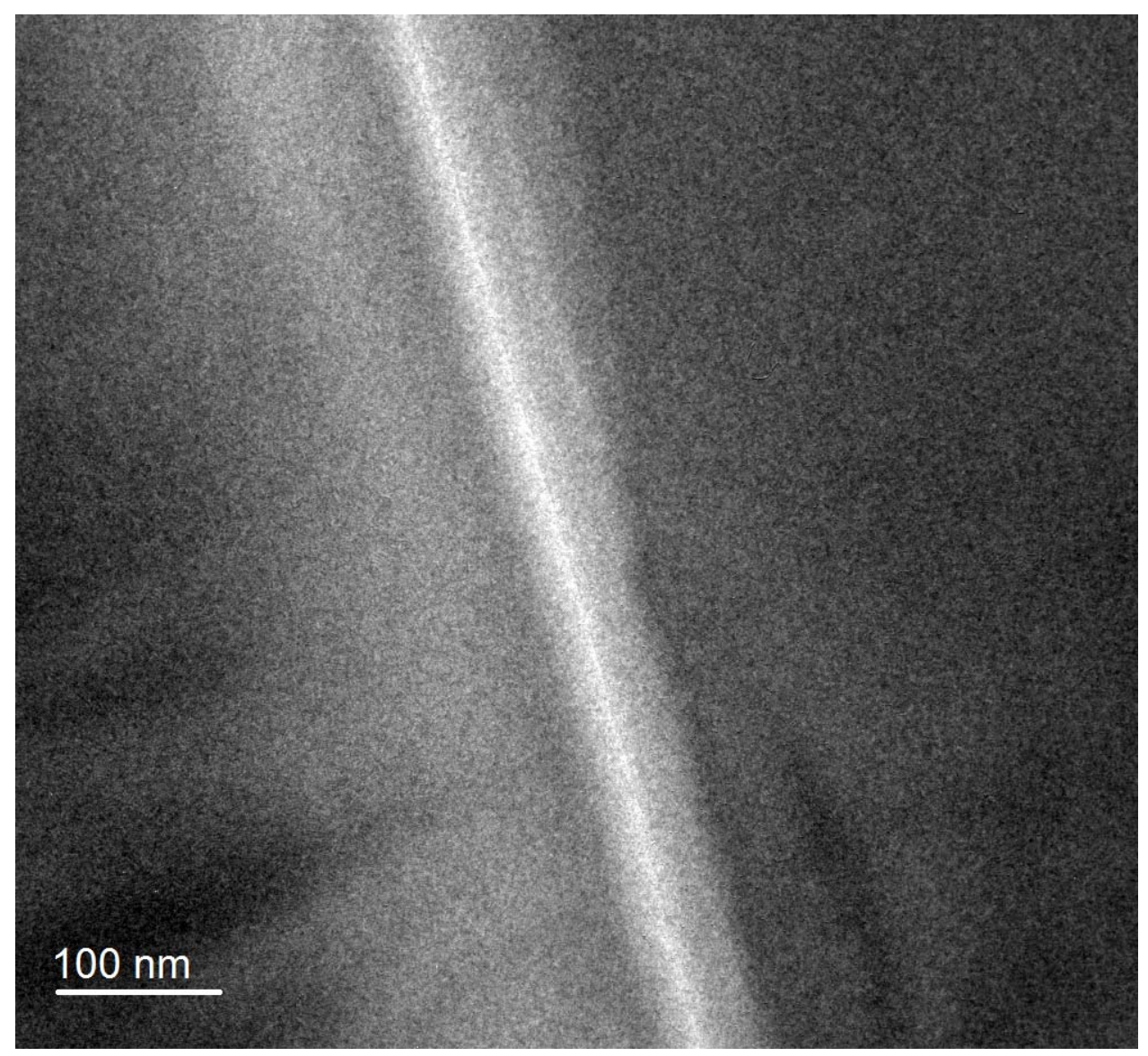

FIGURA 4.4.3.1 - Imagem em campo claro na região do contorno selecionada entre dois grãos da fase matriz no ímã padrão $\left(\operatorname{Pr}_{15} \mathrm{Fe}_{\text {bal }} \mathrm{Co}_{8} \mathrm{~B}_{7} \mathrm{Nb}_{0,05}\right)$ que em baixa magnificação indica uma camada isolante bem determinada. 
Nas FIGS. 4.4.3.2 (a) e (b), estão apresentadas as imagens do ímã padrão $\left(\mathrm{Pr}_{15} \mathrm{Fe}_{\text {bal }} \mathrm{Co}_{8} \mathrm{~B}_{7} \mathrm{Nb}_{0,05}\right)$ que com o aumento na magnificação apresentou um contorno irregular e ausência do material da camada de isolação.

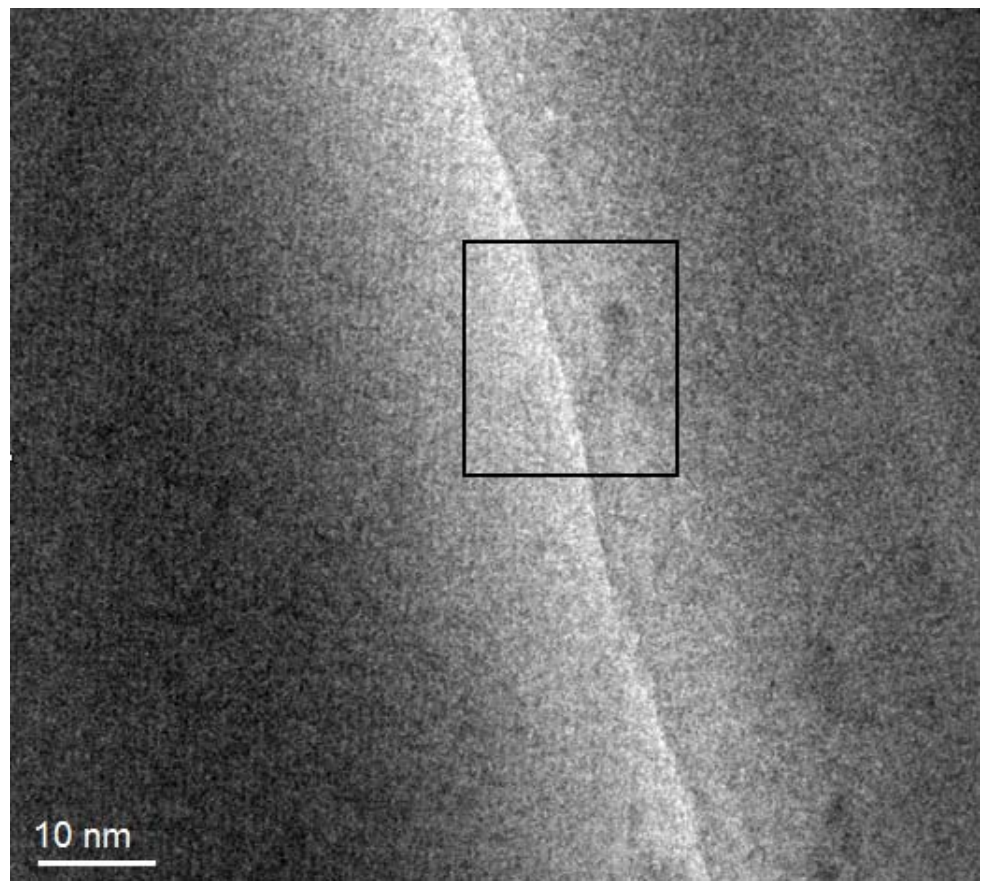

(a)

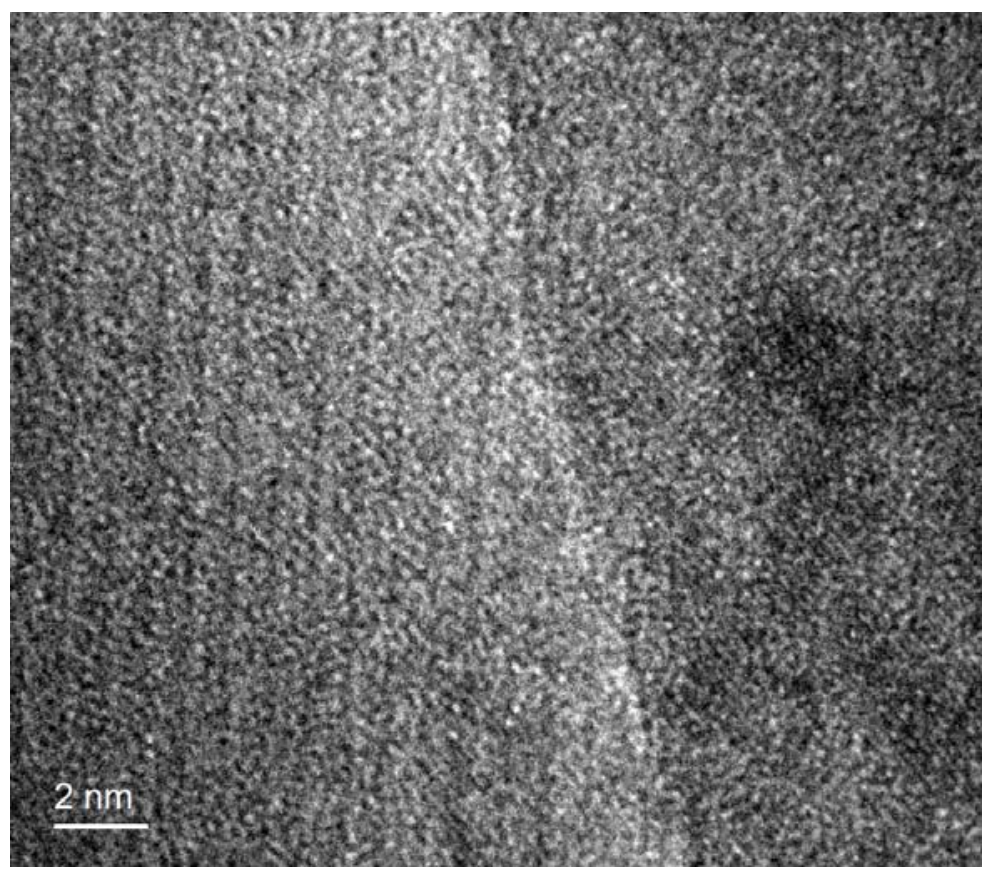

(b)

FIGURA 4.4.3.2 - Imagens em alta resolução na região do contorno entre dois grãos da fase matriz selecionadas na amostra padrão - $\mathrm{Pr}_{15} \mathrm{Fe}_{\mathrm{bal}_{2}} \mathrm{Co}_{8} \mathrm{~B}_{7} \mathrm{Nb}_{0,05}$ mostram irregularidades no contorno e ausência de camada isolante entre os grãos. 
Na FIG. 4.4.3.3, é mostrado o contorno de grãos contínuo e regular do ímã $\mathrm{Pr}_{15} \mathrm{Fe}_{\text {bal }} \mathrm{Co}_{8} \mathrm{~B}_{7} \mathrm{Nb}_{0,05} \mathrm{Ga}_{0,25}$ e a modificação na vizinhança do contorno causada pelo polimento iônico.

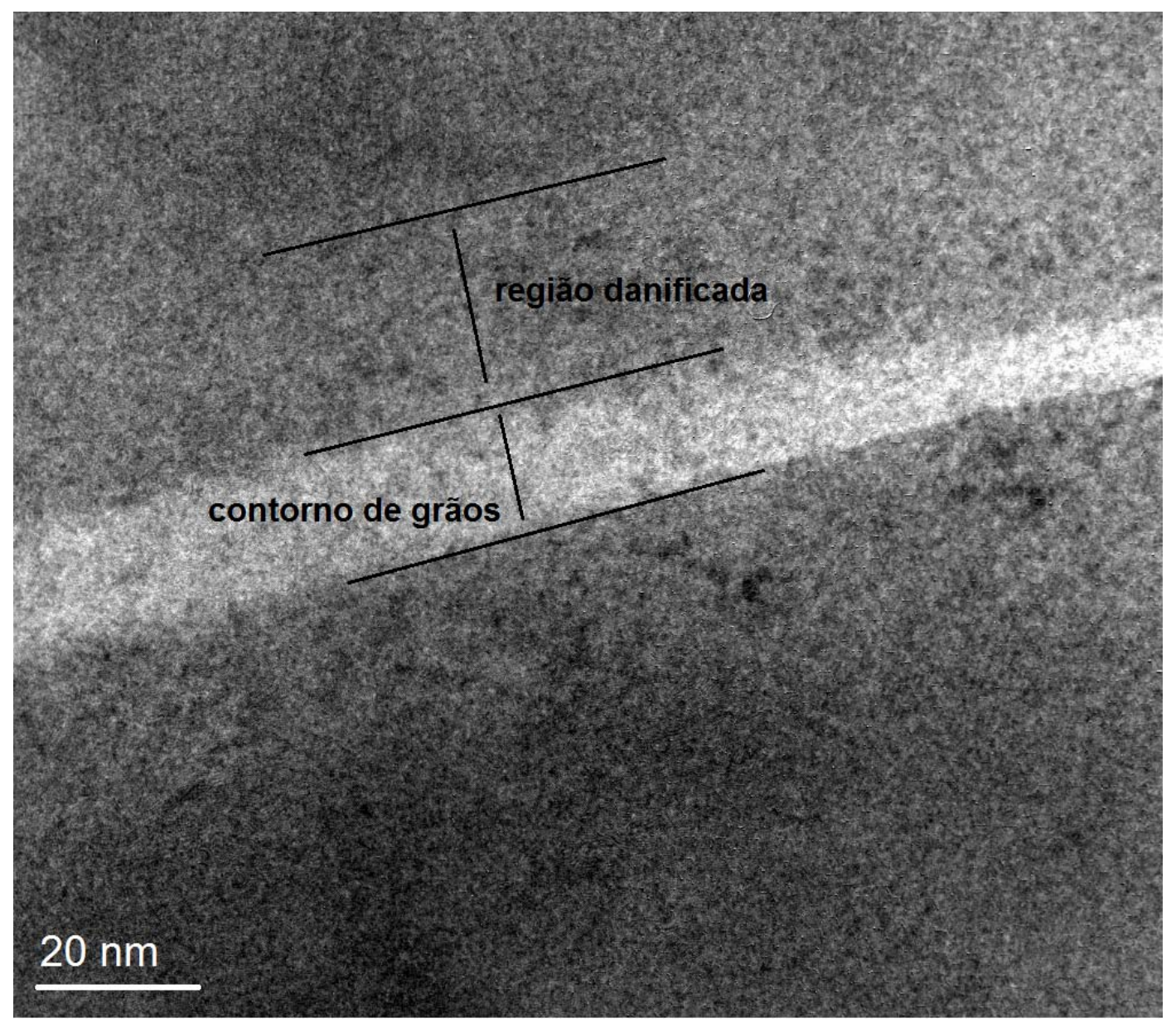

FIGURA 4.4.3.3 - Imagens de alta resolução do ímã $\operatorname{Pr}_{15} \mathrm{Fe}_{\text {bal }} \mathrm{Co}_{8} \mathrm{~B}_{7} \mathrm{Nb}_{0,05} \mathrm{Ga}_{0,25}$ onde a camada de isolação entre grãos magnéticos com boa regularidade e bem definida.

Os contornos localizados no ímã de composição $\operatorname{Pr}_{15} \mathrm{Fe}_{\text {bal }} \mathrm{Co}_{8} \mathrm{~B}_{7} \mathrm{Nb}_{0,05} \mathrm{Ga}_{0,25}$ são contínuos e regulares em toda a extensão, embora tenham sido observadas modificações nas vizinhanças da camada de isolação numa faixa de cerca de $20 \mathrm{~nm}$ provavelmente devido a danos causados pelo polimento iônico (Tsubokawa et al.,1988). Analises realizadas com ímãs de $\mathrm{NdFeB}$ revelaram modificações na estrutura próxima aos contornos devido ao aquecimento causado pelo bombardeamento iônico do "íon milling" e sugerem eventualmente o uso de nitrogênio líquido durante o processo de polimento (Ramesh et al., 1990). 
Na FIG. 4.4.3.4., é mostrada a imagem em alta resolução do ímã com adição de $\mathrm{Ga}$ onde o contorno de grãos tem espessura da ordem de $5 \mathrm{~nm}$.

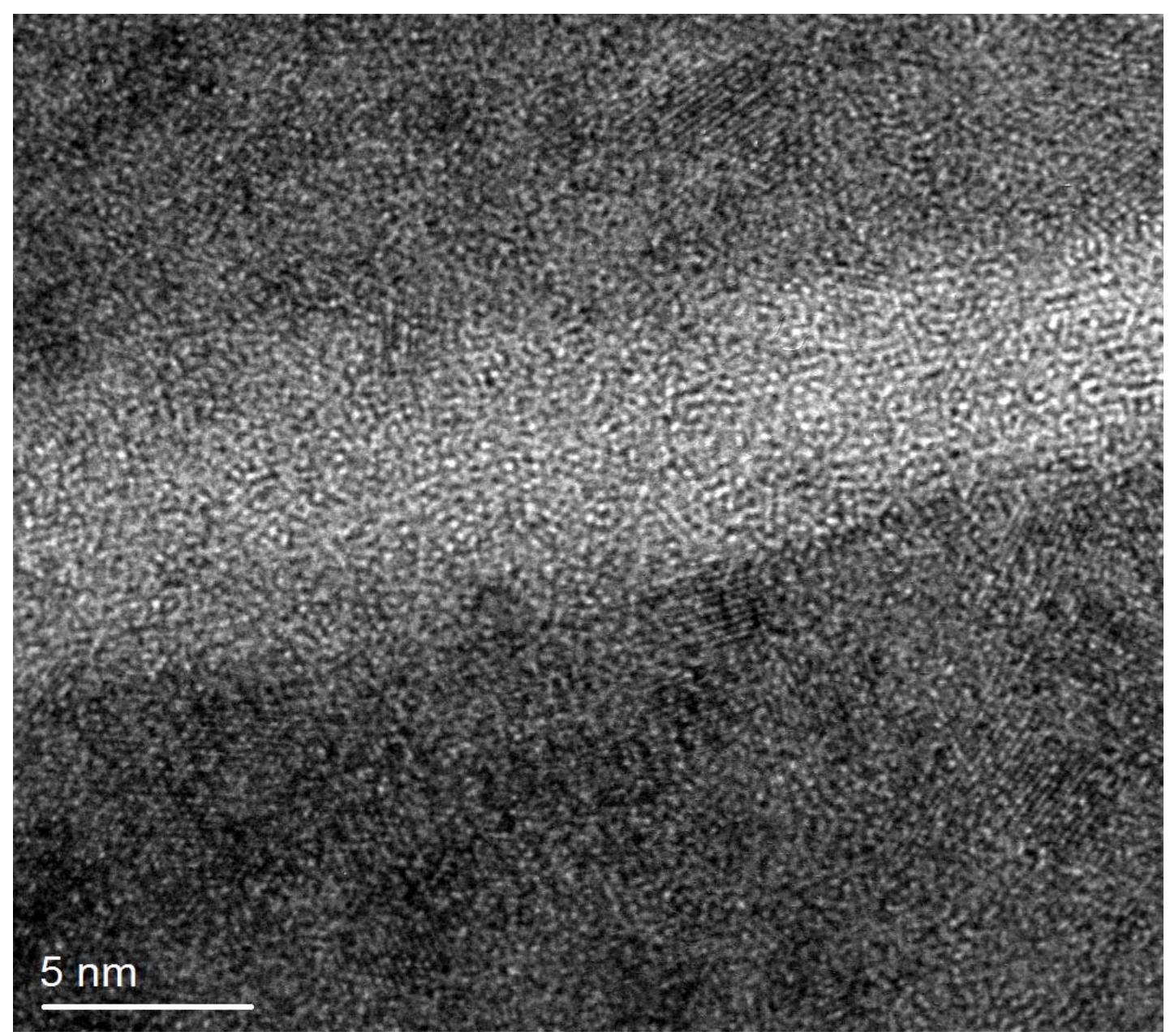

FIGURA 4.4.3.4 - Imagem de alta resolução na região do contorno de grãos com espessura da ordem de $5 \mathrm{~nm}$ e aparência amorfa para 0 ímã $\mathrm{Pr}_{15} \mathrm{Fe}_{\text {bal }} \mathrm{Co}_{8} \mathrm{~B}_{7} \mathrm{Nb}_{0,05} \mathrm{Ga}_{0,25}$.

A imagem do contorno na amostra do ímã $\operatorname{Pr}_{15} \mathrm{Fe}_{\text {bal }} \mathrm{Co}_{8} \mathrm{~B}_{7} \mathrm{Nb}_{0.05} \mathrm{Ga}_{0,25}$ na FIG. 4.4.3.4 comparada com a amostra padrão $\operatorname{Pr}_{15} \mathrm{Fe}_{\text {bal }} \mathrm{Co}_{8} \mathrm{~B}_{7} \mathrm{Nb}_{0.05}$ da FIG 4.4.3.2 (b) indica que o ímã com adição de Ga mostra contornos bem regulares e com uma área de adição bem determinada de aproximadamente $5 \mathrm{~nm}$, ao contrário da amostra padrão. Nesta última observa-se um contorno irregular que, mesmo com maiores magnificações, não permitiu a observação de uma fase intergranular de 
isolação. A localização desse tipo de contorno com microscopia de alta resolução pode ser atribuído a ação do $\mathrm{Ga}$ identificado nos pontos triplos ricos em $\mathrm{Pr}$, que provavelmente migra para a região de isolação e promove melhor molhabilidade na fase líquida de sinterização.

O contorno com aparência amorfa nessa dimensão $(5 \mathrm{~nm})$ está em concordância com Shinba et al., (2005), porém não pôde ser analisado com EDS. Determinações quantitativas com EDS em regiões com interfaces menores que $10 \mathrm{~nm}$, dependem tanto do diâmetro da ponta de prova quanto do processo de espalhamento elástico do feixe incidente na amostra. Esse processo conhecido como "beam broadening" varia significativamente com a espessura da amostra naquela região, onde espessuras maiores que $100 \mathrm{~nm}$ são indesejadas (Fuchs et.al.,1990). 


\subsection{4 - Defeitos e precipitados}

Foram localizados defeitos e precipitados tanto nos contornos de grão (região rica) como nas regiões da fase matriz dos ímãs aqui analisados. Segundo Shinba et al.(2005), essas regiões de campo de tensões gerados ao redor dos defeitos e precipitados interrompem os arranjos dos domínios magnéticos. Em estudos anteriores também se atribui ao Nb influência positiva sobre a coercividade uma vez que o mesmo poderia além de eliminar o Fe livre, realizar o ancoramento das paredes de domínio (Pandian et al., 2001).

A FIG 4.4.4.1 ilustra um ponto de concentração de Nb entre grãos magnéticos da fase matriz com composição determinada com EDS no MET no ímã $\operatorname{Pr}_{15} \mathrm{Fe}_{\text {bal }} \mathrm{Co}_{8} \mathrm{~B}_{7} \mathrm{Nb}_{0,05} \mathrm{Cu}_{0,15}$.

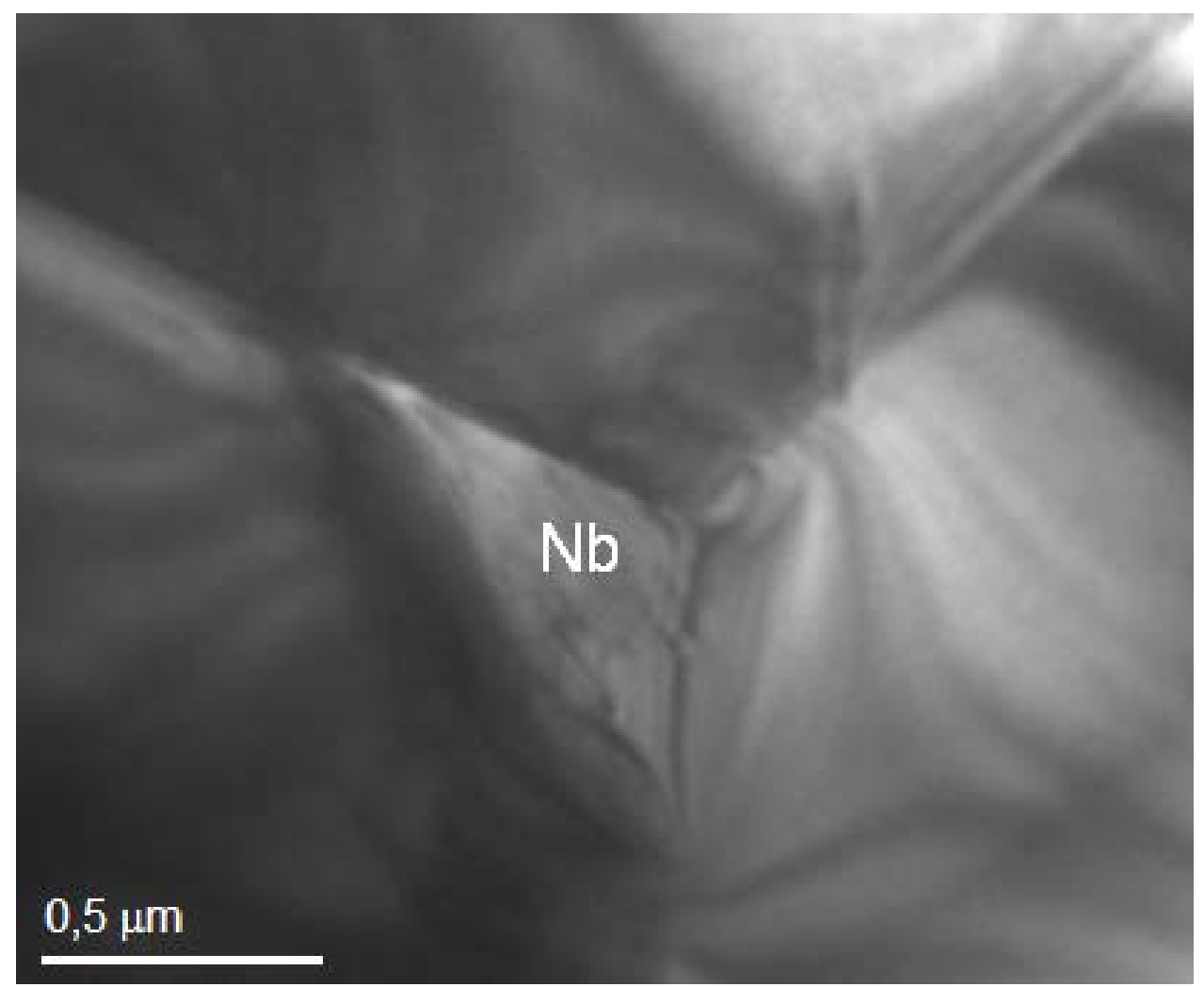

FIGURA 4.4.4.1 - Imagem em campo claro para o ímã com adição de Cu 0,15\% at., com região identificada de um ponto com alta concentração de $\mathrm{Nb}(46 \%)$ revelando precipitados e tensões de rede. 
A FIG. 4.4.4.2 mostra o EDS realizado na área identificada na FIG. 4.4.4.1.

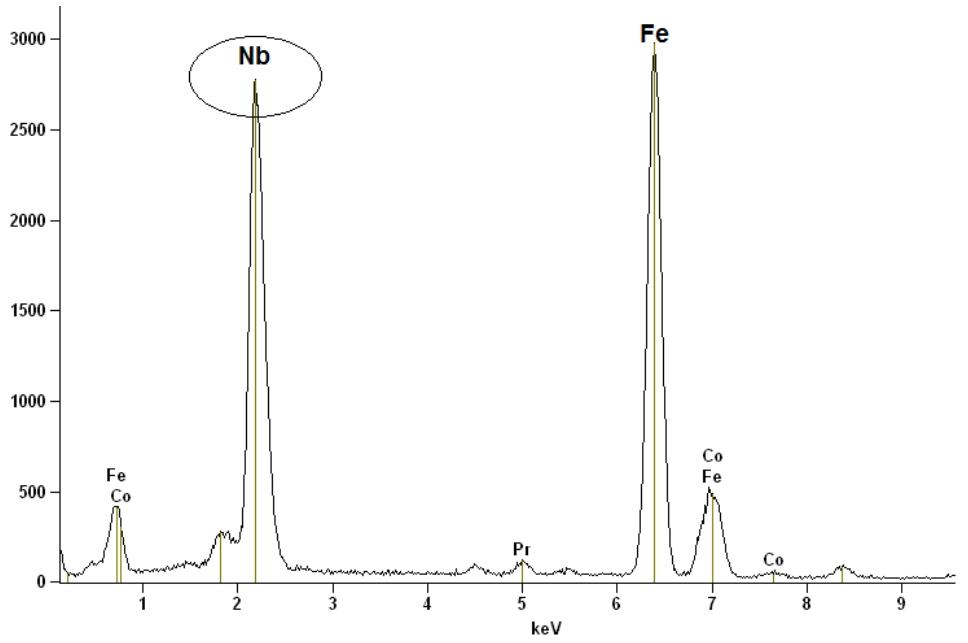

FIGURA 4.4.4.2 - EDS na região central da FIG. 4.4.4.1, com pico de Nb.

A alta concentração de $\mathrm{Nb}$ próximo ao contorno dos grãos da fase matriz apresentada na FIG 4.4.4.1, confirma que esse elemento possui baixa solubilidade. Essa situação gerou tensões de rede que provavelmente prejudicam as propriedades magnéticas, especialmente a coercividade.

A FIG. 4.4.4.3 mostra um precipitado localizado na matriz do ímã com adição de $\mathrm{Cu}(0,15 \%$ at.) onde se observam de tensões geradas ao redor do mesmo e uma composição com alto teor de $\operatorname{Pr}(53,7 \%)$.

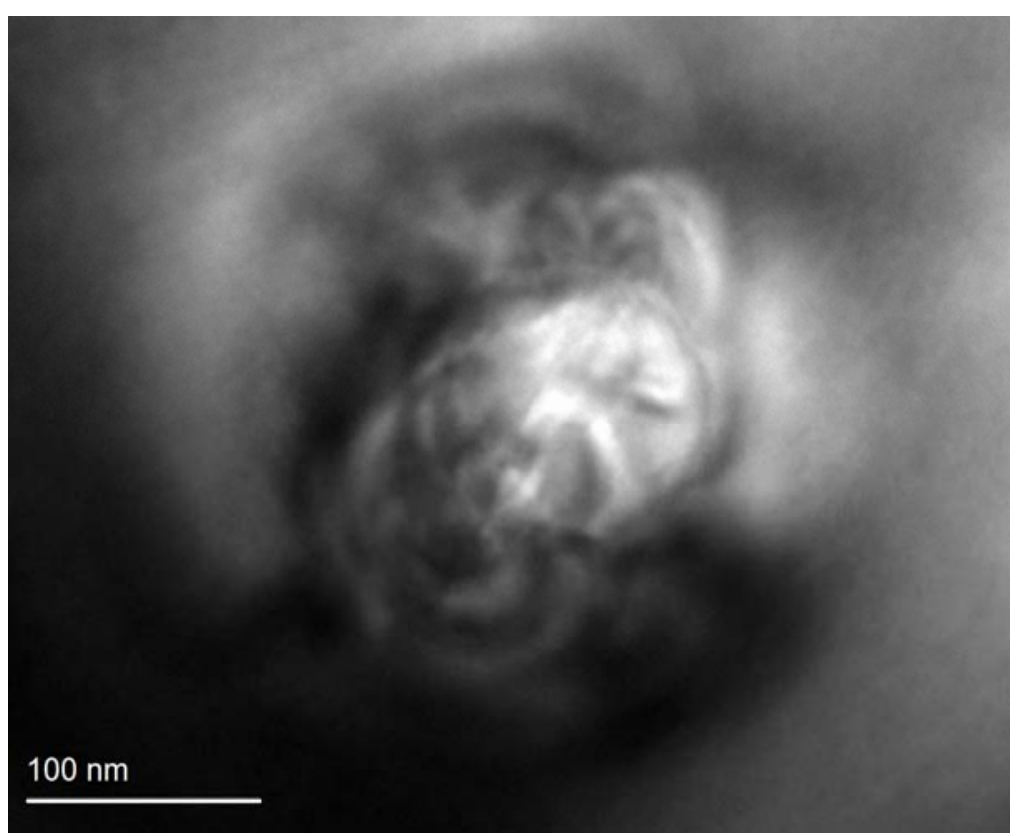

FIGURA 4.4.4.3 - Precipitado da ordem de $100 \mathrm{~nm}$ e composição indicando alta concentração de $\operatorname{Pr}(53,7 \%)$ para o ímã com adição de $\mathrm{Cu}(0,15 \%$ at.). 
A FIG. 4.4.4.4 mostra em (a), tensões de rede na região do contorno de grãos no ímã com adição de $\mathrm{P}(0,25 \%$ at.) e em (b), precipitado na fase matriz do ímã com adição de $\mathrm{Ga}$ (0,25\%at.).

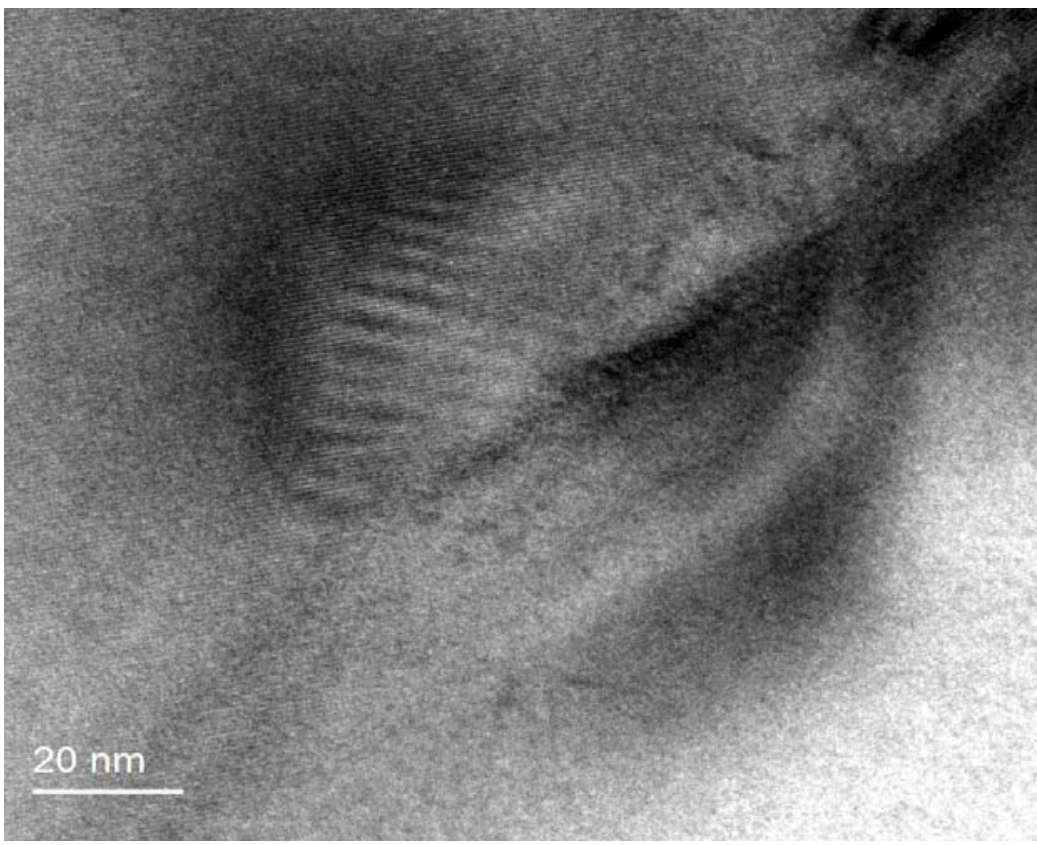

(a)

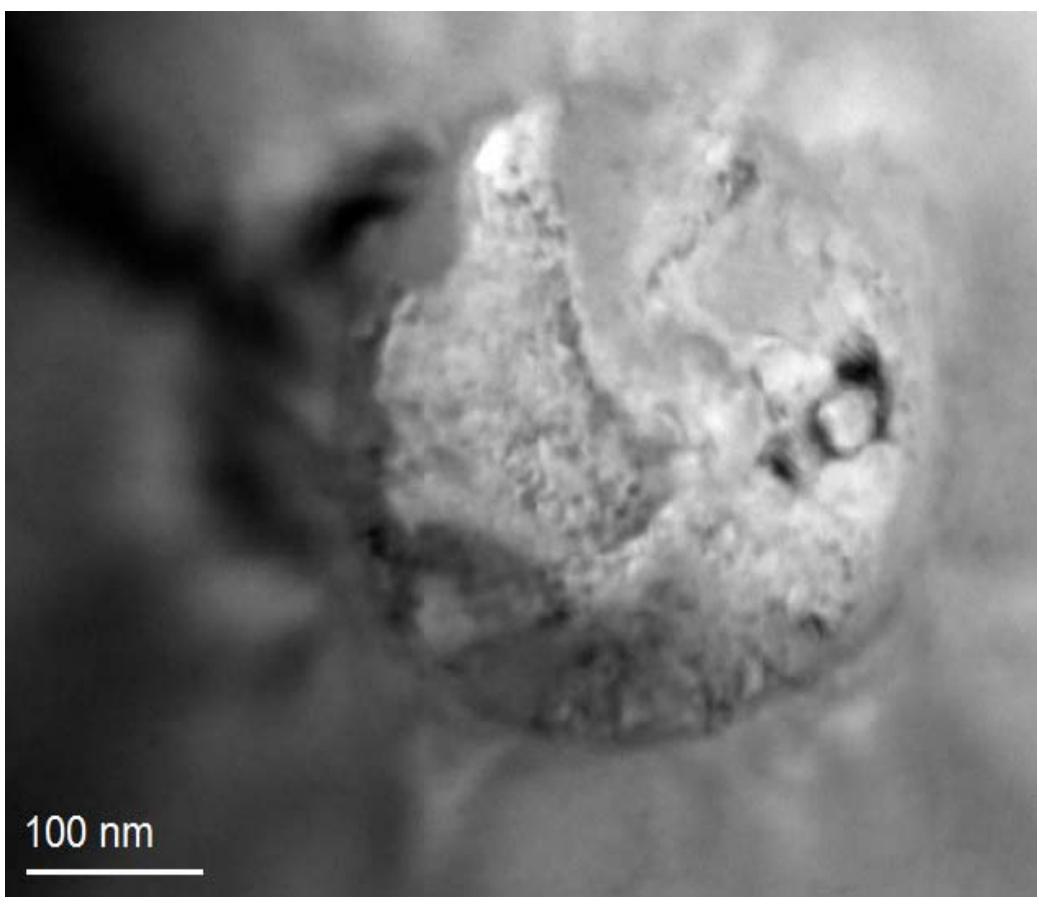

(b)

FIGURA 4.4.4.4 - (a), tensões de rede na região do contorno do ímã $\mathrm{PrFeCoBNbP}_{0,25}$ e (b), precipitado rico em $\mathrm{B}$ na fase matriz do ímã PrFeCoBNbGa 0,25 . 
Na FIG 4.4.4.5 é apresentada a região de contorno para o ímã com adição de $\mathrm{Ga}(0,25 \%$ at. $)$ com distorções de planos atômicos.

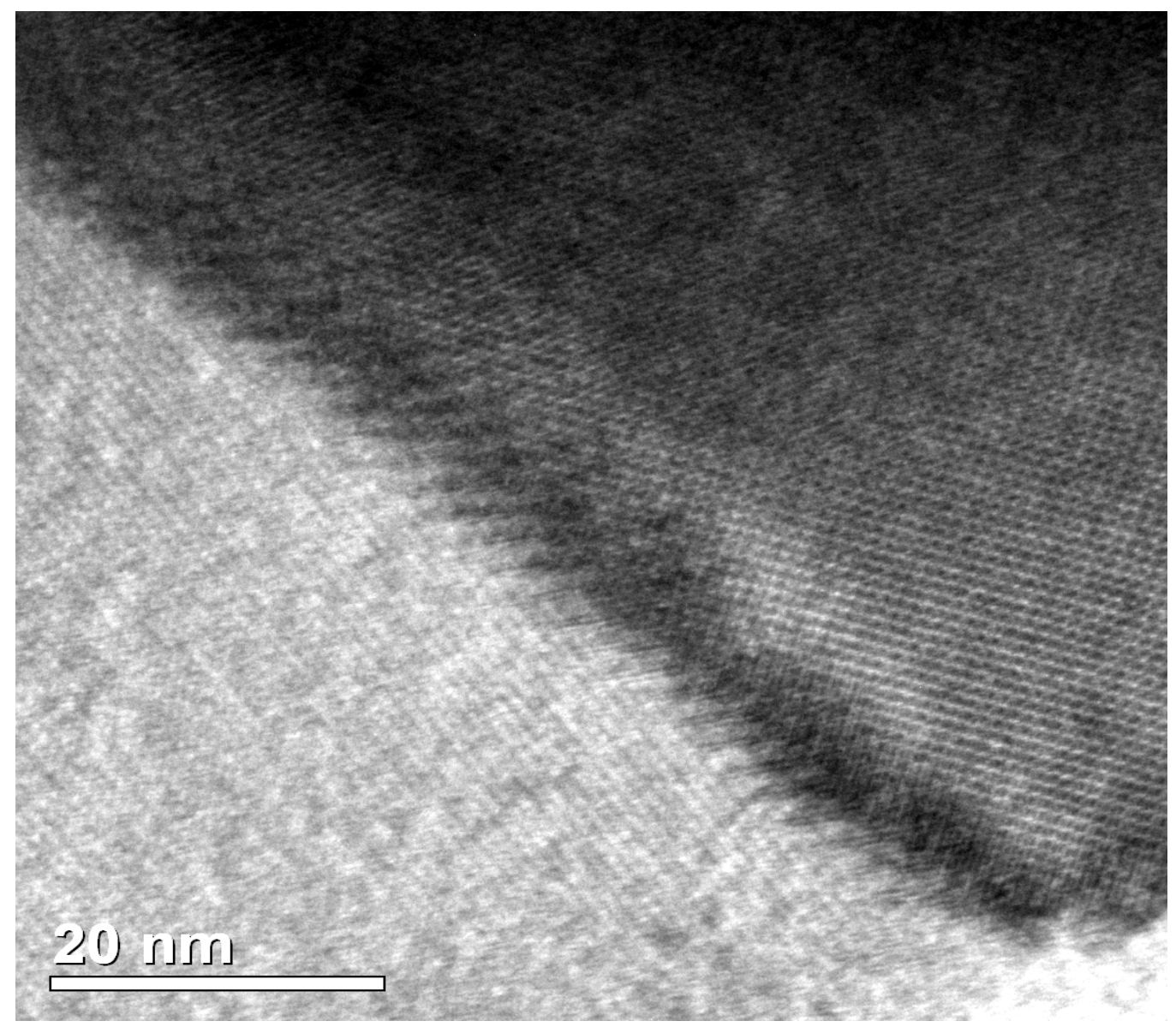

FIGURA 4.4.4.5 - Imagem de alta resolução na região entre dois grãos magnéticos da fase matriz no ímã PrFeCoBNbGa $a_{0,25}$ onde se observam distorções dos planos atômicos e ausência do material de contorno.

Os precipitados localizados nas amostras com adição de $\mathrm{Cu}(0,15 \%$ at.) da FIG. 4.4.4.3, revelaram diâmetro da ordem de $100 \mathrm{~nm}$ e geraram as tensões de rede na fase matriz, cuja composição revelou a presença de $\operatorname{Pr}$ em grande concentração ( $57,3 \%$ at.).

As tensões de rede mostradas FIG 4.4.4.4 (a), geraram distorções de planos na fase matriz (defeito) e provavelmente também contribuíram para a diminuição da coercividade desses ímãs. Esses defeitos já foram relatados em trabalhos anteriores com ímãs à base de Nd, (Shinba et al., 2005). 
Já os precipitados localizados nas amostras com Ga (0,25\% at.) da FIG. 4.4.4.4 (b), apresentaram diâmetro da ordem de $300 \mathrm{~nm}$ e a análise com EDS indicou grande concentração de $\mathrm{B}$, embora a análise desse elemento seja considerada semi-quantitativa.

Também foram observadas, distorções de planos atômicos nos contornos, com imagens de alta resolução mostrada na FIG. 4.4.4.5 do ímã com adição de $\mathrm{Ga}(0,25$ \%at.) entre grãos da fase matriz onde se observa ausência da camada de isolação.

Esses defeitos aqui identificados podem estar presentes de maneira aleatória, decorrentes do processamento das ligas e ímãs e são deletérios às propriedades magnéticas. Portanto, além da busca da intensificação de propriedades magnéticas com as adições aqui estudadas, devem-se observar os cuidados no processamento que também estão relacionados à coercividade. 


\section{CAPÍTULO 5}

\section{Conclusões}

Para o ímã com adição de Ga (0,25\%at.) obteve-se o maior valor de coercividade (1100 mT), comparado ao ímã padrão $\operatorname{Pr}_{15} \mathrm{Fe}_{\text {bal }} \mathrm{Co}_{8} \mathrm{~B}_{7} \mathrm{Nb}_{0,05}$ com 1000 mT. O ímã com adição de P (0,25\%at.) apresentou o melhor resultado do fator de quadratura $(0,89)$.

A proximidade entre os valores do fator de homogeneidade calculados com os parâmetros microestruturais comparados ao fator de quadratura extraído das curvas de desmagnetização confirmam que a correlação adotada neste trabalho constitui uma boa ferramenta para o cálculo do fator de quadratura.

A partir do mapa de elementos executado no MET, para o ímã com adição de $0,25 \%$ at. de fósforo, foi possível a confirmação de alto teor desse elemento na região do ponto triplo. Os contornos de grão, no entanto se mostraram irregulares e com ausência da camada de isolação, fato que pode explicar o baixo valor de coercividade com esse aditivo.

Para o ímã com adição de Ga (0,25\%at.) foram observados contornos suaves e regulares entre grãos da fase magnética, da ordem de $5 \mathrm{~nm}$, indicando boa molhabilidade durante a sinterização com fase líquida. Essas características do contorno de grãos e o alto teor de Ga identificado nas regiões de pontos triplos e nas fases ricas em $B$ indicam que as migrações desse aditivo para os contornos e bons resultados de coercividade podem estar relacionadas.

As imagens com alta resolução também permitiram a observação de nítidas distorções dos planos atômicos e espessura da camada de interface não uniforme indicando que nem todos os contornos apresentam boa regularidade ou, eventualmente, sequer possuem camada de isolação. A presença de defeitos, precipitados e campos de tensão na rede cristalina, podem ter influência negativa sobre a coercividade, uma vez que favorecem a formação de campos de nucleação reversa. A presença de precipitados de $\mathrm{Nb}$ observados em grãos da 
fase matriz devido à baixa solubilidade do $\mathrm{Nb}$ provavelmente também contribui para queda da coercividade. Também foi observado que em regiões próximas à borda da fase matriz houve modificação causada pelo bombardeio iônico, provavelmente devido ao aquecimento local excessivo desse processo.

A busca da intensificação da coercividade com adições de elementos de liga sem a utilização do Dy constitui uma tendência na obtenção de ímãs sinterizados com desempenho superior, bem como a questões ligadas aos parâmetros de processamento que também afetam essa propriedade. 


\section{6- REFERENCIAS BIBLIOGRÁFICAS}

BAI, G.; GAO. R. W.; SUN, Y.; HAN G. B.; WANG, B. Study of high-coercivity sintered NdFeB magnets. J. Mag. Mag. Mat., v. 04, p. 029, 2006.

BROWN D.; BAO, M. M.; CHEN, Z. Developments in the processing and properties of NdFeb-type permanent magnets. J. Mag. Mag. Mat., v. 248, p. 432440, 2002.

BUSCHOW, K.H.J.; DE BOER, F. R.; Physics of Magnetism and Magnetic Materials. Kluwer Academic Publishers, 2004.

CHENG, W. H.; LI, W.; LI,C. J.; DONG, S. Z. The magnetic properties, thermal stability and microstructure of $\mathrm{Nd}-\mathrm{Fe}-\mathrm{B} / \mathrm{Ga}$ sintered magnets prepared by blending method. J. Mag. Mag. Mat., v.234, p. 274-278, 2001.

CONRADO, R. M. A.; BETTINI, J. Apostila de Preparação de Amostras para microscopia eletrônica de transmissão - Laboratório Nacional de Luz Síncrotron - LNLS 2009.

CORFIELD, M. R.; HARRIS, I. R.; WILLIAMS , A. J. Influence of oxygen content on grain growth in $\mathrm{Pr}-\mathrm{Fe}-\mathrm{B} / \mathrm{Nd}-\mathrm{Fe}-\mathrm{B}$ sintered magnets. Journal of Alloys and Compounds. v.463, p. 180-188, 2008.

DURST, K. D.; KRONMULLER, H. The coercive field of sintered and melt-spun NdFeB magnets. J. Mag. Mag. Mat., v.68, p. 63-75, 1987.

FARIA, R. N.; TAKIISHI, H.; LIMA, L. F. C. P.; COSTA I. Praseodymium-based HD-sintered magnets produced using a mixture of cast alloys. J. Mag. Mag. Mat., v. 237 , p. $261-266,2001$.

FARIA, R. N.; TAKIISHI, H.; CASTRO, A. R. M.; LIMA, L.F.C.P.; COSTA I.; Chemical microanalysis of rare-earth-transition metal-boron alloys and magnets using scanning microscopy. J. Mag. Mag. Mat., v. 246, p. 351 - 359, 2002.

FARIA, R. N.; LIMA, L. F. C. P. Introdução ao Magnetismo dos Materiais. EDUSP, 1Ed., 2003.

FERNENGEL, W. Magnetic properties of sintered Nd-Fe-Si-B magnets. J. Mag. Mag. Mat., v.80, p. 27-30, 1989.

FIDLER J. Analytical Microscope Studies of Sintered Nd-Fe-B magnets. IEEE Trans. Mag., v.21 (5), p. $1955-1957,1985$.

FIDLER, J.; KNOCH, K.G. Electron Microscopy of Nd-Fe-B based magnets. J. Mag. Mag. Mat., v.80, p.48-56, 1989. 
FIDLER, J.; KNOCH, K.G.; KRONMULLER, H.; SCHNEIDER, G.; Analytical TEM study of Al-doped, "two phase" Nd-Fe-B sintered magnets. J. Mater. Res. v.4 (4), p. 806-813, 1989.

FIDLER, J.; SCHEFL, T. Overview of Nd-Fe-B magnets and coercivity. Symposium on High Performance Magnets and Coercivity. J.Appl.Phys, v.79 (8), p. $5029-5034,1996$.

FIDLER, J.; The role of the Nd-rich phases in sintered Nd-Fe-B magnets. IEEE Trans. Magn. Mag. v.23(5), p. 2106-2108, 1987.

FUCHS, E.; OPPOLZER, H.; REHME, H. Particle Beam Microanalysis, Fundamentals and Applications. VHC Federal Republic of Germany, 1990.

G. A. BAXES, Digital Image Processing: Principles and Applications Wiley, New York, 1994

GRIEB, B.; KNOCH, K.G.; HENIG, E.-TH.; PETZOW, G.; Influence of Al-based additions on coercivity and microstructure in Fe-Nd-B magnets. J. Mag. Mag. Mat. v. 80, p. $75-79,1989$.

GRIEB, B.; PITHAN, C.; HENIG, E.TH.; PETZOW, G.; Replacement of Nd by an intermetallic phase in the intergranular region of Fe-Nd-B sintered magnets. J.Appl.Phys., v. 70 (10), p. 6354-6356, 1991.

GROSSINGER, R.; KOU, X.C.; KREWENKA, R.; KIRCHMAYR, H.R.; TOKUNAGA, M. Studies on Nd ( $\left.\mathrm{Fe}_{0.92-\mathrm{x}} \mathrm{B}_{0.08} \mathrm{Ga}_{\mathrm{x}}\right)_{5.5}$ Sintered Permanent Magnets. IEEE Trans. Magn. Mag., v.26 (5), p. 1954-1956, 1990.

HERBST, J. F.; CROAT, J. J.; YELON, W. B. Structural and magnetic properties of $\mathrm{Nd}_{2} \mathrm{Fe}_{14}$ B. J. Appl. Phys., v.57 (1), p. 4086- 4090). 1985 (a).

HERBST, J. F.; W. B. YELON Crystal and magnetic structure of $\operatorname{Pr}_{2} \mathrm{Fe}_{14} \mathrm{~B}$ and Dy ${ }_{2} \mathrm{Fe}_{14}$ B. J. Appl. Phys., v.57 (1), p. 2343-2345, 1985 (b).

HERBST J. F. $\mathrm{R}_{2} \mathrm{Fe}_{14} \mathrm{~B}$ materials: Intrinsic properties and technological aspects. Rev. Mod. Phys., v. 63 (4), p. 819-882, 1991.

HIRAGA, K.; HIRABAYASHI, M.; SAGAWA, M.; MATSUURA, Y. A study of Grain Boundaries in Sintered Fe77Nd15B8 Permanent Magnet by High-Resolution Electron Microscopy. Japanese Journal of Applied Physics, v. 4 (6), p. 699703, 1985.

HIROSAWA, S.; TSUBOKAWA, Y. The Nd-Fe-B Materials for Permanent Magnets. J. Mag. Mag. Mat., v. 84, p. 309 -316, 1990.

JILES, D., Introduction to Magnetism and magnetic materials. Chapman \& Hall, London, 1998. 
JINFANG, L.; HELIE, L.; JIANG, W.; Magnetic properties and electron microscopy analysis of $\mathrm{Nb}-$ containing ( $\mathrm{NdDy}$ )FeB sintered magnets. J. Mag. Mag. Mat., v. 103 , p. $65-72,1990$.

JINGHUA, T.; YINYING, H.; JINGKUI L.; The Pr-Fe-B ternary system. Scientia Sinica, v. 30 (6), p. 607-619, 1987.

KAUFMANN, E.N.; Characterization of Materials. John Wiley \& Sons, v.1, 1 ed., 2003.

KIANVASH, A.; HARRIS, I.R.; The production of a Nd16Fe76B8 sintered magnet by the hydrogen decrepitation / hydrogen vibration route. J. Alloys Compd., v. 282, p. 213, 1999.

KIM. A. S. Magnetic properties of Nd Dy Fe Co Al B alloys. J. Appl. Phys., v. 63 (8), p. 3975- 3977, 1988.

KIM, A. S.; CAMP, F.E. High Performance NdFeB magnets. J.Appl.Phys., v. 79 (8), p. 5035-5038, 1996.

KIM, M. J.; KIM, Y. B.; C. S. KIM, T. K. Magnetocrystalline anisotropy of Pr2Fe-4B. J. Mag. Mag. Mat., v.222, p. 86-88, 2000.

KITTEL, C. Physical Theory of Ferromagnetic Domains. Reviews of Modern Physics, v.4 (4), p.560, 1949.

KNOCH, K. G.; GRIEB, B.; HENIG, E.-TH.; KRONMULLER, H.; PETZOW, G.; Upgraded Nd-Fe-B-AD (AD = Al, Ga) magnets: wettability and microstructure. IEEE Trans. Mag., v. 26 (5), p. 1951-1953,1990.

KNOCH, K. G.; KIANVASH, A.; HARRIS, I. R.; Nd -Fe - B - Cu HD Processed Sintered Magnets: Properties Microstructure. IEEE Trans. Mag., v.28 (5), p.21422144, 1992.

LANDGRAF, F. J. G.; Processamento de materiais magnéticos. Escola Politécnica-USP, Cap. 6, (Anotações de aula), 2008.

LI, W.F.; OHKUBO, T.; HONO, K.; Effect of post-sinter annealing on coercivity and microstructure of Nd-Fe-B permanent magnets. Acta Materialia, v. 57, p. 13371346, 2009.

LI, W.F.; OHKUBO,T.; AKIYA,T.; KATO, H.; HONO; K.; The role of Cu addition in the coercivity enhancement of sintered Nd-Fe-B permanent magnets J. Mater. Res., v. 24 (2), p. 413-420, 2009.

MATSUURA, Y.; Recent development of $\mathrm{Nd}-\mathrm{Fe}-\mathrm{B}$ sintered magnets and their applications. J. Mag. Mag. Mat., v. 303, p. 344-347, 2006. 
MCGUINESS, P. J.; KOBE, S.; SKULJ I.; BOLLERO, A.; GU, D.TFLEISCH, O.; DEVELIN, E.; NIARCHOS, D.; Coecivity variations with Pr-and Zr substituted NdDyFeB-based HDDR powders. J. Mag. Mag. Mat., v.237, p. 267 -275, 2001.

MENDES, T.; SILVA, S. C.; PÉRIGO, E. A.; FARIA, R. N.;TAKIISHI, H. The Effect of $\mathrm{Cu}, \mathrm{P}, \mathrm{Ga}$ And $\mathrm{Gd}$ on Microstructure and magnetic properties in the PrFeCoNb HD sintered magnets, Materials Science Forum , v. 660-661 p. 273-278, 2010.

MENUSHENKOV, V. P. Phase transformations and coercivity in rare-earth permanent magnets. v. 290, p. 1274-1277, 2005.

MO, W.; ZHANG, L.; LIU, Q.; SHAN, A.; WU, J.; KOMURO, M.; Dependence of the crystal structure of the Nd-rich phase on oxygen content in an Nd-Fe-B sintered magnet. Scripta Materialia, v.59 179-182, 2008.

MOTTRAM, R.S.; YARTY, V.; GUEGAN, P.W.; HARRIS; I.R.; Application of hydrogen vibration milling in the processing of $\mathrm{NdFeB}$ and $\mathrm{Nd} \mathrm{PrFeB}$ permanent magnets International Journal of Hydrogen Energy 24, 257-261. 1999.

MOTTRAM, R.S.; WILLIAMS, A. J.; HARRIS; I.R.; Blending additions cobalt to Nd16Fe76B8 milled powder to produce sintered magnets. J. Mag. Mag. Mat. v. 217 , p. 27-34, 2000.

NEIVA, A. C.; TSCHIPTSCHIN, A. P.; MISSELL, F. P.; Phase diagram of the PrFe-B system. Journal of Alloys and Compounds, v.217, p.273 - 282. 1995.

OHKUBO, W. F. LI, HONO, T. K.; Effect of post-sinter annealing on the coercivity and microstructure of $\mathrm{Nd}-\mathrm{Fe}-\mathrm{B}$ permanent magnets. Acta Materialia. v. 57, p.1337-1346, (2009).

GOODHEW, P. J.; HUMPHREYS, J.; BEANLAND, R.; Electron Microscopy and Analysis, Taylor \& Francis, ${ }^{\text {rd }}$ edition, London, (2001).

PANDIAN, S.; CHANDRASEKARAN,.; IYER, K. J. L.; RAMA RAO, K. V. S.; Investigations on the metallurgical features and properties of $\mathrm{Nd}_{16,8} \mathrm{Fe}_{75,7-x} \mathrm{Al}_{\times} \mathrm{B}_{7,5}$, 0 x 6. IEEE Trans. Magn. Mag. v. 37, NO. 4, 2001.

PANDIAN, S.; CHANDRASEKARAN,.; IYER, K. J. L.; RAMA RAO, K. V. S.; Microstructural and magnetic processed $\left(\mathrm{Nd}_{14.9} \mathrm{Dy}_{1.9}\right)\left(\mathrm{Fe}_{65.0} \mathrm{Co}_{8.0} \mathrm{Cu}_{1.0} \mathrm{Ga}_{1.0}\right.$ $\left.\mathrm{Nb}_{0.7}\right) \mathrm{B}_{7.5}$ alloy. , J.Mater.Science. 36, 5903 - 5907, 2001.

PANDIAN, S.; CHANDRASEKARAN, MARKANDEYULU, V. G.; IYER, K. J. L.; RAMA RAO, K. V. S.; Effect of Al, $\mathrm{Cu}, \mathrm{Ga}$, and $\mathrm{Nb}$ additions on the magnetic properties and microstructural features of sintered NdFeB. J.Appl.Phys v. 92, N. 10, 2002.

PARKER, S. F. H.; GRUNDY, P.J.; FIDLER, J.; Electron Microscope Study of Preciptation in a Niobium-Contaning (Nd, Dy) - Fe- B Sintered Magnet. J. Mag. Mag. Mat. v. 66, p. $74-78,1987$. 
PÉRIGO, E. A., TAKIISH, H. I., MOTTA C. C.; R. N. FARIA; Microstructure and squareness factor: A quantitative correlation in ( $\mathrm{Nd}, \mathrm{Pr}) \mathrm{FeB}$ sintered magnets. J.Appl.Phys p.102, 113912, 2008.

RAMESH, R., THOMAS, G. B. M.; Magnetization reversal in nucleation controlled magnets.II.Effect of grain size and distribution on intrinsic coercivity of Fe-Nd-B magnets. J.Appl.Phys. v. 64, p. 6416-6423, 1988.

RAMESH, R.; A microstructure based magnetization reversal model in sintered Fe-Nd-B magnets. I. J.Appl.Phys. v. 68, p. 5767-5771, 1990.

RAMESH, R.; A microstructure based magnetization reversal model in sintered Fe-Nd-B magnets. II. Effect of post sintered treatments. J.Appl.Phys. v. 68, p. 5772-5777, 1990.

RODEWALD, W.; FERNENGEL, Properties of sintered Nd-Fe-TM-B Magnets W.; IEEE Trans. Magn. Mag. 24, 1638, 1988.

RODEWALD, W.; WALL, B.; Structure and magnetic properties of sintered Nd-FeNb-B magnets. J. Mag. Mag. Mat, v. 80, p.57-60, 1989.

SAGAWA, M.; FUJIMURA, S.; TOGAWA, N.; YAMAMOTO, H.; MATSUURA Y.; New material for permanent magnets on a base of Nd and Fe. J.Appl.Phys, v. 55 (6), p.2083-87, 1984.

SAGAWA, M.; HIROSAWA, S. Magnetic hardening mechanism in sintered R-FeB permanent magnets, J.Mater.Res. v. 3, p. 45, 1988.

SEEGER, M.; BAUER, J.; KRONMULLER, H.; BERNARDI, J.; FIDLER, J.; Magnetic and microstructural properties of sintered FeNdB based magnets with Ga and Nb additions. J. Mag. Mag. Mat, v. 138, p.294-300, 1994.

SCHREY, P.; TEM Studies of Sintered Fe-Nd-B magnets. IEEE Trans. Magn. Mag. MAG-22 NO.5, 1986.

SINTON, C. W.; BCC Report, p.17-31, 2004.

SWANSON ET AL.; Natl. Stand. Bur. (U.S.). Circ. 539 4, 26, (1956).

TAKIISHI, H.; LIMA, L. F. C. P.; FARIA, R. N. The production of rare-earthsintered magnets by a low-cost - powder technique. Powder Technology, v.127, p. 223-225, 2002.

TAKIISHI, H.; LIMA, L.F.C.P.; COSTA, I.; FARIA, R.N.; The influence of process parameters and alloy structure on the magnetic properties of NdDyFeBNb HD sintered magnets. Journal of Materials Processing Technology ,v.152, p. 1-8, 2004. 
TAYLOR, M.G.; DAVIES, B.E.; HARRIS, I.R.; A comparative study of the sintering behaviour of NdFeB and PrFeB for permanent magnet applications, J. Mag. Mag. Mat, v. 242-245, p.1375-1377. 2002.

TIAN, J.; HUANG, Y.; LIANG, J.; The Pr-Fe-B ternary system. Sci Sin. V. 30, n.6, p.607-619,1987.

TOKUNAGA, M.; KOGURE, H.; TOBISE, M.; MEGURO, N.; HARADA, H.; Microstructure of R-Fe-B sintered magnet . IEEE Trans. Magn. Mag. MAG-22 NO.5, 1986.

TOKUNAGA, M.; KOGURE, H.; ENDOH, M.; Improvement of thermal stability of $\mathrm{Nd}$-Dy-Fe-Co-B sintered magnets by additions of $\mathrm{Al}, \mathrm{Nb}$ and $\mathrm{Ga}$. IEEE Trans. Magn. Mag. V. 23, NO. 5, 1987.

TSUBOKAWA, Y.; SHIMIZU, R.; HIROSAWA, M.; Effect of heat treatment on grain boundary microstructure in Nd-Fe-B sintered magnet. J.Appl.Phys. v. 63(8), p. 3319-3320, 1988.

VIAL, F.; JOLY, F.; NEVALAINEN, E.; SAGAWA, M.; HIRAGA, K.; PARK, K. T.; Improvement of coercivity of sintered $\mathrm{NdFeB}$ permanent magnets by heat treatment. J. Mag. Mag. Mat. V. 242-245, 1329-1334, 2002.

SHINBA, Y.; KONNO, T. J.; ISHIKAWA, A. K.; HIRAGA, K.; Transmission electron microscopy study on Nd-rich phase and grain boundary structure of Nd-Fe-B sintered magnets, J.Appl.Phys. v. 97, p.053504, 2005.

WANG, S. C.; LI, Y.; In situ TEM study of Nd-rich phase in NdFeB magnet. J. Mag. Mag. Mat, v. 285, p.177-182. 2005.

WILLIAMS, D.B.; CARTER, C.B.; Transmission Electron Microscopy - Textbook for materials science, V.1, Plenum Publishing- New York. 1996.

YANG, J. P.; PI, S.H.; KIM, Y.P.; KIM, Y.G.; Effects of cyclic heat treatment on coercivity and microstructure of sintered $\mathrm{Nd} 15$ Fe77B8 magnets. Materials Science and Engineering B18, p. 78-82, 1993.

YIN, X. J.; JONES, I.P.; HARRIS, I. R.; Analytical TEM studies of Nd-Fe-B containing V, Co and Dy. J. Mag. Mag. Mat. v. 116, 325-335. 1992.

YIN, X. J.; HALL, JONES, M.G.; I.P.; FARIA, R. N.; HARRIS, I.R.; The microstructural characterization of Nd-Fe-B alloys. I: Light element microanalysis.

J. Mag. Mag. Mat. v.12.5, p.78-90, 1993. (a).

YIN, X. J.; JONES, M. G.; HARRIS, I.R. The microstructural characterization of $\mathrm{Nd}-\mathrm{Fe}-\mathrm{B}$ alloys. II: Microstructural investigation of cast Nd-Fe-B materials. J. Mag. Mag. Mat., v.12.5, p.91-102, 1993. (b). 